\title{
NICOTINE FADING, BEHAVIORAL CONTRACTING, AND EXTENDED TREATMENT: \\ EFFECTS ON SMOKING CESSATION
}

\section{BY}

Thomas Glenn Bowers

Dissertation submitted to the Faculty of the Virginia Polytecinic Institute and State University in partial fulfillment of the requirements for the degree of DOCTOR OF PHILOSOPHY in

Psychology

APPROVED :

R. A. Winett, Chairperson

G. A. Clum

L. W. Frederiksen
R. M. Eisler

W. G. Herbert

September, 1983

Blacksburg, Virginia 


\title{
NICOTINE FADING, BEHAVIORAL CONTRACTING \\ AND EXTENDED TREATMENT: \\ EFFECTS ON SMOKING CESSATION
}

\author{
by
}

Thomas Glenn Bowers

(ABSTRACT)

Two approaches to smoking cessation were evaluated. One approach, the standard condition, utilized a nicotine fading procedure, group support, and an attendance contingent monetary contract. The other approach, the maintenance condition, utilized nicotine fading, group support, and a smoking-contingent monetary contract. The maintenance condition also received two additional post-cessation sessions and additional instructions for cessation. Both conditions significantly improved over the course of the study. The maintenance condition achieved significantly better outcome on the reported average cigarettes per day, cessation rates, and co levels for the follow-up periods. The maintenance condition also had significantly lower SCN levels at the three month follow-up. The maintenance condition also had significantly lower diastolic and systolic blood pressure at the six month follow-up when compared to the standard condition. However, few other significant health differences emerged when smoking subjects were compared with reduced smoking or nonsmoking subjects for this study. The maintenance concition wass shown to be more cost effective than the standard 
condition. The results were interpreted as indicating the promise of nicotine fading and behavioral contracting procedures. Limitations of the wide-scale application of these methods was noted, however. In particular, group smoking cessation projects reach limited subjects, successful projects still have only moderate success rates, and the wide-spread application of these methods would strain available resources. It is recommended that further research and clinical efforts continue with nicotine fading, behavioral contracting and rapid smoking cessation programs. In addition, efforts at applying behavioral contracting principles without therapeutic support was suggested. Finally, more research on the functional determinants of tobacco smoking was recommended. 


\section{ACKNOWLEDGEMENTS}

Numerous individuals have aided in the research described here. To these individuals, I would like to extend my sincere appreciation. Dr. Winett has given me encouragement, as well as thought-provoking and timely advice. Dr. Clum has consistently aided me in relating my work to the broader field of psychotherapy. Dr. Eisler's research in the addictions has challenged my interests for several years. Dr. Frederiksen has conducted valuable rearch on smoking, and he has willingly shared his expertise in this area. Dr. Herbert has provided expertise in the area of physiological assessment. In addition, I am grateful for the use of Dr. Herbert's Human Performance Lab. I am also thankful for the use of Dr. Young's laboratory and the assistance of his staff. Several graduate students - Donna Chinn, Nancy Miniszek, Anne Riley and Debbie Weaver - provided excellent cotherapy for the groups. I would like to extend my appreciation to these cotherapists, In addition, I am grateful to Laura Stanowicz for the emotional support and encouragement she has provided to me. Finally, my parents, by their caring and concern, gave me the freedom to pursue my research. For this remarkable assistance, I am humbly grateful. 


\section{ABSTRACT}

ACKNOWLEDGEMENTS

LIST OF TABLES

vi

INTRODUCTION

METHOD

RESULTS

DISCUSSION

104

SUMMARY AND CONCLUSIONS

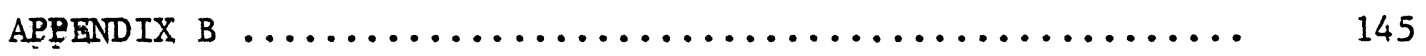

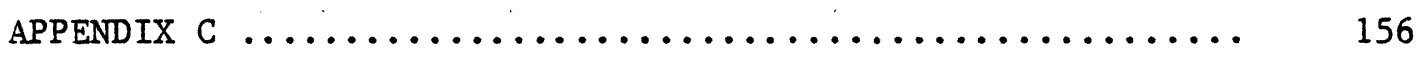




\section{LIST OF TABLES}

$\underline{\text { Table }}$

Page

I. Pretreatment demographic and history data for standard and maintenance conditions. . . . . . .

II. Intercorrelations between reported average cigarettes per day, Carbon Monoxide Alveolar \% (COa\%) and

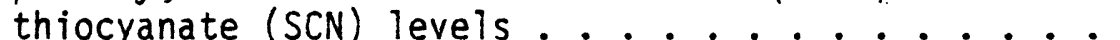

III. MANOVA summary table for smoking measures (cigarettes/ day, $\mathrm{COa} \%$, and $\mathrm{SCN}$ ) between the treatment conditions and assessment periods . . . . . . . . . .

IV. Analysis of variance summary table for simple effects on cigarettes per day. ............

V. Mean cigarettes smoked per day for the maintenance and standard conditions for each assessment. . . . . . .

VI. Analysis of variance summary table for carbon monoxide levels (COa\%), simple effects..........

VII. Means and standard deviations of carbon monoxide

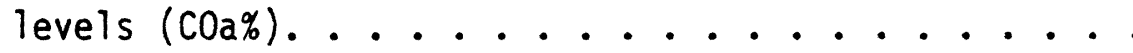

VIII. Analysis of variance summary table for saliva thiocyanate (SCN) levels, simple effects ......

IX. Means and standard deviations of saliva thiocyanate (SCN) levels in ug/ml. .............

$x$. Cessation and smoking frequency for standard and maintenance conditions at post, one month, two months, three months and six months after quit day ......

XI. MANOVA summary table for self-report measures (HLOC) and (STAI) .................. 70

XII. Analysis of variance summary table for Health Locus of Control (HLOC) ............... 71

XIII. Means and standard deviations for HLOC . . . . . 72

XIV. Analysis of variance summary table for simple effects for the STAI ............. 73 
XV. Means and standard deviations for STAI scores. . . . 74

XVI. MANOVA summary table for health measures: Systolic Blood Pressure (SBP), Diastolic Blood Pressure (DBP), Heart Rate (HR), Weight (KG), Forced Expiratory Volume, 1 second (FEV $)$ and Forced Expiratory Volume, .5 seconds (FEV.5) ............ 76

XVII. Simple effects analysis of variance table for SBP. . . 77

XVIII. Mean and standard deviations of systolic blood pressure (SBP) readings in $\mathrm{mm} \mathrm{Hg}$....... 78

XIX. Simple effects analys is of variance summary table for DBP ................... 80

XX. Means and standard deviations of diastolic blood pressure (DBP) readings in $\mathrm{mm} \mathrm{Hg}$........ 81

XXI. Simple effects analysis of variance summary for HR. . . 82

XXII. Means and standard deviations for heart rate (HR) in beats per minute (BPM)......... 83

XXIII. Simple effects analysis of variance summary for weight

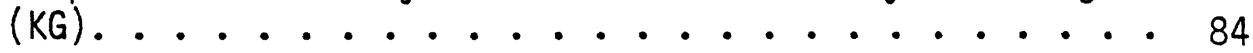

XXIV. Means and standard deviations of weight in KG ... 85

XXV. Simple effects analysis of variance summary table for

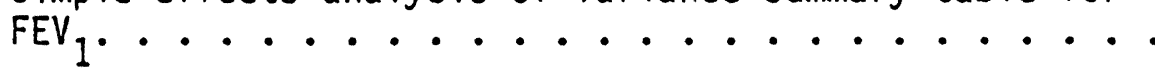

XXVI. Means and standard deviations for one-second Forced Expiratory Volume $\left(\mathrm{FEV}_{1}\right)$ in liters....... 88

XXVII. Simple effects analysis of variance summary table for one-half second Forced Expiratory Volume $\left(\right.$ FEV $_{.5}$ ). . . 89

XXVIII. Means and standard deviations of one-half second Forced Expiratory Volume $\left(\mathrm{FEV}_{.5}\right)$ in liters ....... 90

XXIX. Multiple regression on cigarettes per day at six month follow-up: Results of a stepwise multiple regression

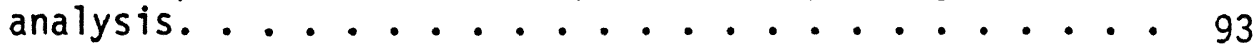


$X X X$. MANOVA summary table for change scores on health measures for successful and unsuccessful subjects at three month follow-up ............ 96

XXXI. MANOVA summary table for health change scores of successful and unsuccessful subjects at six month follow-up ..................... 97

XXXII. Mean change scores on health assessment variables at three and six month follow-up for successful and unsuccessful subjects ............ 98 


\section{INTRODUCTION}

\section{Health and Tobacco Smoking}

Smoking tobacco products clearly and unequivocally poses prominent risks to the health and mortality of the tobacco user. Smoking cigarettes is the single most important preventable environmental factor contributing to illness, disability and death in the United States (USDHEW, 1979). The mortality ratio of smokers is 1.7 deaths to each death of non-smokers (Rogot, 1979; USDHEW, 1979). The mortality ratio increases as the amount of tobacco smoked increases. The sources of the increased mortality ratio include cancer, cardiovascular heart disease (CHD), and pulmonary disease. The strong increase of CHD associated with smoking has been described by Matarazzo (1982) as one of the most important challenges to psychology and behavioral health. Understanding how tobacco use endangers health has become an important concern for psychology.

Cancer. Analysis of the manner by which smoking contributes to increased mortality has revealed both causal and associative links between smoking and pathogenesis. In the case of cancer, causal links have been established between smoking tobacco and lung cancer, cancer of the larnyx, oral cancer, and cancer of the esophagus (USDHEW, 1979). Lung cancer has an extremely high mortality rate. Associative links between smoking tobacco and cancer of the urinary bladder, kidney and pancreas have also been found (USDHEW, 1979). 
Several carcinogenic elements have been identified in both the particulate matter ("tar") and gaseous matter of tobacco smoke. While all of the potential active carcinogenic materials of tobacco are too numerous to list here, prominent examples include formaldehyde, dimethynitrosamine, dialkylinitrosamines, nitropyrrolidine, nitrosopiperidine, hydrazine, and vinyl chloride. The concentrations of these materials range from a single $\mathrm{ng}$ per cigarette to as much as 100 ug per cigarette. The varied concentrations of the substances has made implicating a single or a single set of active carcinogens difficult, but laboratory research has indicated numerous substances in tobacco smoke capable of promoting tumor growth or increasing tumor incidence. Obe (1981) also noted the mutagenic qualities of acetaldehyde from ethanol use, as well as the mutagenic qualities of tobacco smoke. The effects of two or several sources of carcinogens has not been established, but the effects may be synergistic. Broos and Combs (1976), for example, found alcohol and tobacco use in women yielded onset of oral cancer fifteen years earlier than women who did not use alcohol or tobacco. Exposure to tobacco alone produced only a slight age shift, and exposure to alcohol alone yielded no age shift.

In terms of "tar" levels, there has been consistent findings of dose-response gradients for tar level and tumor yield in laboratory cultures (USDHEW, 1979). However, the reduction of tumors in tissue cultures with the reduction of tar levels may be negated by other mutagenic elements in tobacco smoke and behavioral qualities of smoking. Hammond, Garfinkel, Seidman and Lew (1976) indicated that reductions of 
tar and nicotine did not make smoking safe, but that there was a slight reduction of risk by switching to low tar and nicotine cigarettes. Even so, the mortality ratio of non-smokers was only .66 for each death of a low tar and nicotine smoker. Further, the lung cancer mortality ratio of non-smokers from lung cancer was only .15 for each death of low tar and nicotine smokers from lung cancer. There has also been evidence that smokers, especially dependent smokers, may compensate for low nicotine levels by deeper and more frequent puffs (Russel1, Epstein and Dickson, 1983). Behavioral qualities as compensation for low tar and nicotine may account for the lack of benefit from "safer" cigarettes.

In sum, prospective and retrospective epidemological studies have indicated causal links between tobacco smoking and lung cancer, cancer of the larynx, cancer of the esophagus and oral cancer. Associative links implicate smoking tobacco with cancers of the urinary bladder, kidney, and pancreas. The mechanisms of the mutagenicity appear to be multiple, and possibly synergistic with other mutagenic elements. There has been research suggesting that the mutagenic potential of tobacco smoking can be reduced (Hammond et al., 1976), but there has been no findings of any level or manner of smoking tobacco which reduced mutagenic rates to near those of non-smokers.

Cardiovascular Disease. Cancer is not the only risk to increased mortality from smoking tobacco. The evidence regarding causal links between smoking and cardiovascular disease has been particularly strong. More coronary and aortic atherosclerosis occurs among tobacco users, although the mechanism is uncertain. Myocardinal infarction has causal 
links with tobacco use, probably related to the acute and chronic effects of nicotine use. Nicotine aggravates angina, by increasing both oxygen demand and cardiac output. Not surprisingly, sudden cardiac death has been found to be greatly elevated among smokers (USDHEW, 1979). For sudden cardiac death, the mortality ratio of smokers has been found to be 1.9 for each non-smoker death, when smokers average 10-20 cigarettes per day. The mortality ratio for smokers increased to 3.36 for each non-smoker death, when smokers average more than 20 cigarettes per day (USDHEW, 1979).

Angina pectoris has been induced by tobacco use. Angina pectoris has been related to nicotine and carbon monoxide from cigarettes. Carbon monoxide levels as low as $2.68 \%$ have yielded angina under exercise conditions. Cerebrovascular disease mortality ratios have been shown to be greatly elevated by tobacco smoking. Tobacco users mortality ratio have been shown to be 5.7 for each non-smokers death for cerebrovascular disease. The tobacco may interact with birth control pills among females to produce a higher mortality ratio, but this effect has been described as "not well established" (USDHEW, 1979). Peripheral vascular disease, as thrombosis and clauidication in the leg, increases with tobacco smoking. Further, the peripheral vascular effect appears to be synergistic with diabetes. Aortic aneurism with the atherosclerotic type has been linked with tobacco use. Again, the mechanism of the aneurysm has remained uncertain. Hypertension has been linked to cigarette use. Chronic hypertension has not appeared to be induced by tobacco use, but chronic hypertensives greatly improve mortality ratios 
by stopping smoking. Smoking has been related to paroxysmal arterial hypertension, with elevations of aterial blood pressure of greater than $50 \mathrm{~mm} \mathrm{Hg}$ systolic and $20 \mathrm{~mm}$ diastolic.

Pulmonary Distress. Other links between smoking and pulmonary disorders have been noted by researchers. Cigarette smoking has been linked to chronic bronchitis, emphysema, impairment of respiratory symptoms (Rogot, 1974; USDHEW, 1979). Prospective studies have indicated that the overall risk ratio of dying from bronchitis and emphysema among cigarette smokers was 6.1 relative to non-smokers risk of 1.0 (USDHEW, 1964). In addition, there has been a great deal of evidence of increased morbidity associated with cigarette smoking, particularly increased prevalence of respiratory symptoms (Higgins, 1975). The mechanisms of tobacco-induced pulmonary distress appear to be related to the ciliatoxic effects and cytotoxic influence of tobacco smoke on pulmonary cells.

In sum, the health threats posed by tobacco smoking have been well researched, with a great deal of convergent and consistent evidence. Smoking tobacco increases the incidence of several kinds of cancer, cardiovascular heart disease and pulmonary disease. The evidence for these links between tobacco smoking and disease have been unequivocal, although the manner and mechanisms of the pathogenesis has not been unambiguously established (see USDHEW, 1976). Behavioral methods for smoking cessation have sometimes not fully considered the specific health threats posed by tobacco use in the design of interventions. Both rapid smoking and nicotine fading methods, for example, carry some 
specific potential problems which were not fully considered when the methods were first impiemented. For this reason, consideration of the kinds of health threats posed by tobacco use and the mechanism of the health threats has considerable clinical utility.

\section{Mechanisms of Tobacco-Induced Disease}

Research on the mechanics of tobacco-induced disease has suggested four general areas where tobacco could influence disease processes. First, ciliatoxic activity of cigarette smoke has been noted (Gori, Ballista, Thayer, Guerin \& Lynch, 1976). Ciliatoxicity refers to the inhibition of cilia action, with the resulting loss of avelor space or activity. Hydrogen cyanide (HCN), formaldehyde and carbon monoxide have all been implicated as ciliatoxic agents, although $\mathrm{HCN}$ has shown the strongest relationship $(\underline{r}=91)$. Second, cytotoxicity of tobacco smoke has been noted (Gori et al., 1976). Cytotoxicity refers to the influence of tobacco smoke components upon growth and development of cell cultures. Formaldehyde and weak acids of cigarette smoke have been shown to be related to cytoxicity most strongly (Gori, et al., 1976). Charcoal filters reportedly reduce cytotoxic effects (Thayer \& Kensler, 1964). Third, alveolar macrophage inhibition (AMI) has been advanced has a mechanism of tobacco-induced pathogenesis. The process of AMI refers to the inhibition of bacteria from suspension by aveolar macrophages. Loss or reduction of AMI activity could result in increased morbidity through increased infection rates. Reductions in 
AMI activity have been associated with high carbon monoxide and carbon dioxide levels (Gori et al., 1976; Green \& Canolin, 1967). Finally, the acute and chronic effects of nicotine have consequences for cardiovascular function.

The specific influences of nicotine have been known to be complex. Nicotine increases the release of catecholamines, norepinepherine and epinephrine. The increased arousal then results in increased blood pressure, heart rate and cardiac output. Stroke volume, velocity of contraction and myocardial countractile force all increase. 0xygen consumption of the heart increases, as does the coronary blood flow. Arrythmias occur with nicotine use. In terms of metabolic function, nicotine use results in mobilization and utilization of free fatty acids. There are also hyperglycemic effects. The half-life of nicotine is approximately 20-30 minutes after administration. It is nicotine that has been most frequently described as the probable addictive agent of tobacco smoking (USDHEW, 1979).

In sum, multiple consituents of tobacco smoke have been implicated as health-threatening agents. The multiple cancerogenic agents present in the particulate matter of smoke has been noted. Further, hydrogen cyanide, formaldehyde and carbon monoxide from cigarettes act in a manner which could yield pulmonary distress and disease. The activity of formaldehyde and weak acid components of tobacco smoke make recovery from pulmonary distress more difficult. In a similar way, carbon dioxide and carbon monoxide from tobacco smoke may inhibit the ability of lungs to cope with foreign agents. Finally, both nicotine and carbon 
monoxide have acute cardiovascular effects that carry demonstrable risks. The long-term consequences of nicotine and carbon monoxide loads are associated with CHD, but the mechanism remains uncertain (see USDHEW, 1976). The manner in which tobacco constituents pose health risk carry implications for possible "safer cigarettes" and controlled smoking efforts. In particular, the multiple manners in which tobacco can pose health risk indicates the difficult task the development of a "safe cigarette" faces. In a similar way, the multiple avenues for morbidity indicates controlled smoking efforts must alter inhalation of particulate matter, gaseous components and nicotine levels. Further, controlled smoking ideally would need to develop methods to improve the ability with pulmonary tissue to recover or repair damage. These are - difficult concerns for both the development of "safer cigarettes" and controlled smoking.

Clinical Utility. Because the knowledge that cigarette smoking is dangerous to health is widespread, there has been a tendancy to neglect the specific manner by which smoking threatens health. This neglect has been evident in the design of psychological interventions aimed at reducing smoking as well. for example, Glasgow, Klesges and Gegelman (1983) claim demonstration of significant treatment effects. However, Glasgow et al. (1983) did not reduce smoking levels to the point that subjects would be expected to incur reduced risk in terms of morbidity or mortality. Thus, the effectiveness claimed by Glasgow et al. (1983) appears to be overstated. 
Knowledge of the mechanisms of tobacco induced health problems suggest psychological treatment programs need to monitor aspects of the health of subjects attepting smoking cessation. Assessment of carbon monoxide (CO) levels can indicate some of the acute cardiovascular risk a subject faces. Carbon monoxide levels below $2.0 \% \mathrm{COa}$ have not been found to be associated with any evident impairment of health. Assessment of thiocyanate ( $\mathrm{SCN}$ ) levels may correspond to hydrogen cyanide intake, although this has not been established. Monitoring of even rudimentary cardiovascular functioning, such as blood pressure and pulse, have not been done in psychological research on smoking cessation. There has been recent concern regarding the possibility of behavioral compensation resulting in increased ingestion of toxic substances when subjects switch to low-nicotine cigarettes (McMorrow and Foxx, 1983). There has been a great deal of research in this area, al though the results remain ambiguous at this time. However, there has been no method to evaluate the influence of smoking cessation efforts on the inhalation of tar or particulate matter. Evaluation of pulmonary functioning of subjects in smoking cessation programs has been provided only in a few studies (Paxton and Scott, 1981). Thus, there has been little direct assessment of health functioning in smoking cessation programs. the lack of direct assessment makes the contribution of smoking cessation efforts to health uncertain. Further, there has been some suggestion that some psychological treatments of smoking may actually result in increased health risk. Rapid smoking has been noted to pose risk for acute cardiovascular dysfunction (Horan, Hackett, 
Nicholas, Linberg, Stone and Lukaski, 1974). The possibility that behavioral compensation may actually increase health risk when nicotine fading procedures are used have not been ruled out.

In sum, evaluation of smoking cessation efforts needs to directly monitor indices of health functioning. Monitoring of health functioning can indicate the specific areas of risk reduction influenced by smoking cessation. In addition, monitoring of health functioning can indicate iatrogenic effects of some cessation methods promptly.

\section{Smoking Tobacco: An Addictive Process?}

There has been a great deal of debate regarding the addictive potential of cigarette smoking, including the existence of nicotine regulation and compensation (McMorrow and Foxx, 1983). Efforts to assist smoking cessation, in particular, seemed to neglect any addictive processes in the early smoking cessation programs. Emphasis, instead, was on the learning-habit processes that influenced smoking (Yates, 1975).

Addiction is a persistent and compulsive manner of behavior in regard to the use of substance with pharmacological properties. Addiction to a substance can be defined by three conditions:

(1) The development of tolerance to the substance.

(2) The presence of withdrawal symptoms when the substance is removed or unavailable. 
(3) The use or administration of the substance across a wide variety of situations or circumstances. (Jaffe, 1975).

In considering cigarettes in this context, the evidence indicates cigarette use can be addictive, and nicotine appears to be the most likely agent. The confusion regarding the addictive potential of cigarettes may spring from rigid notions of addiction. Addiction is not characterized by maintenance of "flat" physiological homostatic levels. Solman and Corbit (1973) indicated, in fact, that addiction may be considered as systematic alterations of psychological functioning. Titration is not necessary for addiction, but some tendency toward titration is expected. For example, heroin users do not maintain consistently somnolent states, but rather alter their level of arousal within broad ranges of functioning. Animals self-administering addictive substances show similar ranges in titration. Addictive is a labile phenomenon, rather than one of consistent blood levels of a substance. McMorrow and Foxx's (1983) consideration of nicotine regulation and compensation may obscure the labile nature of addictive phenomenon. Perfect (or even close) nicotine regulation is not to be expected between radically differing nicotine concentrations. Behavioral compensation for varied nicotine levels, on the other hand, is to be expected. For example, behavioral compensation need not necessarily be efficient or effective in maintaining nicotine regulation. Recent research (Benowitz, Hall, Herning, Jacob, Jones and Osman, 1983) indicated exactly this effect. Smokers of low yield cigarettes still maintain similar blood levels of cotinine, a metabolite 
of nicotine. Benowitz et al. (1983) indicated that subjects may even overcompensate for low nicotine levels yielding high blood cotinine levels for low cigarette nicotine ratings.

Tolerance. Tolerance to nicotine develops rapidly in both an acute and a chronic manner. The half-life of nicotine is approximately 20 to 30 minutes, yielded rapid and brief acute effects that are primarily related to cardiovascular arousal (Stolerman, Fink \& Jarvik, 1973). The metabolic and behavioral effects last as long as 90 days (Russell, 1976). The components of cigarette smoke that contribute to tolerance have been reported to be nicotine and carbon monoxide. Nicotine tolerance develops to metabolic functioning and nausea. The levels of nicotine excretion increase as the number of cigarettes per day increases. Nicotine excretion also varies inversely with $\mathrm{pH}$ levels. Tolerance to carbon monoxide also develops to cardiovascular effects. Cross-tolerance develops to caffeine and theophyline, with both of these substances becoming metabolized more rapidly as tolerance develops to tobacco.

Withdrawal. A withdrawal syndrome to tobacco use occurs. Described as the Tobacco Abstinence Syndrome, the withdrawal is marked by central nervous system (CNS) and cardiovascular system (CVS) effects. Prominent effects are reduced pulse, blood pressure, epinephrine and norepinephrine secretion. The behavioral characteristics are craving, tension, irritability, restlessness, depression, and problems with concentration. Withdrawal is also characterized by hypoarousal and increases in low frequency and high amplitude EEG. Some individuals 
experience sleep disturbances, restlessness, and gastrointestinal constipation (Russel1, 1976). Further, there is a metabolic slowing, eventually resulting in more efficient metabolic functioning and, hence, weight gain (Glauser, Glauser, Reidenburg, Rusy and Taharida, 1970). The metabolic slowing is marked by heart rate reductions, reduced glucose levels and lowered oxygen consumption.

Extensive Use. Cigarettes are used across a variety of circumstances and settings. Cigarettes particularly lend themselves to high frequency use, with only limited social sanctions to date. Inhalation of cigarette smoke yields a boli of nicotine, which peaks rapidly to a plasma concentration of over $30 \mathrm{ug} / \mathrm{ml}^{-1}$. The boli goes from the lung to the blood-brain barrier in approximately 7.5 seconds, more rapidly than would an intravenous injection from the arm. The nicotine readily passes the blood-brain barrier. For a person smoking twenty cigarettes per day, with 7-10 puffs per cigarette, more than 7,300 bolus per year would be taken (Russel1, 1976). The pervasive self-administration of a stimulating substance appears likely to become associated with a variety of cues (Siegel, 1977).

Summary. In sum, the evidence indicates that the theoretical parameters for addiction to cigarettes are excellent. However, addiction is not wholly a pharmacological phenomenon, as can be noted in the cases where addiction occurs to a low dose of a substance. Nor is addiction the inevitable result of persistent use of a substance known to have addictive qualities. Addiction is enhanced by conditionability to environmental cues in the case of smoking. At the same time, 
addiction is moderated by alterations in smoking topography. Lack of inhalation of cigarette smoke reduces the nicotine boli to only .1 to .3 $\mathrm{ng} / \mathrm{ml}^{-1}$ of plasma (Russe11, 1976). However, observations of smoking patterns and research suggest that nicotine is an addictive, if not the single addictive agent, in cigarettes. Rarely are non-nicotine cigarettes smoked for more than few attempts. The demonstrations of tolerance, withdrawal and self-administered persistent use are clear. Further, nicotine appears to induce the necessary hedonic tone or effect as well. Smoking patterns generally approximate the half-life of nicotine. Utilization of CNS nicotine antagonists have been shown to increase cigarette consumption. Problems with the attribution of the addictive potential of cigarettes to nicotine include the covariation of tar levels with nicotine. Carbon monoxide appears to lack sufficient hedonic characteristics to qualify as an addictive agent. The cautious but consensual decision regarding nicotine has been that nicotine is a necessary, but not sufficient condition for addictive potential in cigarettes (USDHEW, 1979).

Clinical Utility. The clinical utility of considering the possibility of human addiction to cigarettes appears to be unfulfilled. The mechanism of cigarette addiction appears to be nicotine, but the evidence for nicotine regulation itself has been debated (McMorrow and Foxx, 1983). Nicotine regulation, the maintenance of a characteristic level of nicotine in the body, has been demonstrated by some basic research, but not applied research (Russe11, 1980). McMorrow and Foxx (1983) claim that nicotine regulation must be demonstrated before 
assessing behavioral compensation. Some authors have indicated that smoking patterns maintain blood nicotine levels (Russell, 1980). However, the research results have been inconsistent. Possible explanations include the motivations of the subjects. The lack of nicotine regulation in applied research may occur because the subjects were motivated to not compensate for low nicotine levels. Further complications can occur if the subjects are not dependent upon nicotine. Finally, as noted earlier, even addiction does not imply any tendency to maintain any homostatic balance, but rather to strive to maintain hedonic - ahedonic variations in functioning.

The results of research on behavioral compensation for low nicotine levels support this view. For example, Turner, Sillett and Ball (1974) noted that the number of cigarettes smoked per day increased as nicotine levels fell. However, calculations indicated that even with the increase in the number of cigarettes, the dose of nicotine in $\mathrm{mg} /$ day fell drastically. No data was provided on any smoking topography changes. Russell, Wilson, Patel, Cole and Feyeraband (1973) also indicated that subjects smoking low nicotine cigarettes increased their smoking rate. However, the subjects smoking low nicotine cigarettes again did not approach the cumulative nicotine levels of the subjects in the high or normal nicotine conditions. In a similar study, Russell, Wilson, Cole, Idle and Feyeraband (1973) compared the carbon monoxide percent of smokers smoking "extra mild" and "non-mild" cigarettes. The subjects were instructed to puff every 40 seconds, and the number of puffs were controlled for each subject. Thus, only mild compensation 
(if any) could occur. Under those circumstances, the carbon monoxide percent were lower for the "mild" cigarettes. Finally, Russell, Epstein and Dickson (1983) demonstrated that during rapid smoking trials, subjects using low nicotine cigarettes took more puffs, with more volume, and a larger puff and trial duration. It was difficult to assess the Russell et al. (1983) data, but it did not appear that subjects completely compensated for nicotine levels. Ashton, Stephney and Thompson (1979) also indicated that subjects compensated for nicotine levels, but less than expected by mechanically dictated nicotine smoking. Fayerstrom and Bates (1979) indicated that more dependent subjects smoked cigarettes more effectively (i.e. more puffs, longer puffs) than less dependent subjects. In addition, weaker nicotine cigarettes were smoked more effectively than stronger nicotine cigarettes.

The complexity of the manner of behavioral compensation was indicated by Ossip-Klein, Epstein, Winter, Stiller, Russell and Dickson's (1983) report. In the Ossip-Lein et al. (1983) study, one group was "brand-faded" to lower tar/nicotine level cigarettes while the other group was not "brand-faded". There was no significant difference in the number of cigarettes smoked during brand fading. However, the "brandfaded" group did evidence significantly greater puff duration and puff volume compared to the non-faded group. Again, it appeared unlikely that the behavioral compensation could have fully compensated for the reduced nicotine levels. Prue, Krapfl and Martin (1981) did not find that progressive reductions of nicotine were compensated for by $\mathrm{CO}$ 
levels, thiocyanate levels or the number of cigarettes smoked per day among subjects in a smoking cessation program. As McMorrow and Foxx (1983) noted, only direct nicotine assessment, perhaps by blood or urine content analysis could address the question of how effective nicotine regulation is in regards to behavioral compensation. In general, however, it does appear that subjects compensate for FTC low nicotine levels behaviorally, but the subjects do not fully compensate for the low nicotine levels.

Clinically, this suggests that nicotine fading can potentially aid cessation efforts, especially among motivated subjects. In addition, judicious fading may reduce some of the aversive "b" state withdrawal symptoms that return to smoking may relieve and hence reinforce smoking.

Managing the positive, reinforcing effects of nicotine use appears to be more difficult. Nicotine provides both arousal and skeletal muscle relaxation, yielding a positive "relaxed alertness". Strong secondary reinforcement may come from peers. The tobacco industry has been notorious for its' efforts to associate smoking with sex, well-being, fitness, masculinity and femininity. For the primary positive reinforcement, the initial subjective sense of "relaxed alertness" fades rapidly. In twenty minutes, the rewarding physiological effects of smoking are absent or greatly reduced. Again, this is near an ideal addictive paradigm. There appear to be no long-term sense of psychological well-being after a period of smoking (Costa and McCrae, 1981). Nor has cessation from smoking been associated with any significant psychological costs. Pertschuk, Pomerlan, Adkins and Hirsch 
(1979) did not find any affective problems, increased use of mental health facilities, or increased use of psychotropic medication or alcohol among subjects who had stopped smoking. Thus, it seems that the prominent, positive primary reinforcement of nicotine has been the most troublesome aspects in cessation. Levinson, Shapiro, Schwartz, and Tursky (1971) may have encountered the problem of strong positive reinforcement when they noted their subjects had the greatest difficulty when they were only smoking 12-14 cigarettes per day. Levinson et al. (1971), appropriately suggested combining psychological and physiological elements in the treatment of smoking to manage such problems.

Facilitation of the use or effects of one substance by another can sometimes suggest mechanisms of activity. In terms of an addictive substance, synergistic or antagonist responses may even indicate sites of neuroactivity. For nicotine, the coffee and tea cross-tolerance effect has already been noted (Russe11, 1976). This cross tolerance does indicate the stimulant qualities present in nicotine. Marshall, Epstein and Green (1980) also noted another aspect when they tested the cigarette smoking among subjects drinking water, a coffee substitute, coffee and decaffinated coffee. The subjects with coffee and decaffinated coffee smoked more cigarettes, leading the authors to conclude that coffee provides the setting which encourages smoking. Griffiths, Bigelow and Liebson (1976) demonstrated that tobacco use could be facilitated by entanol administration. It has been difficult to fully integrate the evidence of the ethanol facilitation effects, as the authors appeared to rule out most competing social-environmental 
explanations. These may be pharmacological events influenced by ethanol which increase nicotine or tobacco use, but these events have not been identified.

Conclusion. In terms of addictive processes, it can be concluded that tobacco use can be addictive in the classical meaning of the term addiction. The addictive element in tobacco is probably nicotine. Like all addictive processes, nicotine interacts strongly with environmental and contextual cues. Nicotine has been shown to be cross-tolerant to common stimulants as caffeine and theophyline. Nicotine use has been shown to be facilitated by ethanol, although the mechanism of this facilitation remains undetermined. Nicotine, however, produces tolerance, can yield withdrawal signs, and lends itself well to compulsive, high frequency use. Most of these factors have been neglected in the psychological assistance of smoking cessation efforts.

\section{Smoking Cessation Methods}

Given the serious and overwhelming scientific concensus on the threatening nature of cigarette smoking, it has not been surprising to see extensive efforts to assist smoking cessation. Unfortunately, these efforts to assist smoking cessation have not been very effective. Varied strategies of smoking cessation have been attempted, with promising short-term results, but little maintenance of cessation. Today, while thirty million smokers have stopped smoking, one-third of Americans still smoke. Smoking has actually increased in young 
females. Because of the continuing prevalence and the concern with the associated risks, efforts to improve smoking cessation programs have continued. Worksite initiatives (Orleans and Shipley, 1982), as well as traditional therapeutic strategies, appear to still be developing. Wynder and Hoffman (1979) recommend three approaches to combat the continuing smoking problem. First, antismoking programs to prevent youth from getting the habit. Second, smoking cessation programs for current smokers. Third, a less harmful cigarette for smokers who will not quit.

Early reviews of smoking cessation programs were critical of the seminal programs (Bernstein, 1969; Hunt and Matarazzo, 1973). McFall and Hammen (1971) noted a post-treatment abstinence range of $7 \%$ to $40 \%$, with the average being $26 \%$. The abstinence rate after six months post therapy fell to a range of only $9 \%$ to $17 \%$, with the average being about 13\%. Recent reviews have been less pessimistic, but problems still abound. Leventhal and Cleary (1980) noted that smoking cessation has been marked by the following qualities. First of all, there has been a strong post treatment cessation effect that decays over time as relapse to smoking occurs. Second, there has been a high dropout rate in the smoking programs. Third, the relapse that does occur has been substantial and nearly eliminated treatment effects. Fourth, there appears to be little difference in the success rates of various programs. Leventhal and Cleary suggest that new smoking cessation research focus on factors effecting dependence and self-regulation of smoking. 
Despite these pessimistic reviews, some methods of smoking cessation appear to have considerable promise. Rapid smoking methods (Lichtenstein, Harris, Birchler, Wald and Schmahl, 1973) have reported promising abstinence rates. Nicotine facing procedures appear to have yielded high initial cessation rates followed by $40 \%$ abstinence rates 1-1/2 years later (Foxx, Brown, and Katz, 1981). Topographical analys is of smoking behavior has not yet been widely applied in cessation programs, but preliminary research indicated that alteration of smoking patterns can generalize to other situations and other smoking patterns (Frederiksen and Simon, 1978a,b). Controlled smoking strategies have shown promise, especially with the use of a contingency contract to achieve reduction (Frederiksen, Peterson and Murphy, 1976). Broad spectrum approaches to smoke cessation, incorporating a number of diverse strategies to aid cessation have also reported favorable results (Lando, 1977). Problems still have occurred in the more promising recent treatment of smoking, however. Rapid smoking has been criticized for the health risk posed by the use of the technique itself (Horan, Hackett, Nicholas, Linberg, Stone and Lukaski, 1974). Nicotine fading requires wider research to confirm the promise of the non-aversive methods. Controlled smoking efforts appeared to be logically consistent with operant shaping principles, but the appropriateness of controlled use of addictive-type substances has been the source of considerable controversy. Broad-spectrum or comprehensive programs have not always achieved results as promising as the work of Lando (1977). In all 
areas, the crucial question of the methods best able to prevent or postpone relapse remains.

The development of rapid-smoking came from the search for a more response-compatible aversive stimuli for smoking. Early aversive methods utilized electric stimulation as the aversive method. Russell, Armstrong, and Patel (1976) were not able to show superior smoking cessation results for contingent shock when compared to non-contingent shock. However, Dericco, Brigham and Garlington (1977), in a multiple baseline design, indicated that 6-12 mAmp shock administered to the forearm contingent upon smoking was effective in suppressing smoking. The treatment required 18 sessions of approximately thirty minutes with 24 shocks per session. Problems in maintenance and generalizability may be severe in such a treatment paradigm, however. The lack of any intrinsic relationship between shock and smoking, the experimentlaboratory basis of the treatment, and the brevity of the treatment, al1 pose problems for maintenance and generalizability.

Rapid smoking appeared to be a superior method of delivering aversive stimulation contingent upon smoking. Rapid smoking has consisted of inhaling a cigarette once every six seconds until a degree of discomfort or distress was reached. Rapid smoking promised to be superior to other aversive methods because it was self administered and influenced the same sensory channels as the smoking itself. Lando (1975) reported 64\% post-treatment abstinence utilizing this method. However, the abstinence rate fell to $36 \%$ in the two month follow-up. Lichtenstein et al. (1973) also indicated a marked smoking reduction via 
rapid smoking at termination of treatment, as well as slightly more than $50 \%$ abstinence rate at six month follow-up. Raw and Russell (1980) reported that rapid smoking reduced the reported desire for smoking, but this appeared to be a short-lived, subjective effect. Subtle variations of the rapid smoking method may explain the variety of outcomes reported for rapid smoking. For instance, Merbaum, Avimier and Goldbery (1979) noted that the development of a strong aversion (i.e. vomiting) was related to subsequent cessation. In general, research appeared to indicate that rapid smoking methods contributed to abstinence (Schmal, Lichtenstein and Harris, 1972; Hackett and Horan, 1979).

Rapid smoking procedures have been shown to alter physiological functioning, at times in a manner which imposes some risk. Significant increases in heart rate, blood pressure and respiration have been noted (Poole, Sanson-Fisher, German and Harker, 1980). Horan, Linberg and Hackett (1977) indicated that nicotine poisoning may be the aversive element in rapid smoking. In addition to altered respiration and heart rate, Horan, Linberg and Hackett (1977) noted a 7-10\% increase in carboxyhemoglobin and the occurrence of cardiac arrhythmias. The mean lethal dose (MLD) of nicotine approximates $60 \mathrm{mg}$. Rapid smoking could yield as high of a dose of $40 \mathrm{mg}$ of nicotine. The great risks possible in rapid smoking methods lead to cautionary notes (Horan, Hackett, Nicholas, Linberg, Stone and Lukaski, 1974; Hauser, 1974). Other reports investigating the effects of rapid smoking acknowledge the risks, but point to rapid smoking as a beneficial method for heal thy subjects (Hall, Sachs and Hall, 1979). Some researchers have attempted 
to develop safe alternative methods for acquiring a smoking aversion (Hackett and Horan, 1978).

Comprehensive approaches, often incorporating aversive methods, also yield good short-term results. Lando's (1977) study may be especially important because the broad spectrum approach also yielded impressive maintenance, with $70 \%$ abstinence at six month follow-up. Elliott and Denney (1978) found a multiple component treatment approach was superior to both a no-treatment control and a placebo treatment control. Elliott and Denney's multiple component treatment was also superior to rapid smoking alone as well. Other comprehensive approaches, such as Best, Owen and Trentadue (1978) appear promising. Lando (1978) has cautioned that comprehensive programs may become overly complex and hence less effective, however.

Nicotine fading (Foxx and Brown, 1979; Foxx, Brown and Katz, 1981) appeared to be one of the most promising non-aversive methods, with $40 \%$ abstinence at 1-1/2 years follow-up. The development of methods focusing on altered smoking topography may also hold future promise as a component in a comprehensive program. Lando (1977) points to the inclusion of booster sessions, structured group support, and behavioral contracts as maintenance enhancing strategies.

Contingency contracting in smoking, a seemingly obvious intervention, has not been widely researched. Very good short term results appear evident, however, as noted in the Elliott and Tighes (1968) research and the work of Winett (1973). Elliott and Tighe (1968) achieved $84 \%$ abstinence rates at post-treatment, but the effects were 
maintained only moderately at one year follow-up, however, with $38 \%$ abstinence. The longest contract only extended 16 weeks, however. Winett (1973) also found positive effects for a contingency monetary contract, although the results faded for the longer follow-up. Spring, Spipich, Trimble, and Goechkner (1978) also achieved $71 \%$ abstinence rates with a monetary contingency in a brief program. Spring et al. (1978) recommended the study of varied contract length. Paxton (1980) noted that monetary deposit contingency group smoked less in the short-term follow-up than smokers without the monetary contingency. In a similar study, Paxton (1981) varied the amount and frequency of repayments, finding that increasing the amount of money returned improved abstinence rates. Increasing the rate of monetary returns also improved abstinence. Paxton recommended further research on schedule effects of contingent contracts.

The problems in treating cigarette smoking were not fully appreciated in early efforts. Short-term cessation appeared to be achievable, but long-term maintenance difficult. The addictive aspects of nicotine may have been underestimated. Smokers may adjust smoking topography to compensate for altered nicotine availability (Frith, 1971; Goldfarb, Jarvik and Glick, 1970; Goldfarb and Jarvik, 1972 and Jarvik et al. 1978). The withdrawal symptomology of smokers (Elgerot, 1975) has been noted as decreased adrenalin and noradrenaline excretion, increased irritability and aggression, and a marked decrease in social activities. Speculation of the role of nicotine in the addiction has not been new (Finnegan, Larson and Haag, 1945), but efforts to reduce 
risk by nicotine titration have been a recent development (Gori, 1976). Behavioral compensation for nicotine levels have not always been found (Prue, Krapfl and Martin, 1981). The findings of Prue, Krapfl and Martin indicated that progressive reductions of nicotine and tar did not result in reciprocal changes in smoking topography for individuals in a smoking cessation program. Laboratory methods finding titration effects generally use subjects unmotivated for cessation, perhaps accounting for the discrepancy. Moss and Prue's (1982) findings that the evidence for nicotine regulation does not permit definitive conclusions appears apt at this point.

There has also been a recent interest in the interaction of the pharmacological qualities of smoking with social and learning influences (Schachter, 1977; Schachter, 1978; and Schacter, Silverstein and Perlick, 1977). Miller, Fredericksen and Hosford (1979) noted light smokers were more effected by social conditions than heavy smokers. Light smokers would take more and longer puffs when alone, and would decrease the amount inhaled when involved in social interaction. Schacter, Silverstein and Perlick (1977) have demonstrated how stress-inducing social interactions could alter smoking patterns in at least heavy smokers. Dobbs, Strickler and Maxwell (1981) indicated how stress may increase urinary $\mathrm{pH}$, and hence smoking.

The interaction of learning and pharmacological factors in smoking may be especially compelling. Cigarette smoking can be frequently administered, and has a short latency for a pharmacological effect. Nicotine inhalation alters physiological functioning more rapidly than 
would injection of a similar substance. In addition to these prominent qualities of administration, which make conditioning so readily possible, nicotine use is easy and convenient, socially sanctioned and economical. Unlike other substances with health-threatening properties, nicotine use has been culturally prescribed and systematically encouraged. Social influence, as in peer influence and modeling effects, seems to be a pervasive source for acquisition of smoking behavior. In short, unlike any other substance use, cigarette smoking has pharmacological parameters that enhance conditionability and addictive patterns, and social-cultural prescriptions for use.

Given the pharmacological and socio-cultural patterns affecting nicotine use, it has not been surprising that the use of cigarettes has not corresponded to personality-cognitive dimensions. The notable exceptions appears to be the findings of Best of his colleagues (i.e. Best and Steffy, 1975) that internal locus of control (LOC) subjects respond better to treatment than external subjects under some circumstances. While this effect may appear to be only a specific illustration of the general principle that internal LOC subjects respond better to treatment (i.e. Balach and Ross, 1978), it appeared there may be more complex improvement of internal LOC subjects with satiation techniques, while external LOC subjects did better under no satiation techniques. The results may be due to the self-administered nature of satiation, as later research found smokers who self-initiated cessation had more internal LOC than either smokers who were unsuccessful "quitters" or non-attempters (Rosenbaum and Argon, 1979). 
The study of the relapse process itself indicated that relapse has been associated with negative affect, volitional-cognitive factors, and positive affect or enjoyment. The association of negative affect with relapse has not been found with consistency or strength in some investigations (Flaxman, 1979; Briddell, Rim, Caddy and Dunn, 1979). However, the lack of findings in this area may be due to the difficulty in adequately defining affect. Shiffman (1982) did find that relapse was reported to be associated with negative affect, especially anxiety, anger and depression. The volitional-cognitive factors associated with relapse have been described by Marlatt and Gordon (1978) in some detail. The cognitive process has been described as the "abstinence violation effect," which results in a sudden return to previous levels of substance use. In some ways, the volitional-cognitive factors appear to be depressogenic-like, unrealistic negative cognitions. Once a person has violated abstinence, the ideation suggests helplessness, hopelessness, discouragement and feelings of loss of control. Sjoberg and Johnson (1978) noted the twisted, unrealistic nature of the reasoning which may occur with relapse. Sjoberg and Samsonowitz (1978) described steps individuals attempting to stop could utilize in order to deal with the volitional breakdowns. Finally, positive affect has also been noted as a factor in relapse for smoking (Shiffman, 1982). In particular, being with others smoking, eating and drinking coffee or alcohol has been reported as frequently associated with relapse.

Given the serious degree of relapse found in smoking cessation (Hunt, Barnett \& Branch, 1979; Hunt \& Matarazzo, 1973), attempts to 
improve maintenance of therapeutic gains have been made. Some extensive follow-ups have now been attempted (Lando and McGovern, 1982; Hughes, Hymowitz, Ockene, Simon and Vogt, 1981). Some results have not been encouraging, but behavioral methods appear to be sorting out the effective from ineffective strategies. Lando (1982) found booster aversive treatments of rapid smoking were not helpful. However, continued contacts were an aid to maintenance. Booster sessions or treatments appeared to add little to outcome effects for other researchers (Derden, 1977; Kopel, 1974; Perchacek, 1977). Colletti and Supnick (1980) found increased maintenance at six month follow-up, but not one year follow-up, for a continued contact condition. The subjects estimate of personal efficacy has been found to correspond to actual maintenance (Condiette and Lichenstein, 1981; DiClemante, 1981). On the other hand, methods giving excellent short-term effects have been found to decay rapidly (i.e. rapid smoking, Poole, Sanson-Fisher, and German, 1981). In some cases, strategies intended to enhance maintenance have yielded poorer outcome (Relinger, Bornstein, Carmody \& Zohn, 1977). This may be due to attributional problems induced by the more vigorous treatment strategies. Pomerleau, Adkins and Pertshuk (1978) indicated successful smoking abstainers were initially smoking at lower rates, for shorter periods of time, less overweight and more compliant to the program methods.

The recommendation of Hunt and Matarazzo (1973) for smoking cessation research to pay more attention to maintenance still appears to apply. Even in successful programs, more than one third of the 
participants could be expected to resume smoking (Evans and Lane, 1981). Further, subtle shifts in the nature of the subject pool have been occurring. It has been likely that the participants in smoking cessation programs have been becoming increasingly difficult to treat despite improvements of methodology. Many of the individuals able to spontaneously quit may have done so (Schacter, 1982). Other individuals having stopped for a period of time, may have resumed smoking. These subject-sampling problems have limited the generality of research reports of abstinence rates, but within-study differences retain some degree of generality (McFall, 1978; Nathan and Lansky, 1978). Promising maintenance enhancing strategies reported have included contingency contracting and continued therapeutic contact. Given the importance of maintenance, the investigation of the effects of providing maintenance enhancing strategies appears to be a useful goal. Evaluation of therapeutic maintenance efforts could aid the understanding of the effects of the therapeutic methods and the nature of the relapse events as well. For these reasons, it was planned to compare maintenance-enhancing therapy strategies to a similar but more conventional treatment strategy. In addition, assessment was aimed at evaluating directly the influences that smoking cesstion efforts may have on health functioning. 


\section{METHOD}

Subjects. Subjects were recruited from the Blacksburg, Virginia community to participate in a smoking cessation project through the Virginia Tech Department of Psychology. Recruitment efforts included announcements of the project in the Blacksburg News Messenger, the Roanoke Times \& World-News, the campus Collegiate Times and the university faculty-staff publication, The Spectrum. Recruitment was also done by direct mailings to a sample of campus faculty and staff ( $n=$ 500) at the university. Program announcements were also mailed to university-area physicians and the local cancer society. These efforts resulted in 78 inquiries of interest, and 52 individuals agreeing to attend the orientation meeting. Thirty-five individuals came to the orientation meeting. Of those thirty-five, twenty-eight individuals gave deposits and completed the treatment sessions. One individual refused follow up assessment after the one-month follow up. Subjects were assigned to one of four group times. The treatment conditions were then randomly allocated to the four groups. Fourteen individuals were assigned to each treatment condition. Table I describes the demographic and smoking history of the subjects.

Assessment. Smoking behavior was assessed by a self-report questionnaire, self-monitoring of cigarette use, Horn's (1979) Why do you smoke? questionnaire (see Appendix A), evaluation of carbon monoxide levels and evaluation of thiocyanate levels. These measures allowed assessment of the number of cigarettes smoked, the amount of daily 


\section{TABLE I}

Pretreatment demographic and history data

for standard and maintenance conditions

\begin{tabular}{|c|c|c|}
\hline \multirow[t]{2}{*}{ Variable } & \multicolumn{2}{|c|}{ Condition } \\
\hline & Standard & Maintenance \\
\hline Mean Age in Years (SD) & $30.21(8.57)$ & $35.21(7.64)$ \\
\hline Sex (Male/Female) & $6 / 8$ & $3 / 11$ \\
\hline Mean Years Smoked (SD) & $12.43(7.43)$ & $16.93(7.87)$ \\
\hline Mean Cigarettes/Day (SD) & $31.81(12.20)$ & $28.64(7.83)$ \\
\hline$\%$ History of Health Problems ${ }^{1}$ & $14 \%$ & $29 \%$ \\
\hline $\begin{array}{l}\% \text { History of Family } \\
\text { Health Problems }\end{array}$ & $29 \%$ & $50 \%$ \\
\hline
\end{tabular}

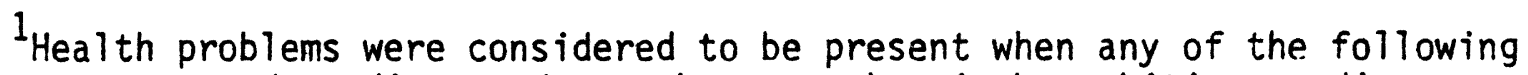
were reported or diagnosed: emphysema, chronic bronchitis, cardiovascular heart disease, hypertension, and oral or lung cancer. 
nicotine use, the smoking history, the affective reasons for smoking, and objective laboratory correlates of smoking behavior. Self-monitoring was implemented as an aspect of the treatment program, while the other measures were administered on pre-treatment assessment and readministered post-treatment and at follow-up. Self-monitoring was re-implemented for the follow-up assessments for individuals continuing to smoke. The why do you smoke? questionnaire was administered only pre-treatment.

Self-report measures were used to investigate the relationship between efficacy expectations, anxiety, locus of control, and group cohesion on outcome. The Pretreatment Confidence Questionnaire (Best and Hakstian, 1978; Condiotte and Lichtenstein, 1981) was used to assess efficacy expectations (see Appendix A). The 45-item list of smoking situations will be rated by the subjects on a 10-interval scale to indicate how likely they would be able to resist the urge to smoke in that situation if they were to try and quit smoking at that time without assistance. Anxiety was assessed by the trait section of Speilberger State-Trait Anxiety Inventory (STAI). Locus of control was as assessed by the Health Locus of Control (HLOC) checklist developed by Wallston, Wallston and DeVellis (1978).

Health-related information was gathered by a brief self-report scale included with the smoking scale (Appendix A). The scale provided information on the incidence and family history of smoking-related health consequences. In addition, physiological measures reflecting health levels were assessed. The four measures included resting heart 
rate (HR), blood pressure (BP), vital capacity $\left(F_{1.0}, F_{.5}\right)$ and weight. These measures were re-administered at post-treatment, one month follow-up, two month follow-up, three month follow-up, and six month follow-up.

Dependent Measures: Reliability and Validity. The self-report outcome measures utilized in this study were the Health Locus of Control ( $H L O C)$, and the trait section of the State Trait Anxiety Inventory (STAI). The reliability and validity of the self-report instruments have been reported elsewhere (Wallston, Wallston and DeVellis, 1978; Balch and Ross, 1975; Best and Steffy, 1975; and Rosenbaum and Argon, 1979) for the locus of control. The STAI has been reviewed by Hedberg (1972). There have been indications that reductions in anxiety may correspond to less cigarette or nicotine use (Flaxman, 1979; and Schachter, Silverstein and Perlick, 1977). Not all research has supported the idea that anxiety management training could improve treatment outcome, however (Beaver, Brown and Lichtenstein, 1981).

Self-Monitoring. The self-monitoring was intended both as a therapeutic strategy and a method of gathering data regarding the smoking of the subject. Small cards, designed to fit in the cellophane of a cigarette pack were provided. The cards consisted simply of a space for a date, and six small boxes following the date. The subjects were instructed to record each cigarette before the cigarette was lighted. The subjects were instructed to monitor in this manner because previous research (Frederiksen and Epstein, 1975) has suggested that 
this monitoring is the most reactive method. The subjects were instructed to record the nicotine content of their cigarettes by noting the nicotine $\mathrm{mg}$. content from the Federal Trade Commission (FTC, 1979). McFal1 (1970) has indicated that monitoring of normal smoking in this manner is a reliable, but reactive procedure. The correlation between self-reported rate of smoking and self-monitored rate of smoking was $\underline{r}=$ .84. There was a slightly higher estimate of smoking rates when selfreport measures were used $(\bar{x}=30.17$ cigarettes $/$ day $)$ when compared to the self-monitored rates $(\bar{x}=24.13$ cigarettes/day) obtained the following week. This was expected given the reactivity of the selfmonitoring procedure (McFall and Hammen, 1971).

Carbon Monoxide. Carbon monoxide assessment was provided by the Ecolyzer (Carboximeter, IADEC, Incorporated, Albany, New York). For the COa measurements, pre-testing indicated that $90 \%$ of the obtained values were within $1 \%$ COa of the actual CO calibration levels. Test-retest correlations, of immediate assessment, were $\underline{r}=.91$. Correlations between the Ecolyzer used for this study and the MINICO analyzer (Carbon Monoxide Indicator, Catalyst Research Corporation, Baltimore, Maryland) were $\underline{r}=.99$. The COa\% figures were transformed to parts per milition (ppm) readings by the formula

$$
\text { PPH }=5(\mathrm{COa} \%)-.5
$$

to render the measures comparable between the two instruments. Rawbone, Coppin and Guz (1976) have indicated that alveolar air co levels correlate with venous CO levels, $\underline{r}=.96$. Hughes, Frederiksen, and Frazier (1978) also noted a correlation of $\underline{r}=.94$ between coa levels 
and $\mathrm{CO}$ blood levels. The MINICO CO analyzer gave more readable low level CO readings, but the obtained $C O$ levels did not differ appreciably. Agreement of the $\mathrm{CO}$ a levels with self-reported smoking or non-smoking status was $93.3 \%$ for the course of the study, when smoking was considered indicated with $\mathrm{COa}>1 \%$. For this study, the correlation between self-reported cigarettes per day, and the $\mathrm{COa}$ readings was $\underline{r}=$ .82. The correlation between the $\mathrm{CO}$ a readings and the reported time since the last cigarette was $\underline{r}=-.50$ in the sample considered in this report. Colletti, Supnick and Abueg (1982) reported COa levels correlated with smoking rate $(\underline{r}=.70)$ and time of cigarette $(\underline{r}=-.62)$. Vogt et al. (1977) reported a correlation of $\underline{r}=.476$ for $C 0$ levels and smoking levels. In general, it appeared that $\mathrm{COa}$ measurement in this study has been consistent with the earlier research indicating co levels are objective indicators of smoking behavior (Frederiksen and Martin, 1979; Lando, 1975). The moderate correlations suggest that co levels may be influenced by smoking topography as well as the number of cigarettes smoked (Frederiksen and Martin, 1979).

Thiocyanate. The saliva thiocyanate $(\mathrm{SCN})$ analyses utilized the methods described by Densen, Davidow, Bass and Jones (1967). The early methods of determination of thincyanate serum levels were developed by Bowler (1944) and Boxer and Rickards (1952). Maliszenski and Bass (1955) first noted the higher concentration of thiocyanate in the body fluids of smokers. Dacre and Tabershaw (1970) and Tenouvuo and Mäkinen (1976) also noted the sharp distinction between smokers and nonsmokers in thiocyanate levels. Some recently developed methods of thiocyanate 
analysis (Butts, Kuehneman and Widdowson, 1974; and Vogt, Selvin, Widdowson and Hulley, 1977) have noted classification rates with $1.8 \%$ false positive and $6.7 \%$ false negative rates. Vogt et al. (1977) also reported the following intercorrelation:

$$
\underline{C / \text { day }} \quad \underline{\mathrm{CO}} \quad \underline{\mathrm{SCN}}
$$

Cigarettes/day

CO

.476

$\mathrm{SCN}$

.479

.571

While positive, the evidence for the $\mathrm{SCN}$ and cigarettes per day relation does not appear as strong as the $C O$ and cigarette per day relationship. As Prue, Martin and Hume (1980) indicated, thiocyanate levels appeared to be a useful index of smoking exposures. Thiocyanate half-life is 10 to 14 days, thus complementing the 5 hour half-life of CO (Hughes, Frederiksen and Frazier, 1978). In addition, SCN is a metabolite of cyanide, hence a direct gauge of the hydrogen cyanide intake with cigarette smoking. Hydrogen cyanide is a ciliatoxic agent in cigarette smoke. In addition to the ciliatoxic effects cyanide appears to be the agent contributing to the development of tobacco amblyopia (Pettigrew and Fell, 1972).

For this study, saliva samples were obtained by having the subjects chew on a cotton ball or a dental roll. The saliva was then drained from the roll with a syringe into a test tube and refrigerated. The laboratory analysis utilized $1 \mathrm{ml}$ of saliva obtained from the test sample with a pipet. The saliva sample was then diluted with $1.5 \mathrm{ml}$ of 
distilled water. To this sample $2.5 \mathrm{ml}$ of trichloroacetic acid (20\%) was added to precipitate proteins from the solution. The solution was then filtered. To the filtrate, $5.0 \mathrm{ml}$ of the ferric nitrate - nitric acid reagent was added. The ferric nitrate - nitric acid reagent consisted of $10 \mathrm{~g} \mathrm{Fe}\left(\mathrm{NO}_{3}\right)_{3} \cdot 9 \mathrm{H}_{2} \mathrm{O}$ in 1 liter of $1.5 \mathrm{~N} \mathrm{HNO}_{3}$ (as utilized by Butts et al., 1974). The final solution was then tested within 15 minutes upon a Bausch and Lomb Spectronic 700, at a wave length of 460 mu. The concentration of thiocyanate in the test sample was calculated by comparing the absorbency of the sample with the absorbency of known concentrations of thiocyanate treated in a similar manner. A linear regression formula was constructed between the known concentrations and obtained absorbencies, then applied to evaluate the unknown concentrations. The linear regression fit the obtained concentration curves with $\underline{r}=.95$. The regression formulas were reconstructed for each evaluation period. The investigator conducted the laboratory assessments under the supervision of the Animal Sciences Laboratory at Virginia Tech.

Despite the amount of research on thiocyanate as an objective indicator of smoking status, there has been little research on the reliability of the thiocyanate analysis procedure itself. In this study, the split-sample correlations between saliva samples taken from the same individual at the same time was $\underline{r}=.99$. Like other researchers (Maliszek and Bass, 1955; Pettigrew and Fe11, 1972; and Tenovuo and Mäkinen, 1976), the distribution of smokers and non-smokers thiocyanate levels did not appear to overlap. For this report, the SCN analysis agreed with self-reported smoking or non-smoking status in 
$86.23 \%$ of the cases. The agreement percentage increased to $92.86 \%$ for the three and six month follow-up periods, when a finer grained filter paper (Schleicher and Schnell grade \#605) was substituted to reduce spuriously high colorimetric readings caused by particulate matter suspended in the saliva. High SCN concentrations in saliva have antibacterial action, hence yielding clearer saliva samples. Cloudy, but low SCN concentrations, saliva spuriously raises colorimetric readings. The correlations between the $\mathrm{SCN}$ and self-reported smoking rates was $\underline{r}=$ .51. This compares favorably with the findings of Vogt et al. (1977), where they noted the correlation between self-reported smoking rates and $\operatorname{SCN}$ levels was $\underline{r}=.48$. Table II summarizes the inter-correlations between COa levels, SCN levels, and reported smoking levels for this study.

Lung Function. Vital capacity was assessed by having the subject exhale as rapidly and strongly as possible into a vitalographic spirometer (Vitalometer, Warren E. Collins, Inc., Braintree, Mass.). Readings were taken for 1 second vital capacity $\left(F E V_{1}\right), 1 / 2$ second vital capacity $\left(\mathrm{FEV}_{.5}\right.$ ) and total volume (FEC). The subject exhaled three times, with the order of $\mathrm{FEV}_{.5}$ or $\mathrm{FEV}_{1}$ randomized. Two readings of either $\mathrm{FEV}_{1}$ or $\mathrm{FEV}_{.5}$ were taken to enable a check on reliability. A FEC reading was obtained with each of the three readings. The highest FEC reading was recorded. The test-retest correlations between these reliability checks were $\underline{r}=.90$ for the $\mathrm{FEV}_{1}$ and $\mathrm{FEV} ._{.5}$ readings.

Earlier research has suggested that altered smoking habits can yield improved lung function. McCarthy, Craig and Cherniack (1976) 


\section{TABLE II}

Intercorrelations between reported average cigarettes per day, Carbon monoxide \% ( $\mathrm{CO} a \%)$ and thiocyanate ( $\mathrm{SCN}$ ) levels

Cigarettes

$\mathrm{CO} \% \quad \mathrm{SCN}$

Cigarettes

$\mathrm{COa} \%$

.82

$\mathrm{SCN}$

.51

.38 $-$ 
noted that a reduction in smoking of more than $25 \%$ baseline levels yielded improved lung function assessment. However, the improvement in $\mathrm{FEV}_{1}$ measures were only .1 to .2 liters on the average. Buist, Sexton, Nagy and Ross (1976) also noted that smoking cessation improved lung function measures after cessation. For the Buist et al. study, it was difficult to discover the magnitude of the improvement, however. Paxton and Scott (1981) reported the most promising results, indicating the successful individuals in a smoking cessation project managed to improve their $\mathrm{FEV}_{1}$ reading by .3 liters. Paxton and Scott (1981) indicated that lung function assessment could be utilized as reinforcement of nonsmoking. Because of the sensitive nature of the phenomenon of improved lung function after smoking cessation, this study examined the changes of lung function from both clinical and statistical perspectives.

Blood Pressure and Pulse. Both blood pressure and pulse were taken with the subject reclining. The readings were taken after a two minute rest. All readings were taken from the right arm. First, a pulse was taken manually from the radial artery, for 15 seconds. The blood pressure was then recorded utilizing a mercury gravity manometer and stethoscope. The sphygmomanometer was fully deflated, and the blood pressure reading repeated after a brief rest. Finally, a second pulse was taken and recorded. The correlation between the repeated blood pressures was $\underline{r}=.92$ for the systolic readings and $\underline{r}=.88$ for the diastolic readings. The correlation for the heart rate (HR) in beats per minute (BPM) was $\underline{r}=.69$. It is unclear as to why the HR reli- 
ability figures were so low. However, the manual nature of this assessment may match results in clinical practice.

The relationship of smoking and cardiovascular heart disease (CHD) has been well known for some time (Matarazzo, 1982; USDHEW, 1979). However, the mechanism for most of the increased CHD among smokers has been elusive. Nicotine and $\mathrm{CO}$ levels have been implicated in the etiology of myocardial infarction and sudden cardiac death, respectively. Both nicotine and CO have been related to angina pectoris. Coronary and aortic atherosclerosis, cerebrovascular disease, peripheral vascular disease, aortic aneurysm and chronic hypertension have been shown to be related to smoking, but as noted, the mechanism for smoking's influence remains uncertain. For example, smoking cessation may not relieve chronic hypertension. However, smoking cessation will greatly reduce the risk of death among hypertensive individuals. In addition, smoking contributes to paroxysmal aterial hypertension, probably through the influences of nicotine on cardiac output. Thus, monitoring of rudimentary cardiovascular functioning of the subjects in the smoking cessation project was indicated. On the basis of nicotine's acute effects on cardiovascular functioning, successful subjects were expected to show reduced blood pressure and pulse rates.

Weight. As part of the health assessment, the subjects were weighed. The weight was taken in street clothes, with shoes taken off. The scale utilized expressed weight in kilograms $(\mathrm{kg})$. No reliability checks for the weighing were taken. Weight gain after smoking cessation has been documented as a "side effect" of stopping smoking. Even so, 
the weight gain appears to be moderate and not sufficient to pose any threat to health. Some (e.g. Nash, 1981) have observed that the fear of weight gain has been a common rationalization against stopping smoking. Suggested mechanisms of the weight gain have included increased oral activities, i.e. eating, to replace cigarettes. However, another explanation has been advanced. As nicotine has stimulating properties, it leads to a degree of metabolic inefficiency. Therefore, without nicotine, metabolism rate decreases and weight gain can occur. Thus, more calories are utilized even in the same resting state to maintain the elevated respiration and cardiovascular effects when smoking. Impaired pulmonary functioning may heighten this metabloic inefficiency. Assessment of weight permitted the monitoring of the changes that occur over the course of the smoking program.

\section{PROCEDURE}

Health Assessment. The health assessment was provided at pretreatment, post-cessation, at one month follow-up, two month follow-up, three month follow-up and six month follow-up. The assessments were calculated in the Cardiac Rehabilitation Laboratory of Virginia Tech. The assessments were provided by the researcher, although parts of the assessments were conducted by the co-therapists who were uninformed as to the exact nature of the investigation. The subjects were first asked to fill out the relevant questionnaires. Next the clients were weighed, with shoes removed. The vital capacity was then assessed. A saliva sample was obtained. The subjects were then sent to the adjacent room, 
where their $\mathrm{COa} \%$ levels were assessed. Deposit checks were returned at that time, or the loss of the check was discussed. Significant others were contacted later to verify reports of smoking abstinence. Finally, the subject was taken to a couch and instructed to lie down and rest for approximately two minutes. Blood pressure and pulse rates were then evaluated. The subject was then thanked for their participation and reminded of upcoming assessments. If the subject had resumed smoking, the events leading to the return to smoking were discussed. Strategies to aid in stopping again were discussed, and the individual was encouraged to try stopping smoking again.

Treatment. The groups met once weekly for six weeks in the standard contract condition and once weekly for eight weeks for the maintenance contract condition. The groups met between October 20th and December 15th. The group leaders were graduate clinical psychology students at Virginia Tech. The investigator was a group leader in each of the groups, and a different co-therapist assisted with each group. The plan for the group session was:

Group 1: Introduction, Beginning

Self-monitoring

Group 2: Begin nicotine fading

Deposits due

Introduction to buddies 
Group 3: Charting smoking and nicotine levels .

Discuss self-management steps

Group 4: Set quit date goal

Time fading as an alternative procedure

Group 5: Alternative rewards

Relapse prevention

Quit date set

Group 6: Last quit date!

Responsibility for health

The maintenance group had two additional sessions after the quit date.

The focus of these sessions included:

Group 7: Recovery from smoking

Group 8: Coping with anger, depression and anxiety

Finally, there were two follow-up sessions for both conditions. At the one month follow-up, a cheese and crackers party was held to discuss progress. Behavioral exercises to practice refusing cigarettes were modelled. For the two month follow-up, a beer, wine and cheese reception was held. Again, a brief assertion exercise for refusing cigarettes was modelled. Encouragement of physical activity and a focus on self-image were also discussed. 
The nicotine fading procedure has been developed and discussed elsewhere (Foxx and Brown, 1978). In general, cigarette smoking is presented as an addictive process dependent upon nicotine. After establishing the nicotine use level by self-monitoring, the subjects were then instructed to reduce their nicotine intake by $20-30 \%$ (with a goal of 25\%) per week. Most subjects were instructed to reduce their nicotine intake by brand-fading. The subjects were instructed to switch to a cigarette with $20-25 \%$ less nicotine, while maintaining or reducing the number of cigarettes smoked per day (see Nash, 1981). As individuals reached or approached low levels of nicotine, they were then instructed to reduce the number of cigarettes smoked. Time-fading procedures (Winett, 1973) were outlined for this step. The subject would block off a section of the self-monitoring cards during times when it would be relatively easy to not smoke. The subjects were instructed not to attempt to time-fade more than $20 \%$ of the available smoking time per week. Once subjects reached 10-12 cigarettes per day, with low nicotine intake, they were instructed to stop abruptly rather than continue to fade out cigarettes. The subjects were also instructed to implement self-management strategies relatively early in the program. For example, at home they were instructed to smoke only in a particular room in a specific chair. After the quit date, the subjects were then instructed to alter or remove the chair. Similar steps were encouraged for workplace settings. The subjects were asked to discuss specific attempts or efforts they made to alter stimulus aspects associated with 
their smoking. Review of the self-monitoring was utilized to suggest areas where self-management efforts could focus.

For the buddy system, subjects were allowed to chose one other group member as a buddy. The two buddies exchanged phone numbers. The buddies were instructed to call one another at least once per week. Subsequent sessions checked to insure the actual phone contact was made. It was emphasized that phone calls and support was especially important around the quit days.

In latter sessions, self-reward strategies were explored. The subjects discussed and explored their own patterns of use of rewards. Substitution of specific and easily administered rewards was encouraged. The subjects were instructed to provide their own rewards for their progress in the program. Subjects whose self-monitoring suggested that their smoking constituted some time-out or reward were especially encouraged to provide themselves with specific rewards instead of smoking. Common rewards included breath mints, lifesavers, 1011ipops, reading time, movies, coffee or tea, a brief walk, a glass of water or fruit juice, and viewing a pleasant view. Increasing physical exercise levels was also encouraged as a rewarding activity, and in the same session, relapse was discussed.

Relapse was discussed as a common part of many successful efforts to stop smoking. The abstinent violation effect was described, and more realistic views of relapse were encouraged. Relapse was described as a situation where circumstances overpowered the individual's self-management skills. Relapse episodes, then, were taken to indicate areas where 
smoking is especially likely. Specific skills and strategies to cope with the risky area could then be developed. Further, it was noted once an individual relapses, they commonly stop smoking again. Final quit dates were also established in this session. Subjects were encouraged to quit prior to the final quit day in order to "experiment" with events that could yield relapse.

For the sixth session, the role of the individual in their own health and happiness was discussed. The subjects were encouraged to take the view that they were directly responsible for their own health and welfare. The subjects were described as competent, resourceful individuals best capable of managing their own health. Expert assistance was described as necessary or desirable in some circumstances, but the power. of a person's lifestyle was noted as the most significant influence over health. Thus, the subjects were encouraged to stop their smoking and substitute other healthful and enjoyable practices.

The two subsequent sessions for the maintenance conditions covered the process of recovery from smoking and management of difficult affective-ladden situations. These two sessions were provided subsequent to the quit dates. The standard contract condition did not meet again until the one-month cheese and cracker party. Recovery from smoking was described as a gradual, positive process. At first, some coughing would occur, as the cilia became more active and began to clear the lungs. Gradually, breathing would become easier, the subjects would become less winded with exertion. Taste and smell would return after only a few days. Carbon monoxide levels would decrease to very low levels. The 
vital capacity as measured by the lung function test would increase slightly. Pulses would decrease, and blood pressures may also decrease. Weight may increase, although it was emphasized that the gain would be small and temporary. It was explained that the weight gain was due to a temporary gap in metabolic adjustment and once the person re-adjusted to the lack of stimulation by nicotine, the weight gain would be lost. Physical activity would also naturally increase. Sedentary subjects or those over thirty years old were encouraged to take walks. The subjects were instructed to walk up stairs rather than take elevators. Active subjects under thirty were encouraged to participate in enjoyable physical activity. Examples of enjoyable physical activity included tennis, bicycle riding, running, skiing, racketball and basketball. Subjects over thirty were instructed to discuss strenuous exercise with a physician prior to becoming heavily involved in strenuous activity. However, mild exercise, as walking, was encouraged under any circumstances. Physical activity, it was explained, would become more pleasurable after smoking ceased. The subjects were told that they would probably not experience significant withdrawal reactions, such as anxiety or problems sleeping, because of the nicotine fading procedure. However, such reactions, when they occurred, were not cause for alarm, but only an indication that the person is becoming re-adjusted to the absence of nicotine.

For the final session of the maintenance condition, strategies for coping with anger, depression and anxiety were described. Affectivelycharged situations have frequently been associated with relapse 
(Shiffman, 1982). The practice of any coping skill may avoid relapse. Basic assertion strategies were advocated to cope with difficult or emotional interpersonal situations. The subjects were encouraged to objectively describe the circumstances, express their feelings, and suggest methods for resolving the difficulties. The subjects were also encouraged to involve others in resolving problematic situations.

In addition to the formal treatment process, two other maintenance strategies were provided. First of all, the maintenance group received a packet intended to support a non-smoker in the first two weeks of cessation. The packets, developed by the American Health Foundation, were to be read daily (American Health Foundation, New York). Second, both treatment conditions were instructed to contact the therapist or buddy if a relapse situation occurred or seemed imminent. The participants were asked to delay resuming smoking until they had discussed the situation with the therapist or buddy. In evaluating the relapse, the therapist explored the activities the person was engaged in at the time, the affective tone of the situation, whether any food, alcohol, coffee or drugs, were consumed, the presence of withdrawai symptoms, the use of any coping responses and the outcome of the relapse crisis. After assessing the relapse crisis, the subject was then asked to explore his or her initial decision to quit. The subject was then asked to reassess these personal goals. Finally, the subject was asked to choose between three strategies of smoking management.

The first strategy would be to quit abruptly by throwing out the remaining cigarettes. The second strategy was to reintroduce self- 
monitoring of cigarette nicotine content and systematically reduce consumption by $20 \%$ per day, with specific quit day. The therapist would then call the subject back on the quit day. The third strategy, for individuals who no longer wished to quit, was to encourage controlled smoking. Controlled smoking was not considered until a subject failed to stop after relapse to smoking. In controlled smoking, the subject was given instructions to alter smoking topography. The subject was instructed to take the following steps: (1) Smoke low tar and nicotine cigarettes. (2) Reduce or eliminate inhaling. (3) Take shorter puffs. (4) Reduce the number of puffs per cigarette to less than six. Restrict smoking to only a single location at home or work. (6) Put out cigarettes when only half-finished.

Deposit Contracts. For the maintenance condition, the deposit was returned for stopping smoking. For the standard condition, the deposit was returned for completing the treatment and assessments. The criteria for the smoking abstinence refund is contained in Appendix $B$. Basically, if the subject reported non-smoking and either the COa or thiocyanate analyses indicated non-smoking the deposit was refunded. Discrepant indications were discussed with the subject. There were no discrepant significant other reports. There were also few discrepant $\mathrm{COa}$ or thiocyanate indications by the criteria chosen ( $\mathrm{COa}>12 \mathrm{ppm}$ or $2.5 \% \mathrm{SCN}>150 \mathrm{mg} / 1$ for smoking), but these were conservative values chosen to minimize false positives resulting in lost deposits. The most accurate smoking-non-smoking cut off points were $\mathrm{COa} \%$ of $1 \%(4.5 \mathrm{ppm})$ and $\mathrm{SCN}$ concentration of $100 \mathrm{mg} / 1$. These latter points were used to cal- 
culate false positive and false negative rates. When a subject reported non-smoking, but their laboratory results exceeded these latter values, the discrepancy was discussed. Sources of increased COa levels and SCN concentrations exist in addition to smoking. These sources include air pollution, car exhaust, and secondary smoking for $\mathrm{CO} a \%$. However, these factors generally do not raise $\mathrm{COa} \%$ levels above $1.5 \%$ in the rural Virginia setting of this study. Thiocyanate levels may be raised by ingestion of some cabbage-family vegetables, but only moderately. Thiocyanate concentrations may be influenced by diuretics, as diuretics may lower the concentration of SCN. The deposits were returned according to the following schedule:

$\begin{array}{ll}\text { Post quit day } & 30 \% \\ \text { One month follow-up } & 20 \% \\ \text { Two month follow-up } & 20 \% \\ \text { Three month follow-up } & 20 \% \\ \text { Six month follow-up } & 10 \%\end{array}$

The six month follow-up deposit was returned for merely completing the final assessment, regardless of smoking status. The deposits were requested on a sliding scale, ranging from $\$ 50.00$ to $\$ 300.00$. Subjects either gave the deposits to be refunded over the period of the study, or wrote post-dated checks in the indicated amount to be cashed if necessary. Fifty-four percent gave outright deposits while forty-six percent gave post-dated deposits. The subjects in the standard condition deposited an average of $\$ 75.83$, while the subjects in the maintenance condition deposited an average of $\$ 110.00$. The difference in 
deposit amounts was not reliably different statistically. The type of deposit (post-dated or pre-paid) did not influence outcome significantly. The post-dated subjects had a $40 \%$ cessation rate of three month follow-up, while the pre-paid subject had a $38 \%$ cessation rate at three month follow-up. At six month assessment, the cessation rates were $33 \%$ and $23 \%$ respectively. These differences were not significant.

The deposits for the standard treatment condition, like the maintenance condition, was returned according to the following schedule:

$\begin{array}{ll}\text { Post quit day } & 30 \% \\ \text { One month follow-up } & 20 \% \\ \text { Two month follow-up } & 20 \% \\ \text { Three month follow-up } & 20 \% \\ \text { Six month follow-up } & 10 \%\end{array}$

The deposits were returned for completing the treatment sessions, make-up sessions and health assessments, however. The deposits were returned to the subjects so long as the subject attended the program sessions. The forfeited deposits for both groups $(\$ 173.00)$ were redeposited and then divided among subjects who successfulty completed the program without relapse. Thus, the 6 subjects who completed the program without smoking or relapse received $\$ 28.83$ each approximately one month after the six month follow-up.

Data Analysis. Three repeated measures multivariate analyses of variance (MANOVA) were conducted. The first analysis compared the standard and maintenance condition on dependent variables measuring smoking. The three dependent measures of smoking were reported cigar- 
ettes per day, $\mathrm{CO}$ a\%, and $\mathrm{SCN}$ concentration. The second analyses also compared standard and maintenance conditions on health functioning. The 6 measures of health functioning were weight, $\mathrm{FEV}_{1}, \mathrm{FEV}_{.5}$, heart rate $(H R)$, systolic blood pressure (SBP) and diastolic blood pressure (DBP). Third, the two self-report questionnaires were also examined in the repeated measures MANOVA. These two questionnaires were the STAI and HLOC. The MANOVA was followed by univariate repeated measures. BMDP computer programs, especially BMDP4V and BMDP2V, were utilized for the data analysis. Simple main effects were calculated between the two treatment conditions for all dependent variables.

A multiple regression analysis was also performed in a step-wise fashion to assess which factors predicted the average number of cigarettes per day smoked at six month follow-up. The aim of the regression analysis was to determine which elements predict successful outcome in this program. By establishing these elements, it was hoped prognostic indicators could be found. In addition, the regression was intended to account for the effect of any third-variable influences on treatment outcome. The results of earlier research (e.g. Burling, 1981) was used to select some of the variables to predict outcome. The other variables were selected on a rational basis.

Finally, an assessment of the changes in health functioning for successful and less successful subjects was performed. The aim of the evaluation of health changes was to define areas of health function which appear to be either malleable or resistant to changes after smoking cessation. 
In addition to the statistical analysis of the data on outcome, health functioning and self-report measures, there was also data gathered on the patterns of smoking cessation and data gathered on the cost of the respective programs. The data on the patterns of smoking cessation was gathered by asking subjects to call the experimenter in the event of a relapse, or if feeling a relapse was imminent. A $10 \mathrm{~g}$ was kept of the relapse incidents, noting the circumstances, the immediate situation, the response or coping to the incident, and the outcome of the incident within 72 hours. Not all relapse events were logged as planned, due to subjects not calling the experimenter, but a description was obtained of 22 of the 30 relapse incidents within 72 hours. Thus, there was a $73.3 \%$ report rate for relapse episodes. The recordings of the relapse episodes was broken down into major classifications on outcome of the relapse episode and the reported reasons for the relapse occurring. These classifications were broken down into percentages to enable some comparisons. Analysis of the respective costc of the programs was to take into account the costs of administering each program and the relative effects of the programs. The costs were calculated by evaluating the amount of therapist time to administer the treatment mthods, the amount of administrative assistance required for the programs, and the cost for follow-ups and assessments. Overhead costs were estimated as $20 \%$ of the total cost. The effects 
of the programs were assessed by the $\mathrm{COa} \%$ leve1 at six month follow-up as the outcome index. The $\mathrm{COa} \%$ level was expressed in standard units as an effect size (ES), as estimated by Smith and Glass (1977). The relative cost per effect size could then be readily calculated by taking the quotient. 


\section{$\underline{\text { RESULTS }}$}

I. OUTCOME ON SMOKING, SELF-REPORT AND HEALTH MEASURES: MAINTENANCE VERSUS STANDARD TREATMENT CONDITIONS.

In order to control for experiment-wise error rates, multivariate analyses were utilized for three sets of dependent measures. The three sets of dependent measures were smoking outcome measures, health measures, and self-report measures. The smoking outcome measures included the average number of cigarettes smoked per day, the carbon monoxide ( $\mathrm{CO}$ a)\% levels, and the saliva thiocyanate (SCN) levels. The health outcome measures included blood pressure, heart rate, weight, and vital capacity measures. The self-report outcome measures were the Health Locus of Control (HLOC) and State-Trait Anxiety Inventory (STAI). Multivariate analyses were then followed by univariate analyses to indicate specific areas of significance.

\section{SMOKING MEASURES}

The multivariate analysis of variance (MANOVA) indicated a significant effect for follow-up periods on the smoking measures $(F(15,340)=$ 14.77, $P<.01)$. There was a trend for between treatment group significance $(F(3,23)=2.44, P=.09)$. There was no significant period $X$ group interaction effect. Table III summarizes the results of the MANOVA on smoking measures.

Cigarettes Per Day. Univariate analyses for simple effects were conducted on each of the three dependent variables. For cigarettes 


\section{TABLE III}

MANOVA Summary Table for smoking measures (cigarettes/day, $\mathrm{COa} \%$, and $\mathrm{SCN}$ ) between the treatment conditions

over the assessment periods

\begin{tabular}{|c|c|c|c|c|c|c|c|}
\hline Source & $\begin{array}{l}\text { Wilks } \\
\text { Lambda } \\
\end{array}$ & $\underline{D F}$ & $\begin{array}{c}\text { Rao's } \\
\underline{F}\end{array}$ & $I^{2}$ & $\underline{D f}$ & $\underline{F}$ & $\mathrm{p}$ \\
\hline Group & & & & 7.97 & 3,23 & 2.44 & .09 \\
\hline $\begin{array}{l}\text { Periods } \\
\text { - cigarettes } \\
\text { - COa\% } \\
\text {-SCN }\end{array}$ & .250 & 15,340 & $14.77^{\star \star}$ & $\begin{array}{r}* \\
254.56 \\
79.95 \\
129.48\end{array}$ & $\begin{array}{l}5,21 \\
5,21 \\
5,21\end{array}$ & $\begin{array}{l}42.77 \\
13.43 \\
21.75\end{array}$ & $\begin{array}{l}\star \star \\
\star \star \\
\star \star\end{array}$ \\
\hline $\begin{array}{l}\text { Period x Group } \\
\text {-cigarettes } \\
-\mathrm{COA} \% \\
-\mathrm{SCN}\end{array}$ & .870 & 15,340 & 1.17 & $\begin{array}{l}6.86 \\
6.59 \\
9.22\end{array}$ & $\begin{array}{l}5,21 \\
5,21 \\
5,21\end{array}$ & $\begin{array}{l}1.15 \\
1.11 \\
1.55\end{array}$ & $\begin{array}{l}\text { NS } \\
\text { NS } \\
\text { NS }\end{array}$ \\
\hline
\end{tabular}


smoked per day, there was a significant treatment group $X$ follow-up period interaction $(F(5,125)=2.40, P<.05)$. Both the maintenance treatment condition $(F(5,125)=31.38, P<.01)$ and the standard treatment condition $(F(5,125)=16.82, P<.01)$ significantly reduced the number of cigarettes smoked per day. There were no reliable differences between the standard and maintenance conditions on the number of cigarettes smoked per day at pre-treatment assessment. However, the maintenance condition reported smoking significantly fewer cigarettes per day at post-quit date assessment $(F(1,150)=7.65, P<.01, \bar{x}=.15$ versus 10.21). The maintenance condition continued to report smoking significantly fewer cigarettes per day than the standard condition throughout the follow-up periods. The one month follow-up period indicated significantly fewer cigarettes per day for the maintenance condition $(F(1,150)=4.74, P<.05, \bar{x}=.62$ versus 8.50$)$, as did the two month assessment $(F(1,150=7.16, P<.01, \bar{x}=1.01$ versus 10.68$)$, the three month assessment $(F(1,150)=8.83, P<.01, \bar{x}=4.00$ versus 15.96), and the six month assessment $(F(1,150)=6.19, P<.05, \bar{x}=7.98$ versus 17.90). Table IV contains the results of the ANOVA for cigarettes smoked per day. Table $V$ contains the means and standard deviations for the average number of cigarettes smoked per day for the maintenance and standard conditions over the six assessment periods. Carbon Monoxide. The results for the $\mathrm{COa} \%$ measures were similar to the average number of cigarettes smoked per day, al though there was no significant group $X$ periods interaction $(F(5,125)=1.22, P>.05)$. 
TABLE IV

Analysis of variance summary table

for simple effects on cigarettes per day

\begin{tabular}{lrrrrl}
\hline Source & SS & df & Ms & $\underline{F}$ & p \\
\hline Between & & & & & \\
Pre & .89 & 1 & .89 & $<1.0$ & NS \\
Post & 710.04 & 1 & 710.04 & 7.65 & $\star \star$ \\
One & 440.04 & 1 & 440.04 & 4.74 & $\star$ \\
$\quad$ Two & 664.46 & 1 & 664.46 & 7.16 & $\star \star$ \\
$\quad$ Three & 818.75 & 1 & 818.75 & 8.83 & $\star \star$ \\
$\quad$ Six & 574.31 & 1 & 574.31 & 6.19 & $*$ \\
Within Cel1 & 13916.11 & 150 & 92.77 & & \\
& & & & & \\
Within Subjects & & & & & \\
Maintenance & 5024.99 & 5 & 1005.00 & 31.38 & $\star \star$ \\
Standard & 2738.19 & 5 & 547.64 & 16.82 & $\star \star$ \\
Group x Periods & 390.15 & 5 & 78.03 & 2.40 & $*$ \\
Group x Subs & 4069.88 & 125 & 32.56 & & \\
$\quad$ (groups) & & & & & \\
\hline
\end{tabular}

$\star p<.05$

$\star \star \quad p<.01$ 


\section{TABLE $V$}

Mean cigarettes smoked per day for the maintenance and standard conditions for each assessment

\begin{tabular}{|c|c|c|}
\hline & CONDITION & \\
\hline & Maintenance & Standard \\
\hline $\begin{array}{r}\text { Pre } \bar{x} \\
(S D)\end{array}$ & $\begin{array}{l}22.95 \\
(6.07)\end{array}$ & $\begin{array}{c}25.14 \\
(10.26)\end{array}$ \\
\hline Post & $\begin{array}{l}.15 \\
(.55)\end{array}$ & $\begin{array}{c}10.21 \\
(10.85)\end{array}$ \\
\hline One & $\left(\dot{1}^{62} .56\right)$ & $\begin{array}{c}8.50 \\
(10.73)\end{array}$ \\
\hline Two & $\begin{array}{c}1.01 \\
(2.23)\end{array}$ & $\begin{array}{l}10.68 \\
(10.46)\end{array}$ \\
\hline Three & $\begin{array}{c}4.00 \\
(7.48)\end{array}$ & $\begin{array}{l}15.96 \\
(16.00)\end{array}$ \\
\hline Six & $\begin{array}{c}7.98 \\
(8.24)\end{array}$ & $\begin{array}{l}17.90 \\
(14.54)\end{array}$ \\
\hline
\end{tabular}


Both maintenance $(F(5,125)=15.90, P<.01)$ and standard $(F(5,125)$ $=7.09, P<.01)$ conditions reduced $\mathrm{COa} \%$ levels significantly over the follow-up periods. The standard and maintenance conditions did not reliably differ at pre-treatment assessment. The maintenance condition did have significantly lower $\mathrm{COa} \%$ at post-cessation follow-up $(F(1,150)$ $=6.93, P<.01, \bar{x}=.55$ versus 3.24$)$ than the standard condition. The COa\% for the one and two month follow-up periods was lower for the maintenance condition when compared to the standard condition, but the COa\% levels did not differ reliably $(F(1,150)=3.89, P<.10$ and $F(1,150)=3.31, P<.10$, respectively). The three month COa\% levels were reliably lower for the maintenance condition $(F(1,150)=4.54, P<$ $.05, \bar{x}=1.26$ versus 3.68 ). The six month $\mathrm{COa} \%$ was also reliably lower for the maintenance condition $((1,150)=4.78, P<.05, \bar{x}=2.04$ versus 4.33). Table VI summarizes these results. The means and standard deviations for the $\mathrm{CO}_{2} \%$ are contained in Table VII.

Thiocyanate. For the SCN results, there were no significant interactions between the group and follow-up periods $(F(5,125)=1.18$, NS). Both the maintenance $(F(5,125)=9.14, P<.01)$ and the standard $(F(5,125)=8.40, P<.01)$ conditions significantly reduced the $\mathrm{SCN}$ levels over the follow-up periods. The $\mathrm{SCN}$ levels did return to approximately the baseline levels on six month assessment, however. The maintenance condition had SCN levels significantly lower than the standard condition at three month follow-up $(F(1,150)=4.39, P<.05, \bar{x}$ $=93.08$ versus 129.16$)$. The treatment conditions did not differ significantly at any of the other assessment periods. Table VIII summarizes 


\section{TABLE VI}

Analysis of variance summary table for carbon monoxide levels ( $\mathrm{CO}$ a\%), simple effects

\begin{tabular}{|c|c|c|c|c|c|}
\hline Source & $\underline{S S}$ & $d f$ & MS & $\underline{F}$ & $\mathrm{p}$ \\
\hline \multicolumn{6}{|l|}{ Between } \\
\hline $\begin{array}{l}\text { Pre } \\
\text { Post }\end{array}$ & $\begin{array}{r}1.78 \\
51.50\end{array}$ & $\begin{array}{l}1 \\
1\end{array}$ & $\begin{array}{r}1.78 \\
51.50\end{array}$ & $<\begin{array}{l}1.0 \\
6.93\end{array}$ & $\begin{array}{l}\text { NS } \\
\star \star\end{array}$ \\
\hline One & 28.91 & 1 & 28.91 & 3.89 & $p<.10$ \\
\hline Two & & 1 & & & \\
\hline $\begin{array}{l}\text { Six } \\
\text { Within Cell }\end{array}$ & 35.51 & $\begin{array}{c}1 \\
150\end{array}$ & $\begin{array}{r}35.51 \\
7.44\end{array}$ & 4.78 & * \\
\hline \multicolumn{6}{|l|}{ Within Subjects } \\
\hline Maintenance & 295.56 & 5 & 59.11 & 15.90 & $\star \star$ \\
\hline Standard & 131.73 & 5 & 26.35 & 7.09 & $\star \star$ \\
\hline Group x Periods & 22.68 & 5 & 4.54 & 1.22 & NS \\
\hline $\begin{array}{c}\text { Group } x \text { Subs } \\
\text { (groups) }\end{array}$ & 464.77 & 125 & 3.72 & & \\
\hline
\end{tabular}

$$
\begin{aligned}
* p & <.05 \\
\star \star \quad p & <.01
\end{aligned}
$$




\section{TABLE VII}

Means and Standard Deviations of

Carbon Monoxide levels ( $\mathrm{COa} \%$ )

\begin{tabular}{|c|c|c|}
\hline & CONDITION & \\
\hline & Maintenance & Standard \\
\hline $\begin{array}{r}\text { Pre } \bar{x} \\
(S D)\end{array}$ & $\begin{array}{c}6.29 \\
(3.00)\end{array}$ & $\begin{array}{l}6.67 \\
(3.14)\end{array}$ \\
\hline Post & $\begin{array}{l}.55 \\
(.28)\end{array}$ & $\begin{array}{c}3.24 \\
(3.42)\end{array}$ \\
\hline \multicolumn{3}{|l|}{ Period } \\
\hline One & $\begin{array}{l}1.10 \\
(1.29)\end{array}$ & $\begin{array}{c}3.10 \\
(3.21)\end{array}$ \\
\hline Two & $\begin{array}{l}1.26 \\
(.89)\end{array}$ & $\begin{array}{c}3.18 \\
(3.00)\end{array}$ \\
\hline Three & $\begin{array}{l}1.25 \\
(2.30)\end{array}$ & $\begin{array}{c}3.68 \\
(3.80)\end{array}$ \\
\hline Six & $\begin{array}{c}2.04 \\
(1.90)\end{array}$ & $\begin{array}{c}4.33 \\
(3.15)\end{array}$ \\
\hline
\end{tabular}


TABLE VIII

Analysis of variance summary table for saliva thiocyanate ( $\mathrm{SCN}$ ) levels, simple effects

\begin{tabular}{|c|c|c|c|c|c|}
\hline Source & $\underline{S S}$ & $\underline{d f}$ & Ms & $\underline{F}$ & $p$ \\
\hline $\begin{array}{c}\text { Between } \\
\text { Pre } \\
\text { Post } \\
\text { One } \\
\text { Two } \\
\text { Three } \\
\text { Six } \\
\text { Within Cell }\end{array}$ & $\begin{array}{r}567.45 \\
1.25 \\
1505.73 \\
443.79 \\
8772.41 \\
2615.84\end{array}$ & $\begin{array}{c}1 \\
1 \\
1 \\
1 \\
1 \\
1 \\
150\end{array}$ & $\begin{array}{r}567.45 \\
1.25 \\
1505.73 \\
443.79 \\
8772.41 \\
2615.84 \\
1997.47\end{array}$ & $\begin{aligned}< & 1.0 \\
< & 1.0 \\
< & 1.0 \\
< & 1.0 \\
& 4.39 \\
& 1.31\end{aligned}$ & $\begin{array}{l}\text { NS } \\
\text { NS } \\
\text { NS } \\
\text { NS } \\
\text { * } \\
\text { NS }\end{array}$ \\
\hline $\begin{array}{l}\text { Within Subjects } \\
\text { Maintenance } \\
\text { Standard } \\
\text { Group } \times \text { Periods } \\
\text { Group } \times \text { Subs } \\
\text { (groups) }\end{array}$ & $\begin{array}{r}70344.64 \\
64634.13 \\
9058.73 \\
192429.56\end{array}$ & $\begin{array}{c}5 \\
5 \\
5 \\
125\end{array}$ & $\begin{array}{r}14068.93 \\
12926.83 \\
1811.75 \\
1539.44\end{array}$ & $\begin{array}{l}9.14 \\
8.40 \\
1.18\end{array}$ & $\begin{array}{l}\star \star \\
\star \star \\
\text { NS }\end{array}$ \\
\hline
\end{tabular}

$\star p<.05$

$\star \star p<.01$ 
the ANOVA results. Table IX contains the means and standard deviations for the SCN measures.

Abstinence Rates. At post-cessation day assessment, the maintenance condition had a significantly higher rate of non-smoking $\chi^{2}(1)=19.91, P<.001$. The quit rate was $93 \%$ for the maintenance condition, and $36 \%$ for the standard condition. For the one month assessment, the maintenance group had significantly higher abstinence rates $\chi^{2}(1)=10.50, P<.01$ than the standard condition, with $86 \%$ and 43\% cessation rates, respectively. The maintenance condition was reliably higher than the standard conditions' abstinence rate at two month follow-up as well, with $\chi^{2}(1)=17.15, P<.001$. The maintenance condition had a $79 \%$ cessation rate for the two month assessment and the standard condition had a $29 \%$ cessation rate for the same period. For the three month follow-up, the maintenance condition continued to have reliably higher cessation rates $\chi^{2}(1)=15.27, p<.001$. The maintenance condition had a $64 \%$ quit rate and the standard condition a $21 \%$ quit rate at three month follow-up. The six month follow-up results also indicated significantly higher cessation rates for the maintenance condition $x^{2}(1)=4.67, P<.05$. The six month cessation rates were $43 \%$ for the maintenance condition and $14 \%$ for the standard condition. Table $X$ contains the cessation rates and the respective chi-square values.

\section{SELF-REPORT MEASURES}

The MANOVA on the HLOC and the Trait Section of the STAI indicated a significant effect for follow-up periods $(F(6,142)=6.52, P<.01)$. 
TABLE IX

Means and Standard Deviations of

saliva thiocyanate (SCN) levels in $\mu \mathrm{g} / \mathrm{ml}$

\begin{tabular}{|c|c|c|}
\hline & CONDITION & \\
\hline & Maintenance & Standard \\
\hline $\begin{array}{r}\text { Pre } \bar{x} \\
(S D)\end{array}$ & $\begin{array}{l}133.10 \\
(37.60)\end{array}$ & $\begin{array}{l}123.20 \\
(29.92)\end{array}$ \\
\hline Post & $\begin{array}{c}53.17 \\
(46.92)\end{array}$ & $\begin{array}{c}54.26 \\
(20.70)\end{array}$ \\
\hline One & $\begin{array}{c}65.68 \\
(51.44)\end{array}$ & $\begin{array}{c}78.66 \\
(51.39)\end{array}$ \\
\hline Two & $\begin{array}{c}87.32 \\
(36.05)\end{array}$ & $\begin{array}{c}95.44 \\
(40.64)\end{array}$ \\
\hline Three & $\begin{array}{c}93.09 \\
(48.04)\end{array}$ & $\begin{array}{l}129.20 \\
(53.00)\end{array}$ \\
\hline $\operatorname{six}$ & $\begin{array}{l}127.40 \\
(59.62)\end{array}$ & $\begin{array}{l}122.40 \\
(47.23)\end{array}$ \\
\hline
\end{tabular}


TABLE $X$

Cessation and smoking frequency for standard and maintenance conditions at post, one month, two months, three months and six months after quit day

\begin{tabular}{|c|c|c|c|c|c|}
\hline & & ABSTAIN & SMOKING & \% ABSTAIN & $x^{2}(1)$ \\
\hline Post & $\begin{array}{l}\text { Maintenance } \\
\text { Standard }\end{array}$ & $\begin{array}{r}13 \\
5\end{array}$ & $\begin{array}{l}1 \\
9\end{array}$ & $\begin{array}{l}92.86 \% \\
35.71 \%\end{array}$ & $19.91 * \star$ \\
\hline One & $\begin{array}{l}\text { Maintenance } \\
\text { Standard }\end{array}$ & $\begin{array}{r}12 \\
6\end{array}$ & $\begin{array}{l}2 \\
8\end{array}$ & $\begin{array}{l}85.71 \% \\
42.86 \%\end{array}$ & $10.50 * \star$ \\
\hline Two & $\begin{array}{l}\text { Maintenance } \\
\text { Standard }\end{array}$ & $\begin{array}{r}11 \\
4\end{array}$ & $\begin{array}{r}3 \\
10\end{array}$ & $\begin{array}{l}78.57 \% \\
28.57 \%\end{array}$ & $17.15^{\star \star}$ \\
\hline Three & $\begin{array}{l}\text { Maintenance } \\
\text { Standard }\end{array}$ & $\begin{array}{l}9 \\
3\end{array}$ & $\begin{array}{r}5 \\
11\end{array}$ & $\begin{array}{l}64.29 \% \\
21.43 \%\end{array}$ & $15.27 \star \star$ \\
\hline Six & $\begin{array}{l}\text { Maintenance } \\
\text { Standard }\end{array}$ & $\begin{array}{l}6 \\
2\end{array}$ & $\begin{array}{r}8 \\
12\end{array}$ & $\begin{array}{l}42.86 \% \\
14.29 \%\end{array}$ & $4.67 \star$ \\
\hline * & $p<.05$ & & & & \\
\hline$\star \star$ & $p<.01$ & & & & \\
\hline
\end{tabular}


In addition, there was a significant group $X$ periods interaction, $(F(6,142)=3.78, P<.01)$. The multivariate significance for the interaction held only for the HLOC variable $(F(3,22)=5.18, P<.01)$, while the interaction for the STAI was non-significant $(F(3,22)=2.18$, NS). Table XI contains the MANOVA summary.

HLOC. Univariate analysis of the HLOC variable indicated a significant interaction of group $X$ periods $(F(2,72)=5.51, P<.01)$. Both the maintenance and the standard conditions demonstrated a significant increase in the HLOC scores over the follow-up periods $(F(3,72)=2.94$, $P<.05$, and $F(3,72)=6.24, P<.01$, respectively). None of the between group differences were significant at pre-assessment, postcessation, three month assessment or six month assessment. The three month follow-up scores indicated a trend towards higher HLOC scores for the standard condition $(F(1,96)=3.78, P=.10)$. However, the HLOC scores for the standard condition fell for the six month follow-up period (see Table XII).

STAI. Univariate analysis of variance for the STAI did not indicate any significant group $X$ periods interaction $(F(3,72)=2.09$, NS). Both maintenance and standard treatment conditions significantly reduced the STAI scores $(F(3,72)=2.67, P<.06$ and $F(3,72)=10.57, P<.01$, respectively). There were no significant differences between the two treatment conditions at any of the follow-up periods. Table XIV contains the ANOVA Summary Table and Table XV contains the means and standard deviations. 


\section{TABLE XI}

MANOVA summary table for self-report measures

(HLOC and STAI)

\begin{tabular}{|c|c|c|c|c|c|c|c|}
\hline SOURCE & $\begin{array}{l}\text { Wi } 1 \mathrm{ks} \\
\text { Lamda } \\
\end{array}$ & df & $\frac{\operatorname{Rao}{ }^{\prime} S}{\underline{F}}$ & $\underline{T}^{2}$ & $\underline{d f}$ & $\underline{F}$ & $\mathrm{p}$ \\
\hline Group & & & & 1.08 & 2,23 & $<1.0$ & NS \\
\hline $\begin{array}{l}\text { Periods } \\
\text {-HLOC } \\
\text {-STAI }\end{array}$ & .6148 & 6,142 & $6.52 \star \star$ & $\begin{array}{l}62.75 \\
20.63 \\
34.45\end{array}$ & $\begin{array}{l}6,19 \\
3,22 \\
3,22\end{array}$ & $\begin{array}{r}8.28 \\
6.27 \\
10.53\end{array}$ & $\begin{array}{l}\star \star \\
\star \star \\
\star \star\end{array}$ \\
\hline $\begin{array}{l}\text { Group } x \\
\text { Periods } \\
\text {-HLOC } \\
\text {-STAI }\end{array}$ & .7437 & 6,142 & $3.78 * \star$ & $\begin{array}{r}24.39 \\
16.94 \\
7.13\end{array}$ & $\begin{array}{l}6,19 \\
3,22 \\
3,22\end{array}$ & $\begin{array}{l}3.22 \\
5.18 \\
2.18\end{array}$ & $\begin{array}{l}\star \\
\star \star \\
N S\end{array}$ \\
\hline$\star p<$ & & & & & & & \\
\hline$\star \star \quad p<$ & & & & & & & \\
\hline
\end{tabular}


TABLE XII

Analysis of variance summary table for Health Locus of Control (HLOC)

\begin{tabular}{|c|c|c|c|c|c|}
\hline Source & $\underline{S S}$ & $\underline{\mathrm{df}}$ & Ms & $\underline{F}$ & $p$ \\
\hline $\begin{array}{c}\text { Between } \\
\text { Pre } \\
\text { Post } \\
\text { Three } \\
\text { Six } \\
\text { Within Cell }\end{array}$ & $\begin{array}{r}92.89 \\
3.57 \\
163.37 \\
100.04\end{array}$ & $\begin{array}{r}1 \\
1 \\
1 \\
1 \\
96\end{array}$ & $\begin{array}{r}92.89 \\
3.57 \\
163.37 \\
100.04 \\
43.24\end{array}$ & $\begin{array}{r}2.15 \\
1.00 \\
3.78 \\
2.32\end{array}$ & $\begin{array}{l}\text { NS } \\
\text { NS } \\
p_{N S}<.10\end{array}$ \\
\hline $\begin{array}{l}\text { Within Subjects } \\
\text { Ma intenance } \\
\text { Standard } \\
\text { Group x Periods } \\
\text { Group x Subs } \\
\text { (groups) }\end{array}$ & $\begin{array}{r}139.91 \\
297.09 \\
262.23 \\
1142.38\end{array}$ & $\begin{array}{r}3 \\
3 \\
3 \\
72\end{array}$ & $\begin{array}{l}46.64 \\
99.03 \\
87.41 \\
15.87\end{array}$ & $\begin{array}{l}2.94 \\
6.24 \\
5.51\end{array}$ & $\begin{array}{l}\star \\
\star \\
\star \star\end{array}$ \\
\hline
\end{tabular}

$\star p<.05$

$\star \star p<.01$ 


\section{TABLE XIII}

Means and standard deviations for HLOC

\begin{tabular}{|c|c|c|}
\hline & CONDITION & \\
\hline & Maintenance & Standard \\
\hline $\begin{array}{r}\text { Pre } \bar{x} \\
\text { (SD) }\end{array}$ & $\begin{array}{l}46.77 \\
(7.12)\end{array}$ & $\begin{array}{l}50.23 \\
(5.72)\end{array}$ \\
\hline Post & $\begin{array}{l}48.46 \\
(6.92)\end{array}$ & $\begin{array}{l}49.46 \\
(3.31)\end{array}$ \\
\hline Three & $\begin{array}{l}49.23 \\
(8.64)\end{array}$ & $\begin{array}{l}54.46 \\
(4.18)\end{array}$ \\
\hline Six & $\begin{array}{l}51.00 \\
(6.53)\end{array}$ & $\begin{array}{l}47.77 \\
(8.30)\end{array}$ \\
\hline
\end{tabular}


TABLE XIV

Analysis of variance summary table for simple effects for the STAI

\begin{tabular}{|c|c|c|c|c|c|}
\hline Source & $\underline{S S}$ & $\underline{d f}$ & Ms & $\underline{F}$ & $\mathrm{p}$ \\
\hline $\begin{array}{c}\text { Between } \\
\text { Pre } \\
\text { Post } \\
\text { Three } \\
\text { Six } \\
\text { Within Cell }\end{array}$ & $\begin{array}{r}128.57 \\
4.32 \\
94.38 \\
4.65\end{array}$ & $\begin{array}{r}1 \\
1 \\
1 \\
1 \\
96\end{array}$ & $\begin{array}{r}128.57 \\
4.32 \\
94.38 \\
4.65 \\
75.77\end{array}$ & $\begin{aligned} & 1.70 \\
< & 1.0 \\
& 1.25 \\
< & 1.0\end{aligned}$ & $\begin{array}{l}\text { NS } \\
\text { NS } \\
\text { NS } \\
\text { NS }\end{array}$ \\
\hline $\begin{array}{l}\text { Within Subjects } \\
\text { Ma intenance } \\
\text { Standard } \\
\text { Group } x \text { Periods } \\
\text { Group x Subs } \\
\text { (groups) }\end{array}$ & $\begin{array}{r}113.85 \\
451.08 \\
89.23 \\
1023.58\end{array}$ & $\begin{array}{r}3 \\
3 \\
3 \\
72\end{array}$ & $\begin{array}{r}37.95 \\
150.36 \\
29.74 \\
14.22\end{array}$ & $\begin{array}{r}2.67 \\
10.57 \\
2.09\end{array}$ & $\begin{array}{l}<.10 \\
\star \star \\
\text { NS }\end{array}$ \\
\hline$\star p<.05$ & & & & & \\
\hline$\star \star p<<.01$ & & & & & \\
\hline
\end{tabular}


TABLE XV

Means and standard deviations for STAI scores

\begin{tabular}{|c|c|c|}
\hline & CONDITION & \\
\hline & Maintenance & Standard \\
\hline $\begin{array}{r}\text { Pre } \bar{x} \\
(S D)\end{array}$ & $\begin{array}{l}38.62 \\
(7.95)\end{array}$ & $\begin{array}{c}44.38 \\
(11.21)\end{array}$ \\
\hline Post & $\begin{array}{l}37.23 \\
(8.63)\end{array}$ & $\begin{array}{l}39.00 \\
(9.04)\end{array}$ \\
\hline \multicolumn{3}{|l|}{ Period } \\
\hline Three & $\begin{array}{l}34.62 \\
(8.64)\end{array}$ & $\begin{array}{l}37.62 \\
(9.96)\end{array}$ \\
\hline Six & $\begin{array}{l}36.00 \\
(7.27)\end{array}$ & $\begin{array}{l}36.85 \\
(7.58)\end{array}$ \\
\hline
\end{tabular}




\section{HEALTH MEASURES}

For the health measures, the MANOVA considered six dependent measures across the six assessment periods. The six dependent measures were systolic blood pressure (SBP), diastolic blood pressure (DBP), heart rate $(H R)$, weight $(K G)$, one-second forced expiratory volume $\left(\mathrm{FEV}_{1}\right)$, and one-half second forced expiratory volume $\left(F E V_{.5}\right)$. Table XVI contains the results of the MANOVA. Across all health measures, there was a significant effect for periods $(F(30,482)=2.11, P<.01)$. There was also a trend for a significant interaction, between groups and periods $(F(30,482)=1.39, P=.08)$. There was multivariate significance for reduction in $\operatorname{SBP}(F(5,21)=2.77, P<.05)$, but there was no significant reduction in DBP. There was also multivariate significance for $H R$ reductions $(F(5,21)=3.15, P<.05)$, and $K G$ increases $(F(5,21)=$ 5.92, $P<.01)$. Both $\mathrm{FEV}_{1}$ and $\mathrm{FEV} .5$ reached significance $(F(5,21)=$ 2.98, $P<.05$ and $F(5,21)=2.69, P<.05$, for $\mathrm{FEV}_{1}$ and $\mathrm{FEV} .5$ values, respectively). There was also a trend toward significance in the group $X$ periods interaction for the HR levels $(F(5,21)=2.30, P=.08)$.

Blood Pressure. Univariate analysis of the SBP did not indicate any significant interaction or any main effect for the assessment periods for either the maintenance or the standard condition. However, the maintenance condition did have SBP significantly lower than the standard condition at six month follow-up $(F(1,150)=3.96, P<.05, \bar{x}=$ 112.8 versus 121.1). None of the other assessment periods comparisons were reliably different for the SBP. Table XVIII contains the means and standard deviations for the SBP measures. 
MANOVA surmary table for health measures: Systolic Blood Pressure (SBP), Diastolic Blood Pressure (BP), Heart Rate (HR), Weight (KG), Forced

Expiratory Volume, 1 second $\left(F^{2} V_{1}\right)$ and Forced Expiratory Volume, .5 seconds (FEV ${ }_{.5}$ )

\begin{tabular}{|c|c|c|c|c|c|c|c|}
\hline Source & $\begin{array}{l}\text { Wilks } \\
\text { Lambda }\end{array}$ & $\underline{D F}$ & $\frac{\operatorname{Rao}^{\prime} s}{\underline{F}}$ & $I^{2}$ & $\underline{D f}$ & $\underline{F}$ & $\underline{p}$ \\
\hline Group & & & & 3.67 & 6,20 & 1.0 & NS \\
\hline $\begin{array}{l}\text { Periods } \\
\text {-SBP } \\
\text {-DBP } \\
\text {-HR } \\
\text {-KG } \\
\text {-FEV } \\
\text {-FEV }{ }^{1} .5\end{array}$ & .6104 & 30,482 & $2.11 \star \star$ & $\begin{array}{r}16.51 \\
5.64 \\
18.74 \\
35.22 \\
16.85 \\
16.00\end{array}$ & $\begin{array}{l}5,21 \\
5,21 \\
5,21 \\
5,21 \\
5,21 \\
5,21\end{array}$ & $\begin{array}{r}2.77 \\
.95 \\
3.15 \\
5.92 \\
2.83 \\
2.69\end{array}$ & $\begin{array}{l}\star \\
\text { NS } \\
\star \\
\star * \\
* \\
\star\end{array}$ \\
\hline $\begin{array}{l}\text { Group } \times \text { Periods } \\
\text {-SBP } \\
\text {-DBP } \\
\text {-HR } \\
\text {-KG } \\
- \text { FEV }_{1} \\
- \text { FEV }^{1} .5\end{array}$ & .7170 & 30,482 & $1.39^{1}$ & $\begin{array}{r}5.46 \\
9.18 \\
13.67 \\
2.21 \\
2.82 \\
17.73\end{array}$ & $\begin{array}{l}5,21 \\
5,21 \\
5,21 \\
5,21 \\
5,21 \\
5,21\end{array}$ & $\begin{array}{l}<1.0 \\
1.54 \\
2.301 \\
<1.0 \\
<1.0 \\
2.98\end{array}$ & $\begin{array}{l}\text { NS } \\
\text { NS } \\
\text { iO8 } \\
\text { NS } \\
\text { NS } \\
\star\end{array}$ \\
\hline${ }^{\star} p \leqslant .05$ & & & & & & & \\
\hline
\end{tabular}


TABLE XVII

Simple effects analysis

of variance table for SBP

\begin{tabular}{|c|c|c|c|c|c|}
\hline Source & $\underline{S S}$ & df & Ms & $\underline{F}$ & $\underline{p}$ \\
\hline $\begin{array}{c}\text { Between } \\
\text { Pre } \\
\text { Post } \\
\text { One } \\
\text { Two } \\
\text { Three } \\
\text { Six } \\
\text { Within Cell }\end{array}$ & $\begin{array}{r}11.57 \\
175.00 \\
128.57 \\
44.57 \\
194.64 \\
472.64\end{array}$ & $\begin{array}{c}1 \\
1 \\
1 \\
1 \\
1 \\
1 \\
150\end{array}$ & $\begin{array}{r}11.57 \\
175.00 \\
128.57 \\
44.57 \\
194.64 \\
472.64 \\
119.42\end{array}$ & $\begin{aligned} &< 1.0 \\
& 1.47 \\
& 1.08 \\
&< 1.0 \\
& 1.63 \\
& 3.96\end{aligned}$ & $\begin{array}{l}\text { NS } \\
\text { NS } \\
\text { NS } \\
\text { NS } \\
\text { NS } \\
\star\end{array}$ \\
\hline $\begin{array}{l}\text { Within Subjects } \\
\text { Maintenance } \\
\text { Standard } \\
\text { Group } x \text { Periods } \\
\text { Group } x \text { Subs } \\
\text { (group) }\end{array}$ & $\begin{array}{r}297.49 \\
367.73 \\
267.53 \\
4970.49\end{array}$ & $\begin{array}{c}5 \\
5 \\
5 \\
125\end{array}$ & $\begin{array}{l}59.50 \\
73.56 \\
53.51 \\
39.76\end{array}$ & $\begin{array}{l}1.50 \\
1.85 \\
1.35\end{array}$ & $\begin{array}{l}\text { NS } \\
\text { NS } \\
\text { NS }\end{array}$ \\
\hline
\end{tabular}

* $p<.05$ 


\section{TABLE XVIII}

Mean and standard deviations of systolic blood pressure (SBP) readings in $\mathrm{mm} \mathrm{hg}$

\begin{tabular}{|c|c|c|}
\hline & CONDITION & \\
\hline & Maintenance & Standard \\
\hline $\begin{array}{r}\text { Pre } \bar{x} \\
(S D)\end{array}$ & $\begin{array}{l}114.9 \\
(8.67)\end{array}$ & $\begin{array}{l}117.3 \\
(10.16)\end{array}$ \\
\hline Post & $\begin{array}{l}111.4 \\
(8.58)\end{array}$ & $\begin{array}{l}116.9 \\
(10.83)\end{array}$ \\
\hline \multicolumn{3}{|l|}{ Period } \\
\hline One & $\begin{array}{l}109.5 \\
(8.41)\end{array}$ & $\begin{array}{c}114.6 \\
(10.99)\end{array}$ \\
\hline Two & $\begin{array}{l}114.0 \\
(12.52)\end{array}$ & $\begin{array}{l}116.6 \\
(11.41)\end{array}$ \\
\hline Three & $\begin{array}{l}110.9 \\
(9.89)\end{array}$ & $\begin{array}{c}120.0 \\
(10.81)\end{array}$ \\
\hline $\operatorname{six}$ & $\begin{array}{l}112.8 \\
(10.05)\end{array}$ & $\begin{array}{c}121.1 \\
(16.09)\end{array}$ \\
\hline
\end{tabular}


Analysis of the DBP readings indicated a similar outcome. There was no significant univariate period $X$ group interaction $(F(5,125)=$ 1.45, NS), and only a trend for the maintenance condition to show reduced DBP over assessment periods $(F(5,125)=2.26, P<.10)$. Again, the six month follow-up indicated the maintenance condition recorded significantly lower $D B P$ readings than the standard condition $(F(1,150)=$ 4.54, $P<.05)$. None of the other comparisons between the standard and maintenance conditions were significantly different on any of the remaining assessment periods (see Table $X I X$ ). The means and standard deviations are contained in Table XX.

Heart Rate. Univariate analysis of variance did not reveal any significant main effects or interactions for HR. Tables XXI and XXII summarizes the HR simple ANOVA, as well as the means and standard deviations for the HR Measures.

Weight. Univariate analysis of variance for simple effects did not reveal any significant main effects or interactions for either the maintenance or standard conditions. There were also no significant differences between the standard and maintenance conditions at any of the assessment periods. Table XXIII summarizes the ANOVA results. Means and standard deviations are summarized in Table XXIV.

Vital Capacity. Analysis on the simple effects of FEV 1 indicated no significant interactions between the group $X$ periods factor. There were also no significant main effects for either treatment conditions over the assessment periods. Testing for main effects between the maintenance and standard conditions did not reveal any significant 
TABLE XIX

Simple effects analysis

of variance summary table for DBP

\begin{tabular}{|c|c|c|c|c|c|}
\hline Source & $\underline{S S}$ & $\underline{d f}$ & Ms & $\underline{F}$ & $\underline{p}$ \\
\hline $\begin{array}{c}\text { Between } \\
\text { Pre } \\
\text { Post } \\
\text { One } \\
\text { Two } \\
\text { Three } \\
\text { Six } \\
\text { Within Cell }\end{array}$ & $\begin{array}{r}14.29 \\
3.57 \\
24.14 \\
124.45 \\
103.74 \\
374.18\end{array}$ & $\begin{array}{c}1 \\
1 \\
1 \\
1 \\
1 \\
1 \\
150\end{array}$ & $\begin{array}{r}14.29 \\
3.57 \\
24.14 \\
124.45 \\
103.74 \\
374.18 \\
82.39\end{array}$ & $\begin{array}{l}<1.0 \\
<1.0 \\
<1.0 \\
1.51 \\
1.26 \\
4.54\end{array}$ & $\begin{array}{l}\text { NS } \\
\text { NS } \\
\text { NS } \\
\text { NS } \\
\text { NS } \\
\star\end{array}$ \\
\hline $\begin{array}{l}\text { Within Subjects } \\
\text { Ma intenance } \\
\text { Standard } \\
\text { Group } \times \text { Periods } \\
\text { Group } \times \text { Subs } \\
\text { (group) }\end{array}$ & $\begin{array}{r}453.54 \\
128.95 \\
291.63 \\
5020.18\end{array}$ & $\begin{array}{c}5 \\
5 \\
5 \\
125\end{array}$ & $\begin{array}{l}90.71 \\
25.79 \\
58.33 \\
40.16\end{array}$ & $\begin{array}{l}2.26 \\
1.0 \\
1.45\end{array}$ & $\begin{array}{l}\mathrm{p}<.10 \\
\text { NS } \\
\text { NS }\end{array}$ \\
\hline
\end{tabular}

$* \mathrm{p}<.05$ 


\section{TABLE XX}

Means and standard deviations of diastolic blood pressure (DBP) readings in $\mathrm{mm} \mathrm{Hg}$

\begin{tabular}{|c|c|c|}
\hline & CONDITION & \\
\hline & Maintenance & Standard \\
\hline $\begin{array}{r}\text { Pre } \bar{x} \\
(S D)\end{array}$ & $\begin{array}{l}74.92 \\
(6.86)\end{array}$ & $\begin{array}{l}73.71 \\
(10.07)\end{array}$ \\
\hline Post & $\begin{array}{l}70.77 \\
(5.69)\end{array}$ & $\begin{array}{l}72.00 \\
(9.86)\end{array}$ \\
\hline One & $\begin{array}{l}70.46 \\
(8.45)\end{array}$ & $\begin{array}{l}73.14 \\
(9.44)\end{array}$ \\
\hline Two & $\begin{array}{l}67.85 \\
(9.54)\end{array}$ & $\begin{array}{c}72.14 \\
(11.41)\end{array}$ \\
\hline Three & $\begin{array}{l}71.08 \\
(8.19)\end{array}$ & $\begin{array}{l}75.00 \\
(9.57)\end{array}$ \\
\hline $\operatorname{six}$ & $\begin{array}{l}67.69 \\
(7.06)\end{array}$ & $\begin{array}{c}75.14 \\
(10.49)\end{array}$ \\
\hline
\end{tabular}


TABLE XXI

Simple effects analysis of variance summary for HR

\begin{tabular}{lccccc}
\hline Source & $\underline{\text { SS }}$ & $\underline{\mathrm{df}}$ & $\underline{\text { MS }}$ & $\underline{\mathrm{F}}$ & $\mathrm{p}$ \\
\hline Between & & & & & \\
$\quad$ Pre & .57 & 1 & .57 & $<1.0$ & NS \\
$\quad$ Post & 9.14 & 1 & 9.14 & $<1.0$ & NS \\
One & 5.14 & 1 & 5.14 & $<1.0$ & NS \\
$\quad$ Two & 16.88 & 1 & 16.88 & $<1.0$ & NS \\
$\quad$ Three & 72.29 & 1 & 72.29 & 2.40 & NS \\
$\quad$ Six & 1.37 & 1 & 1.37 & $<1.0$ & NS \\
Within Ce17 & & 150 & 30.17 & & \\
& & & & & \\
Within Subjects & & & & & \\
Maintenance & 196.72 & 5 & 39.34 & 1.69 & NS \\
Standard & 189.71 & 5 & 37.94 & 1.63 & NS \\
Group x Periods & 132.49 & 5 & 26.50 & 1.14 & NS \\
Group x Subs & 2911.31 & 125 & 23.29 & & \\
$\quad$ (groups) & & & & & \\
\hline
\end{tabular}


TABLE XXII

Means and standard deviations for heart rate (HR) in beats per minute (BPM)

\begin{tabular}{|c|c|c|}
\hline & CONDITION & \\
\hline & Maintenance & Standard \\
\hline $\begin{array}{r}\text { Pre } \bar{x} \\
(S D)\end{array}$ & $\begin{array}{l}66.31 \\
(4.89)\end{array}$ & $\begin{array}{l}66.14 \\
(6.49)\end{array}$ \\
\hline Post & $\begin{array}{l}64.62 \\
(5.12)\end{array}$ & $\begin{array}{l}63.71 \\
(5.08)\end{array}$ \\
\hline One & $\begin{array}{l}64.00 \\
(7.66)\end{array}$ & $\begin{array}{l}62.57 \\
(6.54)\end{array}$ \\
\hline Two & $\begin{array}{l}61.85 \\
(3.87)\end{array}$ & $\begin{array}{l}63.43 \\
(4.11)\end{array}$ \\
\hline Three & $\begin{array}{l}61.54 \\
(3.48)\end{array}$ & $\begin{array}{l}65.43 \\
(7.46)\end{array}$ \\
\hline $\operatorname{six}$ & $\begin{array}{l}62.31 \\
(5.02)\end{array}$ & $\begin{array}{l}61.86 \\
(4.04)\end{array}$ \\
\hline
\end{tabular}




\section{TABLE XXIII}

Simple effects analysis of variance

summary for weight ( $K G$ )

\begin{tabular}{|c|c|c|c|c|c|}
\hline Source & $\underline{S S}$ & df & Ms & $\underline{F}$ & $\mathrm{p}$ \\
\hline $\begin{array}{c}\text { Between } \\
\text { Pre } \\
\text { Post } \\
\text { One } \\
\text { Two } \\
\text { Three } \\
\text { Six } \\
\text { Within Cell }\end{array}$ & $\begin{array}{r}36.34 \\
27.80 \\
.39 \\
57.62 \\
40.12 \\
49.54\end{array}$ & $\begin{array}{c}1 \\
1 \\
1 \\
1 \\
1 \\
1 \\
150\end{array}$ & $\begin{array}{r}36.39 \\
27.80 \\
.39 \\
57.62 \\
40.12 \\
49.54 \\
184.20\end{array}$ & $\begin{array}{l}<1 \\
<1 \\
<1 \\
<1 \\
<1 \\
<1\end{array}$ & $\begin{array}{l}\text { NS } \\
\text { NS } \\
\text { NS } \\
\text { NS } \\
\text { NS } \\
\text { NS }\end{array}$ \\
\hline $\begin{array}{l}\text { Within Subjects } \\
\text { Maintenance } \\
\text { Standard } \\
\text { Group } x \text { Periods } \\
\text { Group x Subs } \\
\text { (groups) }\end{array}$ & $\begin{array}{r}33.62 \\
47.18 \\
46.43 \\
1337.36\end{array}$ & $\begin{array}{c}5 \\
5 \\
5 \\
125\end{array}$ & $\begin{array}{r}6.72 \\
9.44 \\
9.29 \\
10.70\end{array}$ & $\begin{array}{l}<1 \\
<1 \\
<1\end{array}$ & $\begin{array}{l}\text { NS } \\
\text { NS } \\
\text { NS }\end{array}$ \\
\hline
\end{tabular}


TABLE XXIV

Means and standard deviations

of weight in $K G$

\begin{tabular}{cccc}
\hline & CONDITION & \\
\hline & & Maintenance & Standard \\
& Pre $\bar{x}$ & 65.74 & 68.21 \\
$($ SD $)$ & $(14.42)$ & $(11.54)$ \\
& Post & 64.69 & 69.24 \\
Period & & $(19.02)$ & $(11.36)$ \\
& One & 67.62 & 68.84 \\
& Two & $(14.42)$ & $(12.29)$ \\
& & 67.42 & 68.91 \\
& Three & $(14.62)$ & $(12.03)$ \\
& Six & 67.65 & $(10.09$ \\
& $(14.23)$ & 69.96 \\
& 67.25 & $(12.14)$ \\
\hline
\end{tabular}


differences on any of the six assessment periods. Tables XXV and XXVI contain the ANOVA results and the summary data for $\mathrm{FEV}_{1}$.

For $\mathrm{FEV}_{.5}$, there was a significant group $X$ period interaction $(F(5,125)=2.34, P<.05)$. There was a main effect for the standard conditions $(F(5,125)=3.71, P<.01)$ across assessment periods. The main effect for the maintenance condition was non-significant $(F(5,125)$ $=1.42$, NS). Between the treatment conditions, there were no significant differences on the FEV.$_{5}$ measures at any of the assessment periods. However, the standard condition did approach significance at post-cessation assessment for $\mathrm{FEV}_{.5}$, with $F(1,150)=3.38, P<.10$.

Examination of the means in Table XXVIII best summarizes the FEV ${ }_{.5}$ results. Table XXVII contains the ANOVA summary.

\section{SUMMARY OF OUTCOME ON HEALTH MEASURES}

Multivariate analysis indicated significant improvement on health assessment dependent variables over the period of evaluation. Improvement was noted on SBP, HR, FEV 1 and FEV . . Weight also increased significantly in the multivariate analysis. There were equivocal signs of differential improvement between the treatment conditions on health measures, however. Subjects in the maintenance condition recorded significantly lower SBP and DBP measures at six month follow-up than subjects in the standard condition. Subjects in the standard condition significantly improved on the FEV ${ }_{.5}$ measures, while the subjects in the 
TABLE XXV

Simple effects analysis of variance summary table for FEV ${ }_{1}$

\begin{tabular}{llllll}
\hline Source & SS & df & Ms & $\underline{F}$ & P \\
\hline Between & & & & & \\
$\quad$ Pre & .76 & 1 & .76 & 1.21 & NS \\
$\quad$ Post & .44 & 1 & .44 & $<1$ & NS \\
One & .52 & 1 & .52 & $<1$ & NS \\
$\quad$ Two & .47 & 1 & .47 & $<1$ & NS \\
$\quad$ Three & .52 & 1 & .52 & $<1$ & NS \\
Six & .48 & 1 & .48 & $<1$ & NS \\
Within Cell & & 150 & .62 & & \\
& & & & & \\
Within Subjects & & & & & \\
$\quad$ Maintenance & .28 & 5 & .06 & 1.41 & NS \\
Standard & .13 & 5 & .03 & $<1$ & NS \\
Group x Periods &. .19 & 5 & .04 & 1.0 & NS \\
Group x Subs & 4.93 & 125 & .0394 & & \\
$\quad$ (groups) & & & & & \\
\hline
\end{tabular}




\section{TABLE XXVI}

Means and standard deviations for one-second Forced Expiratory Volume $\left(F_{1}\right)$ in liters

\begin{tabular}{|c|c|c|}
\hline & CONDITION & \\
\hline & Maintenance & Standard \\
\hline Pre $\begin{array}{l}\bar{x} \\
(S D)\end{array}$ & $\begin{array}{l}2.52 \\
(.92)\end{array}$ & $\begin{array}{l}2.85 \\
(.80)\end{array}$ \\
\hline Post & $\begin{array}{l}2.84 \\
(.81)\end{array}$ & $\begin{array}{l}2.95 \\
(.78)\end{array}$ \\
\hline \multicolumn{3}{|l|}{ Period } \\
\hline One & $\begin{array}{l}2.65 \\
(.73)\end{array}$ & $\begin{array}{l}2.94 \\
(.74)\end{array}$ \\
\hline Two & $\begin{array}{l}2.70 \\
(.73)\end{array}$ & $\begin{array}{l}2.96 \\
(.76)\end{array}$ \\
\hline Three & $\begin{array}{l}2.61 \\
(.66)\end{array}$ & $\begin{array}{l}2.89 \\
(.78)\end{array}$ \\
\hline Six & $\begin{array}{l}2.72 \\
(.72)\end{array}$ & $\begin{array}{l}2.94 \\
(.76)\end{array}$ \\
\hline
\end{tabular}




\section{TABLE XXVII}

Simple effects analysis of variance summary table for one-half second Forced Expiratory Volume (FEV ${ }_{.5}$ )

\begin{tabular}{|c|c|c|c|c|c|}
\hline Source & $\underline{S S}$ & df & Ms & $\underline{F}$ & $\mathrm{p}$ \\
\hline $\begin{array}{c}\text { Between } \\
\text { Pre } \\
\text { Post } \\
\text { One } \\
\text { Two } \\
\text { Three } \\
\text { Six } \\
\text { Within Cell }\end{array}$ & $\begin{array}{l}.22 \\
2.23 \\
.39 \\
.56 \\
.11 \\
.02\end{array}$ & $\begin{array}{c}1 \\
1 \\
1 \\
1 \\
1 \\
1 \\
150\end{array}$ & $\begin{array}{r}.22 \\
2.23 \\
.39 \\
.56 \\
.11 \\
.02 \\
.66\end{array}$ & $\begin{aligned} & <1 \\
& 3.38 \\
< & 1 \\
< & 1 \\
< & 1 \\
< & 1\end{aligned}$ & $\begin{array}{l}\text { NS } \\
\stackrel{N S}{<} .10 \\
\text { NS } \\
\text { NS } \\
\text { NS }\end{array}$ \\
\hline $\begin{array}{l}\text { Within Subjects } \\
\text { Maintenance } \\
\text { Standard } \\
\text { Group } \times \text { Periods } \\
\text { Group } x \text { Subs } \\
\text { (groups) }\end{array}$ & $\begin{array}{r}.61 \\
1.61 \\
1.01 \\
10.83\end{array}$ & $\begin{array}{c}5 \\
5 \\
5 \\
125\end{array}$ & $\begin{array}{l}.12 \\
.32 \\
.20 \\
.09\end{array}$ & $\begin{array}{l}1.42 \\
3.71 \\
2.34\end{array}$ & $\begin{array}{l}\text { NS } \\
\star \star \\
\star\end{array}$ \\
\hline$\star p<.05$ & & & & & \\
\hline$\star \star p<.01$ & & & & & \\
\hline
\end{tabular}


TABLE XXVIII

Means and standard deviations of one-half second

Forced Expiratory Volume $\left(\mathrm{FEV}_{.5}\right.$ ) in liters

\begin{tabular}{|c|c|c|}
\hline & CONDITION & \\
\hline & Maintenance & Standard \\
\hline $\begin{array}{r}\text { Pre } \bar{x} \\
(S D)\end{array}$ & $\begin{array}{l}2.02 \\
(.84)\end{array}$ & $\begin{array}{l}2.14 \\
(1.10)\end{array}$ \\
\hline Post & $\begin{array}{l}2.02 \\
(.94)\end{array}$ & $\begin{array}{l}2.59 \\
(.84)\end{array}$ \\
\hline Period & $\begin{array}{l}2.16 \\
(.76)\end{array}$ & $\begin{array}{l}2.45 \\
(.94)\end{array}$ \\
\hline Two & $\begin{array}{l}2.19 \\
(.77)\end{array}$ & $\begin{array}{l}2.46 \\
(.63)\end{array}$ \\
\hline Three & $\begin{array}{l}2.17 \\
(.71)\end{array}$ & $\begin{array}{l}2.31 \\
(.68)\end{array}$ \\
\hline Six & $\begin{array}{l}2.22 \\
(.81)\end{array}$ & $\begin{array}{l}2.32 \\
(.62)\end{array}$ \\
\hline
\end{tabular}


maintenance condition did not show significant improvement on the FEV ${ }_{.5}$ variable. However, there were no reliable differences between the standard and maintenance conditions at any of the assessment periods on FEV ${ }_{.5}$ measures. At post-cessation assessment, the standard condition approached significance in the $\mathrm{FEV}_{.5}$ variable relative to the maintenance condition. None of the other assessment periods approached conventional significance levels for the FEV ${ }_{.5}$ measures.

II. RELATIVE CONTRIBUTIONS OF TREATMENT, NICOTINE CONSUMPTION, AND HEALTH STATUS ON OUTCOME:

MULTIPLE REGRESSION ANALYSIS

A step-wise regression analysis was performed in order to assess the contributions of various factors on treatment outcome. Treatment outcome was defined as the number of cigarettes per day the subject was smoking at six month follow-up. Variables considered for the step-wise regression procedure were:

Treatment ( 1 = maintenance, 2 = standard)

Cigarettes per day, pre test

COa\%, pre test

SCN levels, pre test

HLOC, pre test

STAI, pre test

Reported years smoking

Nicotine $(\mathrm{mg} /$ day $=$ cigarette/day $\times$ nicotine $\mathrm{mg} /$ cigarette $)$ 
Health status $(0=$ no problems, $1=$ relatives $C H D$, pulmonary distress, cancer, 3 = reported or diagnosed CHD, pulmonary distress, cancer).

Age in years

Efficacy expectations, pre test

Deposit amount, in dollars

The aim of the regression procedure was to eliminate predictors poorly related to outcome, cross-validate previous regression analys is (Burling, 1981), and develop prognostic indicators.

The first variable entered into the regression was the MG nicotine use per day $(\underline{r}=.49)$. The second variable entered into the equation was the health status variable, with the resulting $\underline{r}=.59$. The dummy variable coded for treatment condition then entered, yiêlding an $\underline{r}=$ .76. The resulting regression formula accounted for $57.91 \%$ of the variance. Table XXIX summarizes the regression analysis results, giving the standardized regression coefficients and F-ratio to enter.

III. ANALYSIS OF HEALTH FUNCTIONING:

SMOKING AND NON-SMOKING SUBJECTS

To evaluate the impact smoking cessation had upon the health assessment, the subjects were divided into two categories on the basis on their reported smoking levels at the six month follow-up. Individuals abstinent or smoking less than $40 \%$ of their baseline smoking 


\section{TABLE XXIX}

Multiple regression on cigarettes

per day at six month follow-up:

Results of a stepwise multiple

regression analys is

\begin{tabular}{llccc}
\hline Step & Variable & Multiple R & F to Enter & Std. Reg. Coeff. \\
\hline 1 & Nicotine mg/day & .486 & 7.75 & .545 \\
2 & Health Status & .590 & 4.10 & .256 \\
3 & Treatment Condition & .761 & 12.63 & .569 \\
\hline
\end{tabular}


$(N=12)$ were considered as the successfur subjects. Subjects smoking more than $40 \%$ of their baseline levels were considered as unsuccessful subjects $(n=15)$. Table XXXI summarizes the MANOVA results for the three month change scores.

Change scores were calculated for the subjects on the health assessment measures for blood pressure, heart rate, weight and vital capacity for both the three and six month follow-ups. The MANOVA assigned equal weights to each outcome measure change score - SBP, DBP, $H R, K G, F E V$ and FEV.$^{.}$. Results of the analysis of change on the health measures for the three month follow-up period indicated that the change scores for the health measures deviated significantly from zero $(F(6,20)$ $=5.97, P<.01)$. Examining each measure individually indicated that there were significant reductions in $\operatorname{HR}(F,(1,25)=5.28, P<.05)$. There was also a significant increase in weight $(F,(1,25)=36.29, P<$ .01) evident at the three month follow-up. None of the remaining health assessment measures deviated significantly from zero. The MANOVA between the successful and unsuccessful on the health change scores for the three month follow-up did not achieve significance $(F,(6,20)=1.37$, NS). There was a significant univariate effect, with successfur subjects showing greater HR reductions compared to unsuccessful subjects $(F(1,25)=7.17, P<.05, x=-7.00$ versus $+.53 \mathrm{BPM})$. However, the lack of multivariate significance makes the interpretation of this result problematic, as the univariate effect may only be the result of multiple tests. Also, the subjects were selected on the basis of their outcome, rather than randomily selected, making the use of inferential statistical 
analysis risky. The health change scores for the subjects who stopped completely were generally more positive than the remaining subjects. For example, the mean HR reduction at the three month follow-up for subjects who completed the six months without smoking was $\bar{x}=-7.78$ BPM. However, the number of subjects in this subset precluded meaningful statistical analysis. Table $X X X$ summarizes the MANOVA results for the three month change scores.

The MANOVA for the health change scores at the six month assessment between the successful and unsuccessful subjects indicated a similar picture. The change scores deviated significantly from zero $(F(6,20)=$ $4.87, P<.01)$. Heart rate scores reduced significantly $(F(1,25)=$ 13.52, $P<.01$ ) and weight change scores increased significantly $(F(1,25)=17.98, P<.01)$. There were no significant differences between the successful and unsuccessful subjects on the MANOVA for health change scores at the six month follow-up. There was a trend for successful subjects to show greater reductions of $\operatorname{DBP}(F(1,25)=3.01, P<$ $.10, \bar{x}=-5.83$ versus .27), however. There were also no other significant univariate differences between the successful and unsuccessful subjects change scores. Table XXXI contains the MANOVA summary table for the six month health change scores. Tabie XXXII contains the mean change scores on health measures. 
TABLE XXX

MANOVA summary table for change scores on health measures for successful and unsuccessful subjects at three month follow-up

\begin{tabular}{|c|c|c|c|c|c|c|}
\hline & Source & $I^{2}$ & df & MS & $\underline{F}$ & $p$ \\
\hline & $\begin{array}{l}A 11 \\
-S B P \\
-D B P \\
-H R \\
-K G \\
-F E V \\
-F E V^{1} .5\end{array}$ & 44.80 & $\begin{array}{l}6,20 \\
1,25 \\
1,25 \\
1,25 \\
1,25 \\
1,25 \\
1,25\end{array}$ & $\begin{array}{r}20.81 \\
8.07 \\
278.79 \\
108.09 \\
.12 \\
.23\end{array}$ & $\begin{array}{rl} & 5.97 \\
< & 1 \\
< & 1 \\
5 & 5.28 \\
& 36.29 \\
< & 1 \\
< & 1\end{array}$ & $\begin{array}{l}\star \star \\
\text { NS } \\
\text { NS } \\
\star \\
\star \star \\
\text { NS } \\
\text { NS }\end{array}$ \\
\hline & $\begin{array}{l}\text { Group } \\
\text {-SBP } \\
- \text {-DBP } \\
-H R \\
-K G \\
-F E V \\
-F E V^{1} .5\end{array}$ & 10.24 & $\begin{array}{l}6,20 \\
1,25 \\
1,25 \\
1,25 \\
1,25 \\
1,25 \\
1,25\end{array}$ & $\begin{array}{r}.07 \\
24.07 \\
378.34 \\
.005 \\
.006 \\
.001\end{array}$ & $\begin{aligned} & 1.37 \\
&<1<1 \\
& 7.17 \\
&<1 \\
&<1 \\
&<1\end{aligned}$ & $\begin{array}{l}\text { NS } \\
\text { NS } \\
\text { NS } \\
\star \\
\text { NS } \\
\text { NS } \\
\text { NS }\end{array}$ \\
\hline & $p<.05$ & & & & & \\
\hline & $p<.01$ & & & & & \\
\hline
\end{tabular}




\section{TABLE XXXI}

MANOVA summary table for health change scores

of successful and unsuccessfui

subjects at six month follow-up

\begin{tabular}{|c|c|c|c|c|c|}
\hline Source & $I^{2}$ & df & MS & $\underline{F}$ & $\underline{P}$ \\
\hline $\begin{array}{l}A 11 \\
\text {-SBP } \\
\text {-DBP } \\
-H R \\
-K G \\
-F E V \\
-F E V{ }^{1} .5\end{array}$ & 36.55 & $\begin{array}{l}6,20 \\
1,25 \\
1,25 \\
1,25 \\
1,25 \\
1,25 \\
1,25\end{array}$ & $\begin{array}{r}6.67 \\
206.59 \\
568.36 \\
73.85 \\
.2081 \\
.5289\end{array}$ & $\begin{array}{r}4.87 \\
<1 \\
2.51 \\
13.52 \\
17.98 \\
1.39 \\
1.54\end{array}$ & $\begin{array}{l}\star * \\
\text { NS } \\
\text { NS } \\
\star \star \\
\star \star \\
\text { NS } \\
\text { NS }\end{array}$ \\
\hline $\begin{array}{l}\text { Group } \\
\text {-SBP } \\
\text {-DBP } \\
\text {-HR } \\
\text {-KG } \\
\text {-FEV } \\
\text {-FEV } 1 \\
.5\end{array}$ & 4.73 & $\begin{array}{l}6,20 \\
1,25 \\
1,25 \\
1,25 \\
1,25 \\
1,25 \\
1,25\end{array}$ & $\begin{array}{c}125.19 \\
248.07 \\
64.07 \\
.33 \\
.02 \\
.0001\end{array}$ & $\begin{array}{l}<1.0 \\
1.18 \\
3.01 \\
1.52 \\
<1.0 \\
<1.0 \\
<1.0\end{array}$ & $\begin{array}{l}\text { NS } \\
\text { NS } \\
P<.10 \\
\text { NS } \\
\text { NS } \\
\text { NS } \\
\text { NS }\end{array}$ \\
\hline
\end{tabular}

$* \quad p<.05$
$\star * \quad p<.01$ 
TABLE XXXII

Mean change scores on health assessment variables at three and six month follow-up for successful and unsuccessful subjects

\begin{tabular}{lcccc}
\hline & \multicolumn{2}{c}{ Three Months } & \multicolumn{2}{c}{ Six Months } \\
\hline & Success & Unsuccess & Success & Unsuccess \\
SBP & -.83 & -.93 & -1.67 & 2.67 \\
DBP & -1.50 & .40 & -5.83 & .27 \\
HR & -7.00 & .53 & -6.17 & -3.07 \\
KG & 2.00 & 2.03 & 1.78 & 1.55 \\
FEV & .08 & .05 & .12 & .06 \\
FEV & .10 & .09 & .14 & .14 \\
\hline
\end{tabular}




\section{RELAPSE EVENTS}

Monitoring of relapse events indicated that there were four major patterns of smoking cessation over the time period of the study. First of all, complete cesstion without any subsequent return to smoking was noted in 21.4\% (6) of the 28 subjects. Most of these subjects (5) were in the maintenance condition. Second, cessation followed by relapse and prompt return to at least $75 \%$ of baseline smoking levels occurred in $25.0 \%$ (7) of the 28 subjects. Most of these subjects (5) were in the standard condition. Two intermediate patterns were evident, however. The third pattern, intermediate between full-blown relapse and total cessation, was one of relapse and gradual increase in smoking levels to near pre-treatment baseline. This pattern was the most frequent, with 46.2\% (13) of the subjects showing this pattern. The two conditions had approximately the same number of subjects showing the gradual relapse pattern. Of the gradual relapse subjects, 5 remained below $50 \%$ of their pre-treatment smoking baseline. Four of these five subjects were in the standard condition. Finally, $7.1 \%$ (2) of the subjects stopped smoking, relapsed, and then stopped smoking again. One subject in each condition demonstrated this stop-start-stop again pattern. These patterns are more complex than simple decay of extinction curves, and imply other factors may interrupt the decay.

A $\log$ was kept of the relapse incidents, the probable explanation of the incident, the response to the relapse and the outcome within 72 hours. Twenty-two relapses were logged, with some subjects having more 
than one relapse. Four individuals stopped again for at least sixty days after a relapse episode. Prominent reasons for the relapse mentioned by the subjects were being in emotionally charged situations $(22 \%)$, interpersonal conflict with others (11\%), drinking in social situations (39\%), feeling anxious (22\%), or feeling the need to smoke at work $(6 \%)$. The presence of a supportive spouse aided in successful resolution of relapse in two cases. Conversely, at least two spouses of participants appeared to covertly undermine attempts to stop smoking.

\section{COST EFFECTIVENESS ANALYSIS AND ANCILLARY RESULTS}

In evaluating the cost per effect, the $\mathrm{COa} \%$ outcome at six month follow-up was used as the outcome index. The $\mathrm{COa} \%$ measure was utilized because it was the most objective and reliable single index of outcome on smoking for the smoking cessation project considered here. The effect size (ES) was estimated by the now familiar formula

$$
E S=\frac{\bar{x} \text { pre }-\bar{x} \text { six }}{S D \text { pre }}
$$

from Smith and Glass (1977). Larger effect sizes indicate more positive outcomes. The ES was calculated for each group.

Costs in administration of each treatment were estimated by assigning hourly wage cost to the co-therapists. Overhead was arbitrarily estimated at $20 \%$ of personnel cost. No cost was estimated for the laboratory facilities, as the instrumentation and equipment had 
previously been obtained and was used without cost to the project. If costs had been incurred for equipment, they would have been split evenly between the two treatment conditions.

Cost Effectiveness Analysis. With the above assumptions, costs were primarily a function of the hours of service:

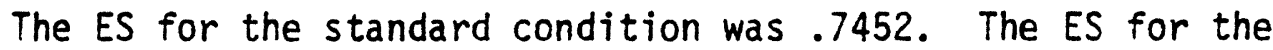
maintenance condition was 1.4144 . The relevant cost/effect ratios, then, were:

$$
\begin{aligned}
& \text { Standard cost/effect }=\frac{\$ 1,032.00}{.7452}=\$ 1,384.82 \\
& \text { Maintenance cost/effect }=\frac{\$ 1,156.80}{1.4144}=\$ 817.88
\end{aligned}
$$

The cost per subject treated was $\$ 73.71$ for the standard condition and $\$ 82.63$ for the maintenance condition. Despite the greater cost per subject for the maintenance condition, the cost per treatment effect size was less for the maintenance condition. In this case the cost/ effect size indicates the cost to achieve a reduction of $3.0 \% \mathrm{COa}$ for the subjects in their respective groups.

Ancillary Findings. Several areas were evaluated to insure uncontrolled third variables could not influence results. Earlier, it was noted that neither the amount of deposit more the type of deposit was related significantly to outcome. In addition, there were no significant differences on cessation rates for males (33\%) and females (28\%) at six month assessment. Scores on the Cohesiveness Scale (Appendix A) were similar between the two conditions, with mean scores of 43.77 for

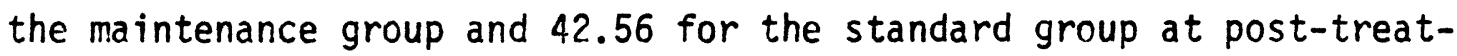


ment. The Cohesiveness Scale was intended to evaluate group process and expectancies of benefit. 
STANDARD:

Six sessions, two therapists

1 a $\$ 6.00$ /hour $x 12$ hours

1 e $\$ 10.00$ /hour $\times 14$ hours

$\$ 72.00$

Administration e $\$ 10.00$ /hour $\times 6$ hours $\frac{60.00}{\$ 272.00}$

$\$ \longdiv { 2 7 2 . 0 0 }$

Follow-up and assessment

1 a $\$ 6.00$ /hour $\times 18$ hours

108.00

1 a $\$ 10.00$ /hour $\times 48$ hours

480.00

$\$ 588.00$

Overhead Cost (o 20\%)

$\$ 172.00$

TOTAL

$\$ 1,032.00$

\section{MAINTENANCE:}

Eight sessions, two therapists

1 \& $\$ 6.00$ /hour $\times 16$ hours

1 a $\$ 10.00$ /hour $\times 20$ hours

$\$ 96.00$

Administration a $\$ 10.00$ /hour $\times 8$ hours

200.00

80.00

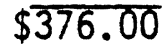

Follow-up and Assessment

1 a $\$ 6.00$ /hour $\times 18$ hours

$\$ 108.00$

1 c $\$ 10.00$ /hour $\times 48$ hours

480.00

$\$ 588.00$

Overhead cost (o 20\%)

$\$ 192.80$

TOTAL

$\$ 1,156.80$ 


\section{DISCUSSION}

The overall outcome of this project was that the maintenance condition smoked significantly fewer cigarettes than the standard condition over each assessment period. This was substantiated by the carbon monoxide levels which were significantly lower for the maintenance condition at post assessment, three month follow-up and six month follow-up. In addition, the thiocyanate levels were significantly lower for the maintenance condition at the three month follow-up. In general, these findings are consistent with other research indicating that behavioral contracting procedures positively influence outcome (Winett, 1973: Paxton, 1980, 1981; Elliot and Tighe, 1968). Thus, while the results seem attributable to the contingent contract, a result similar to Winett (1973), it must be noted that the maintenance condition also had two additional post-cessation sessions and a hand-out packet intended to aid the participants in the first two weeks of cessation.

Despite these differential outcomes, it is apparent that both conditions relapsed to smoking at the same rate. However, relapse was delayed in the maintenance condition and not as marked. There was a lack of significant interaction on the smoking measures. Relapse appeared to occur in a parallel, but not equal fashion for the treatment groups (i.e. $42 \%(6)$ versus $14 \%(2)$ ). The better outcome for the maintenance condition leaves the lack of impact on relapse rates as an important theoretical concern, but it also has practical implications for smoking cessation treatments. 
A crucial concern relates to how the maintenance condition managed to achieve the more positive outcomes. On the one hand, the maintenance contract may act only as extended treatment, leaving the maintenance group to continue to relapse until the results resemble the standard condition. On the other hand, the maintenance condition may have maraged to gain improved outcome and hence gain extended smoking cessation rates as well. Statistical attempts to deal with these questions (i.e. analysis of covariance) are unsatisfactory since treatment for the maintenance condition may only be seen as extended. Instead, a telephone follow-up will be provided for the maintenance condition to estimate cessation rates at nine-month post-cessation date. This will indicate whether better maintenance has been influenced beyond extended treatment.

Clinical Utility. Treatment appears to be economical, both in cost per subject and cost per effect size. In addition, group behavioral therapy of the type provided for this study are likely to continue to be utilized in the future because this type of treatment is consistent with cultural and institutional forces (Zilbergeld, 1983). At the same time, the provision of treatment of this type can not be regarded as the only type of approach to smoking cessation efforts. Extensive recruitment efforts result in only a limited number of subjects, who may not reflect a typical smoking population. Even so, the cost/effectiveness of the program appeared to be markedly lower for the maintenance condition (\$817) compared to the standard condition $(\$ 1,385)$. Thus, a slight increase in treatment groups costs $(\$ 124.80)$ resulted in a marked 
reduction in cost per effect size. Costs per benefit were not assessed, but they are likely to be low given the high health risks of smoking. The cost/benefit was likely to be especially low for the maintenance condition.

Analysis of prognostic factors predicting outcome indicated that subjects most likely to benefit from treatment were subjects using lower levels of nicotine per day and who did not have any health problems or family history of health problems. The prognostic findings of this study need to be cross-validated, as they are not wholly consistent with previous research. Burling (1981) indicated that post-treatment expectancies and pre-treatment cigarettes smoked per day best predicted outcome, for example.

In examining the findings on prognoses, hypotheses can be formed regarding how these factors predict outcome. Nicotine consumption may aid predicting outcome by indicating the degree to which a subject has become physically dependent upon nicotine. In addition, use of high levels of nicotine place the subject at greater risk for health problems. In terms of treatment with nicotine fading procedures, subjects using high levels of nicotine may be more difficult to treat. However, nicotine fading may be an appropriate method to utilize for the initial attempt at smoking cessation therapy. Foxx and Axelroth (1983) recently recommended that nicotine-fading efforts be considered as the "least restrictive" treatment for smoking cessation. For heavily dependent smokers, nicotine fading may result in reduced nicotine levels and health risk even if cessation and titration does not occur. Treat- 
ment by more risky methods, such as rapid smoking, could then be attempted for subjects who do not successfully complete nicotine fading. For health status, poor health may contribute to poor outcome by several processes. Poor health status or risk may be associated with greater severity of smoking, as length of smoking history, high nicotine use and high nicotine yield smoking topography. However, poor health status or risk predicted outcome significantly even when length of smoking history, nicotine levels and amount of smoking per day were controlled for in the regression analysis. The effectiveness of smoking topography (such as puff duration, inter-puff intervals, \% of cigarette smoked, and degree of inhalation) was not evaluated for this study, and hence may account for the contribution of poor health status on outcome. A competing explanation would be that individuals with poor health status or a family history of tobacco-related health problems responded differentially to treatment because of feelings of discouragement and denial. Thus, the individuals with poor health status may deny the severity of their smoking, feel discouragement, depression and a loss of self-efficacy. There may be a tendency to feel there is little to gain by stopping smoking under these circumstances. The depressogenic response to poor health status seemed to be evident in some subjects, although this response was not systematically evaluated. Depressogenic-like responses are similar to the abstinence-violation effect (Marlatt and Gordon, 1979) and may contribute to poor outcome. Future research on the depressogenic effect may be fruitful, especially 
with efforts to tailor treatment for individuals who may be unrealistically pessimistic about smoking cessation (Paul, 1967).

Objective Smoking Measures. Both the $\mathrm{COa}$ and $\mathrm{SCN}$ measures were utilized as objective checks on cigarette smoking levels. The COa measure correlated more strongly with the average number of cigarettes smoked per day than did SCN results. Evidence from other research continues to indicate that the $\mathrm{CO}$ a measure also reflects the $\mathrm{CO}$ yield of the cigarette and elements of smoking topography, such as interpuff intervals and cigarette duration (Burling, Lovett, Richter, and Frederiksen, 1983). COa levels appear to closely match smoking patterns, as demonstrated by Henningfield, Stitzer and Graffiths (1980) monitoring of CO levels over smoking sessions. The results of this study also indicated that $\mathrm{CO}$ a recordings correlated positively with reported cigarettes per day and negatively with the time since the last reported cigarette. In addition, $\mathrm{CO}$ a levels accurately distinguished smoking from non-smoking subjects.

The SCN measure also yielded accurate smoker and non-smoker classifications for this study. However, the classification hit rates were not as high for the $S C N$ measure as reported in previous research, (i.e., Butts, Kuehneman and Widdowson, 1974). The correlation of SCN with reported cigarettes per day was also only moderate $(r=.51)$, while the COa correlation with reported cigarettes per day was high $(\underline{r}=.82)$. The moderate correlation of the SCN with reported smoking levels may reflect either limitations of the SCN analysis or demand qualities of the study influencing the reported levels of smoking. The method of SCN 
analysis was very similar to the methods described in other reports (Jaffe et. al., 1981). The correlation of SCN concentrations with smoking levels was also similar to other reports (Vogt, Selvin, Widdowson and Hulley, 1977). Examination of the mean and standard deviations for the SCN concentration for this study and the Jaffe et. al. (1981) study indicated approximate agreement. The variability of the SCN concentrations appeared large relative to the means for both this study $( \pm 21$ to \pm 53$)$ and the Jaffe et. al. (1981) study $( \pm 42$ to \pm 66$)$. The agreement of the SCN concentrations with previous research, combined with the large relative variability of the scores implies that SCN concentrations may be less sensitive indicators of smoking levels than COa levels. In addition, research is needed to reiate SCN plasma concentrations to cigarette $\mathrm{HCN}$ levels.

An alternative explanation to the moderate $\mathrm{SCN}$ and cigarette smoking correlation is that the reported cigarettes smoked per day were biased. The demand qualities of the study may have encouraged underreported smoking levels. The demand qualities were particularly active for the maintenance condition. The smoking-contingent deposit was returned for either $\mathrm{CO}$ a or SCN levels indicating non-smoking. Further, the COa and SCN levels chosen for criteria were set at high levels to insure deposits were not lost for false positives. Thus, a subject could stop smoking about two to three days before the health assessment and still meet the criteria for deposit refund. However, the subjects were aware that smoking levels were being monitored by accurate laboratory methods. In addition, significant others were contacted to confirm 
reported non-smoking. Results of the significant other contacts were no disconfirmations of smoking status by significant others. Finally, only two subjects illustrated a low COa and high SCN concentration necessary to conform to the demand requirements. These low COa and high SCN levels did not persist across all follow-up periods. Thus, demand qualities appear to be a possible but unlikely explanation of the findings.

Further research on the influence of smoking on SCN levels is indicated. Smoking under experimentally controlled conditions while monitoring plasma SCN levels is needed. Concurrent monitoring of cigarette HCN and plasma SCN would also be useful. Research of this type would aid in the development of SCN concentrations as an objective indication of smoking levels.

Health Changes. Participants improved on health, as represented by the linear combination of the equally weighted variables of DBP, SBP, $H R, K G, F E V_{1}$, and $F E V{ }_{.5}$. Areas of improvement were the SBP, HR, FEV and $\mathrm{FEV}_{.5}$. There was also a significant weight gain ( $2 \mathrm{KG}$ ) noted for the participants.

There was limited evidence of greater improvement in health functioning for the maintenance condition. The SBP and DBP were significantly lower for the maintenance group compared to the standard group at six month assessment. There was trend toward a significant increase in $\mathrm{FEV}_{.5}$ values at post-assessment favoring the standard condition. However, the standard condition then slowly reduced $\mathrm{FEV}_{.5}$ readings, while the maintenance condition slowly increased $\mathrm{FEV}_{.5}$ readings. The 
significant multivariate group $X$ period interaction for $\mathrm{FEV}_{.5}$ favored the interpretation that the maintenance condition showed gradual increases, while the standard condition showed gradual decreases of FEV ${ }_{.5}$. Other than the blood pressure and vital capacity measures, however, there were no reliable differences between the standard and maintenance conditions on health assessment variables. In general, the average health assessment scores favored the maintenance condition.

When examining changes in the health assessment variables for successful and unsuccessful subjects, no marked differences were evident. There was a significantly greater reduction in HR BPM for the successful subjects at the three month assessment. The HR reduction comparison was not significant at the six month follow-up, however. Several explanations may account for the lack of findings in this area. The limited differences in changes of health functioning between successful and unsuccessful subjects may reflect the distinction between clinically detectable changes and epidemologically detectable changes. Small differences may be detectable in large epidemological studies, but not in small clinical groups. It was also difficult to account for related life style changes, such as exercise, eating, stress or personal conflict. Finally, more sensitive measurement methods could aid research with small samples. For example vital capacity measures such as FEV .25-.75\% and FEV $.75-85 \%$ may be more sensitive to pulmonary dysfunction (White and Froeb, 1980). Also, cardiovascular assessment may benefit from use of psychophysiological assessment methods to reduce measurement variability. 
Implications for Treatment Programs. Behavioral contracting, nicotine fading and extended treatment a 11 seem to have been associated with positive outcomes for smoking cessation programs. Research programs for the future may attempt to test these three elements of cessation programs to determine the relative effects of each component. The availability of $\mathrm{CO}$ and $\mathrm{SCN}$ assessment methods will aid in the evaluation of smoking cessation programs, although the SCN methodology needs refinement. Behavioral contracting, unlike nicotine fading or extended therapy, lends itself to large scale application. J Insurance companies and health maintenance organizations (HMO) already have practices which resemble behavioral contracting procedures for smoking cessation, such as reduced fees or rebates. Incentives of the type considered here may not work without group support, but experimental trials are needed to yield data on the influence of incentives without therapeutic support. The maintenance treatment described here was cost effective, but large scale trials without therapeutic support would better match the available resources for smoking cessation programs. One of the premises of nicotine fading -- that cigarette smoking is an addiction, and, therefore, can be managed as an addiction -- has led to the use of the brand fading procedure. The idea the nicotine use through smoking tobacco can be addictive appears to be becoming less controversial (e.g. Goldfarb, Jarvik and Glick, 1970). Recent evidence presented by Benowitz et al. (1983) suggests that the fading procedures utilized in many nicotine fading programs may not be as effective as thought. Benowitz et al. (1983) indicated that the FTC estimate of 
nicotine levels in cigarettes may not be accurate because of smoking topography and actual nicotine content. By chemical assay of the tobacco of various cigarettes, Benowitz et al. (1983) found little variation in the nicotine levels of cigarettes. Thus, brand-fading to lower nicotine levels may not result in the reductions of nicotine plasma levels as previously thought. Still, the clinical impression remains that conscientious brand-fading appears to relieve discomfort and the withdrawal syndrome associated with heavy use of nicotine. Further, these same subjects report marked withdrawal symptoms from previous abrupt cessation. As explanation, Benowitz (1983) indicated actual nicotine delivery probably depends upon burning rates per cigarette. In turn, burning rates depend upon characteristics of the cigarette -- ventilation, paper, additives -- and the typography of smoking -- number of puffs, duration of puffs, degree of inhalation, and so on. Thus, it seems likely that motivated subjects may be able to reduce nicotine consumption by compliance to a behavioral program, much as motivated subjects do not compensate behaviorally for low tar and nicotine levels. Benowitz's, et al. (1983) demonstration that low tar and nicotine level smokers have blood cotinine concentrations similar to the blood cotinine levels of high tar and nicotine levels raise further research question. Do subjects in a smoking cessation program show reductions of blood cotinine levels during brand fading? If cigarette nicotine levels are not the source of blood nicotine levels, as reflected by plasma cotinine levels, then what factors do determine blood nicotine levels? Problems with cotinine assessment 
preclude the use of cotinine as an optimal method for routine evaluation of smoking cessation programs (see Zeidenberg, Jaffe, Lavitt, Langore and Vunakis, 1977). However, the theoretical implications of plasma cotinine assessment during brand-fading for nicotine fading programs are great, because nicotine fading methods depend upon systematic nicotine reductions to reduce withdrawal symptoms.

The influence of smoking on health also needs to be considered and understood in the design of treatment elements for smoking cessation of treatment elements for smoking cessation programs. The results of this study re-emphasize that even marked changes in smoking behavior may yield moderate or attenuated changes in health functioning. Of course, the data presented here is still relatively short term. The slow and moderate changes in health functioning measures may be one of the reasons that subjects find stopping smoking difficult. The level of changes were often too small to be meaningful for a subject. For example, a .2 liter improvement in lung function or a 5 BPM reduction in HR may not seem significant to many subjects. However, for most healthy subjects these would be favorable results. The exception to these slow, moderate change was $\mathrm{COa}$, which rapidly and markedly reduced for all non-smoking subjects. Other research has suggested that $\mathrm{C} 0 \mathrm{a} \%$ feedback was not necessary for successful outcome in a smoking cessation program (Glasgow, Klesges, Godding and Gegelman, 1983). However, in the Glasgow et al. (1983) study it was arguable whether any subjects improved in a meaningful manner. 
The health consequences of smoking pose special difficulty for treatment failures. For this study, controlled smoking was suggested to subjects who elapsed, failed to stop again after at least two efforts, and indicated they wished to continue smoking. Controlled smoking, under these circumstances, was presented as a manner to prepare for later stopping. There has been positive evidence regarding controlled smoking (Frederiksen, 1978; Frederiksen and Simon, 1978a; Frederiksen and Simon, 1978b). Recent replications were not as successful, al though the authors claim success (Glasgow, Klesges and Vasey, 1983; Glasgow, Klesges, Godding and Gegelman, 1983). Glasgow and associates note significant reductions relative to wait-list controls for controlled smoking, but on follow-up controlled smoking subjects were still smoking an average of more than a pack of cigarettes per day with $\mathrm{CO}$ levels of more than $24 \mathrm{ppm}(5.30 \%)$. Both of these levels have been associated with increased mortality and acute effects such as angina (USDHEW, 1979). Evaluation of controlled smoking efforts needs to consider clinical as well as statistical significance. This poses a difficult requirement since tobacco smoking, unlike alcohol use, has no known safe levels. Increased mortality ratios have been demonstrated for smoking rates as low as 1-5 cigarettes per day (USDHEW, 1979). Further, many of the etiological mechanisms of tobacco smoking induced morbidity have not been defined. Some estimates for safer levels of smoking can be estimated from some research, however. Carbon monoxide levels below $2.0 \%$ COa appear to be below the threshold for acute cardiovascular effects (see Russe11, Cole, and Brown, 1973). Particulate matter has been 
reduced by methods of filtration, but probablistic statements regarding mean dose levels and mutagenicity have been complicated by the multiple cancerogenic compounds present in tar. Hydrogen cyanide ( $H C N)$ exerts ciliatoxic effects at approximately 160 ug in rabbits (see USDHEW, 1976), while the concentration of $\mathrm{HCN}$ in tobacco smoke ranges between 16-63 ug per puff. Thus, it appears difficult to achieve controlled smoking at levels below ciliatoxicity unless inhalation is eliminated. The exact relationship between $\mathrm{HCN}$ and $\mathrm{SCN}$ levels has not been established, making the assessment of controlled smoking difficult in regards to the HCN agent. Finally, nicotine content of cigarettes has been markedly reduced recently. However, as noted earlier, the reduced nicotine cigarettes may not yield levels of nicotine blood levels as low as previously believed (Benowitz et al., 1983). In addition, subjects rarely smoke nicotine-free cigarettes more than briefly. Like many of the other health threatening agents from tobacco smoke, the dosage levels of chronic nicotine exposure associated with increased morbidity have not been established. Thus, establishment of controlled smoking faces several unknown parameters when attempting to reduce smoking to levels that are safe or at least significantly safer than previous levels. Research on controlled smoking needs to specifically assess the issues of morbidity. Thus, $\mathrm{CO}, \mathrm{SCN}$ and cotinine evaluations become important for individuals attempting to control smoking. Finally, efforts for controlled smoking also need to relate reduced smoking levels to reduced health risk. 
Evaluation of relapse episodes was consistent with Shiffman's (1982) findings. Emotionally charged situations, situations involving interpersonal conflict and situations involving alcohol were common antecedents to smoking relapse. Utilizing of coping skills and social support may reduce risk for these high probability relapse situations, and future research will continue to address these concerns. Not a11 relapses resulted in full-blown return to smoking, however. Some individuals relapsed and subsequently stopped smoking again. Others relapsed but did not return to or approach previous baseline levels of smoking. Clearly, relapse is more complex than an all-or-none phenomenon, but research seems to assume that relapse is only a dichotomous phenomenon. More fine-grained analysis of relapse may reveal successful coping strategies that enable stopping smoking gain successfully.

Validity and Generalizability. A two-group repeated measures experimental design of the type considered here control for most threats to internal validity (Kirk, 1968). Possible threats to the validity of this study could include a differential interaction between the conditions with the shared historical events. For example, the national smoke out day occurred during the study, just before the groups last quit day. However, both conditions reached this day at the same time in treatment, making the possibility of any interaction implausible. The holiday season preceded the post-quit day follow-up, perhaps contributing to the significant weight gains noted. Again, no differential response between the conditions appeared plausible. Samples of subjects 
from a small college community raise the risk of across condition contamination, resulting either in subjects over-compensating or demonstrating resentful demoralization. Checks on these issues did not reveal any effects of this kind in the project. Thus, in general, the research appears to be internality valid.

The generality of the research is more difficult to evaluate. However, the research results were consistent with other smoking cessation projects (Winett, 1973; Paxton, 1980, 1981; Elliott and Tighe, 1968). Further, the measures were primarily selected with clinical utility in mind. Most of the assessments could be conducted readily in a physician's office. Only the $C O$ and SCN measures were unusual, but these objective checks on smoking status were important to provide unreactive assessment. 


\section{SUMMARY AND CONCLUSIONS}

The outcome of this project was positive, indicating that the maintenance treatment condition resulted in significantly less smoking. There were some signs of moderately better improvement in health functioning for the maintenance condition as well. Finally, the maintenance condition demonstrated less cost per effect size. Thus, the maintenance treatment condition appeared to be effective, to influence positive health changes and to provide these effects in a cost-effective manner. Research with results as positive as this project encourage the implementation of further similar programs.

There is much to be gained from the further implementation of similar programs in the future. Disassembling research strategies may define more specifically the relative contributions of the various treatment components. Important theoretical issues may be researched in the context of providing valuable clinical services. For example, the relationship of SCN plasma levels to smoking patterns could be defined further. Also, examination of blood cotinine levels during brand fading could provide important clues regarding the etiology of smoking behavior. Finally, the implementation of further treatment trials with similar procedures may yield considerable clinical benefit. Clearly, work of this nature will continue and participants will benefit.

There are negative aspects to approaching smoking cessation from this perspective, however. First of all, a limited number of clients can be treated because of the time intensive nature of the treatment. 
Second, only a subsample of the smokers interested in cessation participate in such programs. The participants in smoking cessation programs, for example, tend to over-represent females. Further, while cost effective, approaches such as this pursued as public policy could result in large allocations of treatment staff from the helping sciences. Health care resources are currentiy under great strain to manage delivery of acute care, and under these circumstances, behavioral medicine approaches are likely to receive indifferent support. Finally, even successful cessation programs still have a great deal of unexplained treatment failures. Thus, while the adoption of particular methods can improve outcome, a significant percentage of subjects continue to smoke.

These advantages and limitations lead to the recommendation of three general steps concerning smoking cessation efforts. First, controlled trials of smoking treatment strategies need to continue. The more consistently promising methods (e.g. rapid smoking, nicotine fading and behavioral contracting) have sufficient support to warrant their routine clinical use. Second, community trials of behavioral methods that can be provided without therapeutic support, such as behavioral contracting, needs to be attempted and assessed. For example, insurance companies or health maintenance organizations may experimentally evaluate the influence of rate structures or incentives on smoking behavior. Informed consent must be obtained in such an analysis. However, uncontrolled "experiments" of this type are already going on, for example, in the form of higher insurance rates for smokers. 
Finally, research on the etiology and maintenance of smoking behavior needs to continue. It appears that much still remains unknown about the functional elements effecting smoking behavior. often, 30 to $60 \%$ of participants in successfut smoking cessation programs continue to smoke. This finding underscores the need to study further the influences of smoking. 


\section{REFERENCES}

Ashton, H., Stepney, R., \& Thompson, J. Self-titration by cigarette smokers. British Medical Journal, 1979, 2, 357-360.

Balch, P., \& Ross, A.W. Predicting success in weight reduction as a function of locus of control: A unidimensional and multidimensional approach. Journal of Consulting and Clinical Psychology, $1975,43,119$.

Beaver, C., Brown, R., \& Lichtenstein, E. Effects of monitored nicotine fading and anxiety management training on smoking reduction. Addictive Behaviors, 1981, $6,301-305$.

Benowitz, N., Hall, S., Herning, R., Jacob, P., Jones, R., \& Osman, A. Smokers of low-yield cigarettes do not consume less nicotine. New England Journal of Medicine, 1983, 309 (3), 129-142.

Bernstein, D. Modification of smoking behavior: An evaluative review. Psychological Bulletin, 1969, 71 (6), 418-440.

Best, J., \& Hakstian, A. A situation-specific model for smoking behavior. Addictive Behaviors, 1978, 3, 79-92.

Best, J., \& Steffy, R. Smoking modification procedures tailored to subject characteristics. Behavior Therapy, 1971, 2, 177-191.

Best, J.A., \& Steffy, R.A. Smoking modification procedures for internal and external locus of control clients. Canadian Journal of Behavioral Science, $1975, \underline{7}$ (2), 155-165.

Best, J., Owen, L., \& Trentadue, L. Comparison of satiation and rapid smoking in self-managed smoking cessation. Addictive Behaviors, $1978, \underline{3}, 71-78$.

Bowler, R. The determination of thiocyanate in blood serum. Biochemical Journal, 1944, 38, 385-388.

Boxer, G., \& Richards, J. Determination of thiocyanate in body fluids. Archives of Biochemistry and Biophysics, 1952, 39, 292-300.

Briddell, D.W., Rimm, D.C., Caddy, G.R., \& Dunn, N.J. Analogue assessment, affective arousal, and the smoking taste test. Addictive Behaviors, 1979, 4 (3), 287-295.

Broos, I.D., \& Coombs, J. Early onset of oral cancer among women who drink and smoke. Oncology, 1976, 33, 136-139. 
Buist, A., Sexton, G., Nagy, J., \& Ross, B. The effect of smoking cessation and modification on lung function. American Review of Respiratory Disease, 1976, 114, 115-122.

Burling, T. The effects of relapse prevention training on smoking cessation. Dissertation, Virginia Polytechnic Institute and State University, Blacksburg, Virginia, 1981.

Burling, T., Lovett, S., Richter, W., \& Frederiksen, L. Alveolar carbon monoxide: The relative contributions of daily cigarette rate, cigarette brand and smoking topography. Addictive Behaviors, 1983, 8, 23-26.

Butts, W., Kuehneman, M., \& Widdowson, G. Automated method for determining serum thiocyanate, to distinguish smokers from nonsmokers. Clinical Chemistry, 1974,20 (10), 1344-1348.

Colletti, G., \& Supnick, J.A. Continued therapist contact as a ma intenance strategy for smoking reduction. Journal of Consulting and Clinical Psychology, $1980, \underline{48}$ (5), 665-667.

Colletti, G., Supnick, J., \& Abueg, F. Assessment of the relationship between self-reported smoking rate and ecolyzer measurement. Addictive Behaviors, 1982, I, 183-188.

Condiotte, M., \& Lichtenstein, E. Self-efficacy and relapse in smoking cessation programs. Journal of Consulting and Clinical Psychology, $1981, \underline{49}(5), 648-658$.

Costa, P., \& McCrae, R. Stress, smoking motives, and psychological well-being: The illusory benefits of smoking. Advances in Behaviour Research and Therapy, 1981, 3, 125-130.

Dacre, J., \& Tabershaw, I. Thiocyanate in saliva and sputum. Archives of Environmental Health, 1970, 21, 47-49.

Densen, P., Davidow, B., Bass, H., \& Jones, E. A chemical test for smoking exposure. Archives of Envionmental Health, 1967, 14, 865-874.

Derden, R. The effectiveness of follow-up strategies in smoking cessation. Dissertation Abstracts International, 1977, 38 (5), 2359-B.

Dericco, D.A., Brigham, T.A., \& Garlington, W.K. Development and evaluation of treatment paradigms for the suppression of smoking behavior. Journal of Applied Behavioral Analysis, 1977, 10, 173-181. 
DiClemente, C.C. Self-efficacy and smoking cessation maintenance: A preliminary report. Cognitive Therapy and Pesearch, 1981, $\underline{5}$ (2), 175-187.

Dobbs, S., Strickler, D., \& Maxwe11, W. The effects of stress and relaxation in the presence of stress on urinary $\mathrm{pH}$ and smoking behaviors. Addictive Behaviors, 1981, 6 (4), 345-353.

Elgerot, A. Physiological and psychological changes during tobaccoabstinence in habitual smokers. Reports from the Department of Psychology, U. Stockholm, 1975 (Dec.), No. 462, 9 p.

Elliott, C., \& Denney, D. A multiple component treatment approach to smoking reduction. Journal of Consulting and Clinical Psychology, 1978 , 46 (6), 1330-1339.

Elliott, R., \& Tighe, T. Breaking the cigarette habit: Effects of a technique involving threatened loss of money. Psychological Record, $1968,18,503-513$.

Evans, D., \& Lane, D. Smoking cessation follow-up: A look at post work shop behavior. Addictive Behaviors, 1981, $\underline{6}, 325-329$.

Fagerstrom, K., \& Bates, S. Compensation and effective smoking by different micotine dependent smokers. Addictive Behaviors, 1981, $\underline{6}, 331-336$.

Federal Trade Commission. Tar and nicotine content of cigarettes. DHEW Publication No. (CDC) 78-8703. Washington, D.C.: U.S. Department of Health, Education and Welfare/Public Health Service, 1979.

Finnegan, J.K., Larson, P.S., \& Haag, H.B. The role of nicotine in the cigarette habit. Science, 1945, 102, 94-96.

Firth, C.D. The effects of varying the nicotine content of cigarettes on human smoking behaviour. Psychopharmacologia, 1971, 19, 188-192.

Flaxman, J. Affect-management and habit mechanisms in the modification of smoking behavior. Addictive Behaviors, 1979, $\underline{4}$ (1), 39-46.

Foxx, R., \& Axelroth, E. Nicotine fading, self-monitoring and cigarette fading to produce cigarette abstinence or controlled smoking. Behaviour Research and Therapy, 1983, 21 (1), 17-27.

Foxx, R.M., \& Brown, R.A. Nicotine fading and self-monitoring for cigarette abstinence or controlled smoking. Journal of Applied Behavior Analysis, 1979,12 (1), 111-125. 
Foxx, R., Brown, R., \& Katz, I. Nicotine fading and self-monitoring for cigarette abstinence or controlled smoking: A two and one-half year follow-up. Behavior Therapist, 1981, 4 (2), 21-23.

Frederiksen, L. Controlled smoking: Models, measures and modification. Behavioral Psychotherapy, 1979, 7, 91-100.

Frederiksen, L., \& Epstein, L. Reliability and controlling effects of three procedures for self-monitoring smoking. Psychological Record, 1975, 25, 255-264.

Frederiksen, L.W., \& Martin, J.E. Carbon monoxide and smoking behavior. Addictive Behaviors, $1979, \underline{4}(1), 21-30$.

Frederiksen, L., \& Simon, S. Modification of smoking topography: A preliminary analysis. Behavior Therapy, 1978a, 9, 946-949.

Frederiksen, L., \& Simon, S. Modifying how people smoke: Instructional control and generalization. Journal of Applied Behavioral Analysis, 1978b, 11, 431-432.

Frederiksen, L., Peterson, G., \& Murphy, W. Controlled smoking: Development and maintenance. Addictive Behaviors, 1976, 1 , 193-196.

Glasgow, R., Klesges, R., \& Vasey, M. Controlled smoking for chronic smokers: An extension and replication. Addictive Behaviors, 1983 , 8, $143-150$.

Glasgow, R., Klesges, R., Godding, P., \& Gegelman, R. Controlled smoking, with or without carbon monoxide feedback, as an alternative for chronic smokers. Behavior Therapy, 1983, 14, 386-397.

Glauser, S., Glauser, E., Reidenberg, M., Rusy, B., \& Tallarida, R. Metabolic changes associated with the cessation of cigarette smoking. Archives of Environmental Health, 1970, 20 (3), 377-381.

Goldfarb, T.L., \& Jarvik, M.E. Accommodation to restricted tobacco smoke intake in cigarette smokers. International Journal of the Addictions, $1972, \underline{7}, 559-565$.

Goldfarb, T.L., Jarvik, M.E., \& Glick, S.D. Cigarette nicotine content as a determinant of human smoking behavior. Psychopharmacologia, $1970,17,89-93$.

Gori, G.B. Low risk cigarettes: A prescription. Science, 1976, 194, 1243-1246. 
Gori, G., Battista, S., Thayer, P., Guerin, M., \& Lynch, C. Chemistry and In Vitro bioassay of smoke from experimental filter cigaretts. U.S. Department of Health, Education and Welfare. Public Health Service National Institutes of Health, National Cancer Institute, Smoking and Health Program. DHEW Publication No. (NIH) 76-1076, June 1976,42 p.

Green, G., \& Carolin, D. The depressant effect of cigarette smoke on the in vitro antibacterial activity of alveolar macrophages. New England Journal of Medicine, 1967, 276 (8), 421-426.

Griffiths, R., Bigelow, G., \& Liebson, I. Facilitation of human tobacco self-administration by ethanol: A behavioral analysis. Journal of the Applied Analysis of Behavior, 1976, 25, 279-292.

Hackett, G., \& Horan, J. Focused smoking: An unequivocably safe al ternative to rapid smoking. Journal of Drug Education, 1978, 8 (3), 261-266.

Hackett, G., \& Horan, J.J. Partial component analysis of a comprehensive smoking program. Addictive Behaviors, 1979, 4 (3), 259-262.

Hal1, R., Sachs, D., \& Hall, S. Medical risk and therapeutic effectiveness of rapid smoking. Behavior Therapy, 1979, 10, 249-259.

Hammond, E., Garfinkel, L., Seidman, H., \& Lew, E. "Tar" and nicotine content of cigarette smoke in relation to death rates. Environmental Research, 1976, 12, 263-274.

Hauser, R. Rapid smoking as a technique of behavior modification: Caution in the selection of subjects. Jourral of Consulting and Clinical Psychology, 1974, 42, 625.

Hedberg, A. Review of the State-Trait Anxiety Inventory. Professional Psychology, 1972, 3 (4), 389-390.

Henningfield, J., Stitzer, M., \& Graffiths, R. Expired air carbon monoxide accumulation and elimination as a function of number of cigarettes smoked. Addictive Behaviors, 1980, $5,265-272$.

Higgins, I. Relative risks of various tobacco usages for emphysema and/or chronic bronchitis. In E. Wynder, D. Hoffman, and G. Gori (Eds.), Smoking and Health: 1. Modifying the risk for the smoker. U.S. Department of Health, Education, and Welfare, DHEW Publication No. (NIH) $76-1221,1975,389-405$. 
Horan, J.J., Linberg, S.E., \& Hackett, G. Nicotine poisoning and rapid smoking. Journal of Consulting and Clinical Psychology, 1977, 45, 344-347.

Horan, J.J., Hackett, G., Nicholas, W.C., Linberg, S.E., Store, C. I., \& Lukaski, H.C. Rapid smoking: A cautionary note. Journal of Consulting and Clinical Psychology, 1974, 30, 431-4 $\overline{38 .}$

Horn, D. Why do you smoke? U.S. Department of Health, Education, and Welfare. Public Health Service, National Institute of Health Publication No. 79-1822, Washington, D.C.: U.S. Government Printing Office, 1979.

Hughes, J., Frederiksen, L., \& Frazier, M. A carbon monoxide analyzer for measurement of smoking behavior. Behavior Therapy, 1978, 9 , 293-296.

Hughes, G., Hymowitz, N., Ockene, J., Simon, N., \& Vogt, T. The multiple risk factor intervention triad (MRFIT) V. Intervention on smoking. Preventive Medicine, 1981, 10, 476-500.

Hunt, W., \& Matarazzo, J. Three years later: Recent developments in the experimental modification of smoking behavior. Journal of Abnormal Psychology, 1973, 81 (2), 107-114.

Hunt, W., Barnett, L., and Branch, L. Relapse rate in addictive programs. Journal of Clinical Psychology, 1971, 27, 455-456.

Jaffe, J., Kanzler, M., Friedman, L., Stunkard, A., \& Verebey, K. Carbon monoxide and thiocyanate levels in low tar/nicotine smokers. Addictive Behaviors, 1981,6 , 337-343.

Jarvik, M., Popek, P., Schneider, N., Baer-Weiss, V., \& Gritz, E. Can cigarette size and nicotine content influence smoking and puffing rates? Psychopharmacology, 1978, 58 (3), 303-306.

Kirk, R. Experimental design: Procedures for the behavioral sciences. Wadsworth Publishing Compay, Inc., Belmont, California, 1968.

Kopel, S. The effects of self-control, booster sessions, and cognitive factors on the maintenance of smoking reduction. Dissertation Abstracts International, $1974, \underline{35}$ (8), 4182-B.

Lando, $H$. A comparison of excessive and rapid smoking in the modification of chronic smoking behavior. Journal of Consulting and Clinical Psychology, 1975, 43 (3), 350-355.

Lando, H. An objective check upon self-reported smoking levels: A prel iminary report. Behavior Therapy, 1975, ․ 547-549. 
Lando, H. Self-pacing in eliminating chronic smoking: Serendipity revisited? Behavior Therapy, 1976, I, 634-640.

Lando, $H$. Successful treatment of smokers with a broad-spectrum behavioral approach. Journal of Consulting and Clinical Psychology, 1977, 45 (3) $361-366$.

Lando, H. A factorial analysis of preparation, aversion, and maintenance in the elimination of smoking. Addictive Behaviors, $1982,7,143-154$.

Lando, H., \& McGovern, P. Three-year data on a behavioral treatment for smoking: A follow-up note. Addictive Behaviors, 1982, ㄱ, 177-181.

Leventhal, H., \& Cleary, P. The smoking problem: A review of the research and theory in behavioral risk modification. Psychological Bulletin, 1980,88 (2), 370-405.

Levinson, B., Shapiro, D., Schwartz, G., \& Tursky, B. Smoking elimination by gradual reduction. Behavioral Therapy, 1971, 2, 477-487.

Lichtenstein, E., Harris, D.E., Birchler, G.R., Wahl, J.M., \& Schmaht, D.P. Comparison of rapid smoking, warm smoky air, and attention placebo in the modification of smoking behavior. lournal of Consulting and Clinical Psychology, 1973, 40, 92-98.

McCarthy, D., Craig, D., \& Cherniack, R. Effect of modification of the smoking habit on lung function. American Review of Respiratory Disease, 1976, 114, 103-113.

MCFall, R.M. Effects of self-monitoring on normal smoking behavior. Journal of Consulting and Clinical Psychology, 1970, 35, 135-142.

McFal1, R. Smoking-cessation research. Journal of Consulting and Clinical Psychology, 1978, 46 (4), 703-712.

McFall, R., \& Hammer, C. Motivation, structure, and self-monitoring: Role of nonspecific factors in smoking reduction. Journal of Consulting and Clinical Psychology, 1971, 37 (1), 80-86.

McMorrow, M., \& Foxx, R. Nicotine's role in smoking: An analysis of nicotine regulation. Psychological Bulletin, 1983, 93 (2), 302-327.

Maliszenski, T., \& Bass, D. Journal of Applied Physiology, 1955, $\underline{8}$, 289-291. 
Marlatt, G., \& Gordon, J. Determinants of relapse: Implications for the maintenance of behavior change. In P. Davidson (Ed.), Behavioral Medicine: Changing Health Life Styles. New York, New York: Brunner/Mazel, 1979.

Marshal1, W., Epstein, L., \& Green, S. Coffee drinking and cigarette smoking: I. Coffee, caffeine and cigarette smoking behavior. Addictive Behaviors, $1980, \underline{5}$ (4), 389-394.

Matarazzo, J.D. Behavioral health's challenge to academic, scientific, and professional psychology. American Psychologist, 1982, 37 (1), $1-14$.

Merbaum, M., Avimier, R., \& Goldberg, J. The relationship between aversion, group training and vomiting in the reduction of smoking behavior. Addictive Behaviors, 1979, 4, 279-285.

Miller, P., Frederiksen, L., \& Hosford, R. Social interaction and smoking topography in heavy and light smokers. Addictive Behaviors, 1979, 4, 147-153.

Moss, R., \& Prue, D. Research on nicotine regulation. Behavior Therapy, $1982,13,31-46$.

Nash, J. Taking charge of your smoking. Bull Publishing Company, Palo Al to, California, $1981,250 \mathrm{p}$.

Nathan, P., \& Lansky, D. Common methodological problems in research on the addictions. Journal of Consulting and Clinical Psychology, $1978, \underline{46}(4), 713-726$.

Obe, G. Mutagenicity of alcohol and tobacco smoke. In Y. Isreal, F. Glaser, H. Kalant, R. Popham, W. Schmidt, \& R. Smart, (Eds.), Research advances in alcohol and lung problems, V6, Plenum Press, 1981.

Orleans, C., \& Shipley, R. Worksite smoking cessation initiatives: Review and recommendations. Addictive Behaviors, 1982, $\underline{7}, 1-16$.

Ossip-Klein, D., Epstein, L., Winter, M., Stiller, R., Russel, P. \& Dickson, B. Does switching to low tar/nicotine/carbon monoxideyield cigarettes decrease alveolar carbon monoxide measures? A randomized controlled trial. Journal of Consulting and Clinical Psychology, 1983, 51 (2), 234-241.

Paul, G. Strategy of outcome research in psychotherapy. Journal of Consulting and Clinical Psychology, 1967, 3 (2), 109-118. 
Paxton, R. The effects of a deposit contract as a component in a behavioural programme for stopping smoking. Behaviour Research and Therapy, 1980, 18, 45-50.

Paxton, R. Deposit contracts with smokers: Varying frequency and amount of repayments. Beahviour Research and Therapy, 1981, 19, 117-123.

Paxton, R., \& Scott, S. Nonsmoking reinforced by improvements in lung function. Addictive Behaviors, $1981, \underline{6}, 313-315$.

Pechacek, T. An evaluation of cessation and maintenance strategies in the modification of smoking behavior. Dissertation Abstracts International, 1977, 38 (5), 2380-B.

Pertschuk, M., Pomerleau, 0., Adkins, D., \& Hirsch, C. Smoking cessation: The psychological costs. Addictive Behaviors, 1979, 4 , 345-348.

Pettigrew, A., \& Fell, G. Simplified colorimetric determination of thiocyanate in biological fluids, and its application to investigation of the toxic amblyopias. Clinical Chemistry, 1972, $18,996-1000$.

Pomerleau, 0., Adkins, D., \& Pertschuk, M. Predictors of outcome and recidivism in smoking cessation treatment. Addictive Behaviors, $1978, \underline{3}, 65-70$.

Poole, A., Sanson-Fisher, T., German, G., \& Harker, J. The rapid-smoking technique: Some physiological effects. Behaviour Research and Therapy, $1980, \underline{18}, 581-586$.

Poole, A., Sanson-Fisher, R., \& German, G. The rapid-smoking technique: Therapeutic effectiveness. Behaviour Research and Therapy, 1981, 19, 389-397.

Prue, D., Krapfe, J., \& Martin, J. Brand fading: The effects of gradual changes to low tar and nicotine cigarettes on smoking rate, carbon monoxide and thiocyanate levels. Behavior Therapy, 1981, 12, $400-416$.

Prue, D., Martin, J., and Hume, A. A critical evaluation of thiocyanate as a biochemical index of smoking exposure. Behavior Therapy, $1980,11,368-379$.

Raw, M., and Russer, M. Rapid smoking, cue exposure and support in the modification of smoking. Beahviour Research and Therapy, 1980, 18, 363-372. 
Rawbone, R., Coppin, C., \& Guz, A. Carbon monoxide in alveolar air as an index of exposure to cigarette smoke. Clinical Science and Molecular Medicine, 1976, 51, 495-501.

Relinger, H., Bernstein, P., Bugge, T., Carmody, T., \& Zohn, C. Utilization of adverse rapid smoking in groups: Efficacy of treatment and maintenance procedures. Journal of Consulting and Clinical Psychology, 1977, 45 (2), 245-249.

Rogot, E. Smoking and general mortal ity among U.S. veterans, 1954-1969. DHEW, National Heart and Lung Institute. Epidemiology Branch. DHEW Publication No. (NIH) 74-544, 1974, 65 p.

Rosenbaum, M., \& Argon, S. Locus of control and success in selfinitiated attempts to stop smoking. Journal of Clinical Psychology, 1979, 35 (4), 870-872.

Russe11, M. Tobacco smoking and nicotine dependence. In R. Gibbins, Y. Israel, H. Kalant, R. Popham, W. Schmidt, and R. Smart (Eds.), Research Advances in Alcohol and Drug Problems, 1976, 3, 1-47.

Russell, M. Nicotine intake and its regulation. Journal of Psychosomatic Research, 1980, 24, (5), 253-264.

Russe11, M., Armstrong, E., \& Patel, U. Temporal contiguity in electric aversion therapy for cigarette smoking. Behavioural Research and Therapy, 1976, 14, 103-123.

Russell, M., Cole, P., Brown, E. Absorption by non-smokers of carbon monoxide from room air polluted by tobacco smoke. Lancet, 1973, 1 , (7803), 576-579.

Russe11, P., Epstein, L., \& Dickson, B. Behavioral and physiological effects of low-nicotine cigarettes during rapid smoking. Journal of Consulting and Clinical Psychology, 1983, 51 (2), 312.

Russell, M., Wilson, C., Cole, P., Idle, M., \& Feyerabend, C. Comparison of increases in carboxyheamoglobin after smoking "extramild" and "non-mild" cigarettes. Lancet, 1973, 2 (7831), 688-693.

Russe11, M., Wilson, C., Pate1, U., Cole, P., \& Feyerabend, C. Comparison of effect on tobacco consumption and carbon monoxide absorption of changing to high and low nicotine cigarettes. British Medial Journal, 1973, 4, 512-516.

Schachter, S. Nicotine regulation in heavy and light smokers. Journal of Experimental Psychology, 1977, 106, 5-12. 
Schachter, S. Pharmacological and psychological determinants of smoking. Annals of Internal Medicine, 1978, 88, 104-114.

Schachter, S. Recidivism and self-cure of smoking and obesity. American Psychologist, 1982,37 (4), 436-444.

Schachter, S., Silverstein, B., \& Perlick, D. Psychological and pharmacological explanations of smoking under stress. Journal of Experimental Psychology, 1977, 106, 31-40.

Schmahl, D.P., Lichenstein, E., \& Harris, D.E. Successful treatment of habitual smokers with warm, smoky air and rapid smoking. Journal of Consulting and Clinical Psychology, 1972, 38, 105-111.

Shiffman, S. Relapse following smoking cessation: A situational analysis. Journal of Consulting and Clinical Psychology, 1982, $\underline{50}$ (1), 71-86.

Siegel, S. Morphine tolerance acquisition as an associative process. Journal of Experimental Psychology: Animal Behavior Processes, 1977, $\underline{3}(1), 1-13$.

Sjoberg, L., \& Johnson, T. Trying to give up smoking: A study of volitional breakdowns. Addictive Behaviors, $1978, \underline{3}(3-4)$, 149-164.

Sjoberg, L., and Samsonowitz, V. Volitional problems in trying to quit smoking. Scandinavian Journal of Psychology, 1978, 19, 205-212.

Smith, M., \& Glass, G. Meta-analysis of psychotherapy outcome studies. American Psychologist, 1977, 32, 752-760.

Soloman, R., \& Corbit, J. An opponent-process theory of motivation:

II. Cigarette addiction. Journal of Abnormal Psychoiogy, 1973, 81 (2), 158-171.

Spring, F., Sipich, J., Trimble, R., \& Goeckner, J. Effects of contingency and noncontingency contracts in the context of a self-control-oriented smoking modification program. Behavior Therapy, 1978, 9, 967-968.

Stolerman, I., Fink, R., \& Jarvik, M. Acute and chronic tolerance to nicotine measured by activity in rats. Psychopharmacologia, 1973, 30, 329-342.

Tenovuo, J., \& Makinen, K. Concentration of thiocyanate and ionizable iodine in saliva of smokers and nonsmokers. Journal of Dental Research, 1976, 55, 661-663. 
Thayer, P., \& Kensler, C. Cigarette smoke: Charcoal filters reduce components that inhibit growth of cultured human cells. Science, $1964,146,642-644$.

Turner, J., Sillett, R., \& Ball, K. Some effects of changing to low-tar and low-nicotine cigarettes. Lancet, 1974, 2, 737-739.

U.S. Department of Health, Education and Welfare. The Surgeon General's Advisory Committee: Smoking and Health. Public Health Service Publication No. 1103, 1964.

U.S. Department of Health, Education and Welfare. Smoking and health. Vo1. 1. Modifying the risk for the smoker. DHEW Publication No. (NIH) 76-1221, 1976 .

U.S. Department of Health, Education and Welfare. Public Health Service. Smoking and health: A report of the surgeon general. DHEW Publication No. (PHS) 79-50066, 1979.

Vogt, T., Selvin, S., Widdowson, G., \& Hulley, S. Expired air carbon monoxide and serum thiocyanate as objective measures of cigarette exposure. American Journal of Public Health, 1977, 67 (6), 545-549.

Wallston, K., Wallston, B., \& DeVellis, R. Development of the multidimensional health locus of control (MHLC) scales. Health Education Monographs, 1978, 6, 160-170.

White, J., \& Froeb, H. Small airways dysfunction in nonsmokers chronically exposed to tobacco smoke. New England Journal of Medicine, $1980,302,720-723$.

Winett, R. Parameters of deposit contracts in the modification of smoking. Psychological Record, 1973, 23, 49-60.

Wynder, E.L., \& Hoffmann, D. Tobacco and health: A societal challenge. New England Journal of Medicine, 1979, 300 (16), 894-903.

Yates, A.J. Theory and practice in behavior therapy. John Wiley \& Sons, Inc., New York, N.Y., 1975, 243 p.

Zeidenberg, P., Jaffe, J., Kanzler, M., Levitt, M., Langone, J., \& Vunakis, H. Nicotine: Cotinine levels in blood during cessation of smoking. Comprehensive Psychiatry, 1977, 18 (1), 93-101.

Zilbergeld, B. The shrinking of America: Myths of psychological change. Little, Brown and Company, Boston, MA., 1983. 
134

APPENDIX A 


\section{CONEIDENCE QUESTIONNAIRE}

Rate on a scale of ' 1 ' to ' 10 ' the typical urge to smoke you expertence in each of the following situations. A rating of ' 10 ' indicates an exceptionally strong urge to smoke, while a rating of ' 1 ' indicates no urge at all.

1. When you want to set back and enfoy a cigarette.

2. When you feel anxious.

3. When you feel really happy.

4. When you want something to do with your hands.

5. When you simply become aware of the fact you are not smoking.

6. When you want to reward yourself for something you've done or tell yourself that you can have a cigarette if you complete some task.

7. When you find a cigarette in your mouth and don't remeber having $11 t$ it.

8. When you are resting.

9. When you feel depressed.

10. When you want to cheer up.

11. When you want to take a break from work or some other activity.

12. When you want to feel more mature and sophisticated.

13. When you light up a cigarette to go along with some activity you are doing (for example, when fixing a bicycle, writing a letter, doing housework).

14. When you realize you are lighting a cigarette even though you just put one out.

15. When you feel tense.

16. When you feel embarrassed.

17. When you realize that you won't be able to smoke for awhile.

18. When you are worried.

19. When you are waiting for someone or something.

20. When you feel nervous.

21. When you feel impatient. 
22. When you want to keep yourself busy.

23. When you feel bored.

24. When you are drinking coffee or tea.

25. When you reallze you have run out of cigarettes.

26. When you want to have time to think in a conversation.

27. When you feel uncomfortable.

28. When you feel angry with yourself.

29. When you feel you need more energy.

30. When you want to concentrate.

31. When you want to fell a pause in a conversation.

32. When you want to relax.

33. When you wanc to keep slim.

34. When you are trying to pass time.

35. When you feel angry.

36. When you want something in your mouth.

37. When you feel annoyed.

38. When you want to feel more atrractive.

39. When you are drinking an alcoholic beverage.

40. When you feel tired.

41. When you Eeel frustrated.

42. When someone offers you a cigarette.

43. When you feel restless.

44. When you have fintshed a meal or a snack.

45. When you feel upset.

46. When you see others smoking.

47. When you are overly excited.

48. When you are in a situation inwhich you feel smoking is a part of your self-image. 
49. When you want to avold eating sweets.

50. When you feel over sensitive. 
NAME

1. How of ten did you think your group should meet?

$\begin{array}{lcccc}1 & 2 & 3 & 4 & 5 \\ \text { rarely } & 1 x \text { month } & 2 x \text { moneh } & 1 \times \text { week } & 2 x \text { week }\end{array}$

2. How did you like the group you were in?

$\begin{array}{lcccc}1 & 2 & 3 & 4 & 5 \\ \text { very } & \text { positive } & \text { neutral } & \text { negative } & \text { terrible }\end{array}$

much

3. If most of the members of your group decided to dissolve the group by leaving, would you like an opportunity to dissuade them?

2

4

s

not at probably no not sure yes

certainly

all

4. Do you feel that working with the group you were in enabled you to attain most of your goals?

$\begin{array}{lcccc}1 & 2 & 3 & 4 & 5 \\ \text { certainly } & \text { yes } & \text { not sure } & \text { no } & \text { defin tely no }\end{array}$

5. If you could replace some of your group with ideal members, how many would you replace?

4

6. To what degree do you feel that you were included by the group in the group activities?

$\begin{array}{lcccc}1 & 2 & 3 & 4 & 5 \\ \text { very much } & \text { often } & \text { sometimes } & \text { rarely } & \text { never }\end{array}$

7. How do you feel about your participation in and contribution to the group work?

$\begin{array}{lcccc}1 & 2 & 3 & 4 & 5 \\ \text { very poor poor } & \text { okay } & \text { good } & \text { very good }\end{array}$

8. What do you feel about the lengthof the group meetings?

$\begin{array}{lcccc}1 & 2 & 3 & 4 & 5 \\ \text { far too } & \text { long } & \text { about } & \text { short } & \text { far too } \\ \text { long } & & \text { right } & & \text { short }\end{array}$

9. How do you feel about the group leaders?

$\begin{array}{lcccc}1 & 2 & 3 & 4 & 5 \\ \text { very } & \text { positive } & \text { okay } & \text { negative } & \text { very } \\ \text { positive } & & & & \text { negative }\end{array}$


10. Are you ashamed of being in the group?

$\begin{array}{lcccc}1 & 2 & 3 & 4 & 5 \\ \text { very } & \text { yes } & \text { not sure } & \text { no } & \text { not at all }\end{array}$

12. Compared to other groups, how well would you imagine your group worked together?

1

very good

3

poor

5

well

average

poor

very

poor 
Smoking Questionnaire

Name:

Address :

City

21p

Home Phone:

Office Address:

Office Phone:

Occupat1on:

Name of a person whom you could be contacted through:

Name :

Phone:

Address :

City

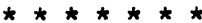

Health Information:

Height:

Welght:

History of cardlovascular disease (please specify type):

Personal

Family (specify relation)

History of cancer (please specify type):

Personal

Family (specify relation)

History of resplratory illness (please specify type):

Personal

Family (specify relation)

Current involvement in treatment:

Medication currently taken

Treatment or therapy currently involved in

Other health-related activity (diets, exercise): 
Other health information or treatment:

1. When did you first start smoking tobacco products?

2. How long have you smoked tobacco products?

3. Have you ever quit smoking before?

4. How many times?

5. How long (for the longest time)?

6. Have you ever been in a smoking cessation program?

7. If yes, what were the results?

8. Do you now smoke tobacco products? yes no If yes, complete the following:

9. What kind of tobacco products?

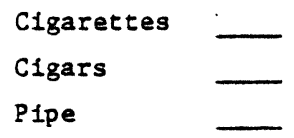

10. Over a typlcal week, how much would you smoke?

1 - 2 cigarettes a day

3 - 5 cigarettes a day

6 - 9 cigarettes a day half a pack (10) a day

11 - 15 cigarettes a day

16 - 19 cigarettes a day

one pack (20) a day

21 - 25 cigarettes a day

26 - 29 cigarettes a day

One and a half pack a day

31 - 35 cigarettes a day

36 - 39 cigarettes a day
Two packs a day

More than 2 packs a day

Specify amount:

1 - 2 cigars a day

3 - 4 cigars a day

5 - 6 cigars a day

7 - 8 cigars a day

9 - 10 cigars a day

More than 10 per day

Specify amount: 
11. Your brand of cigarettes:

Your brand of cigars:

12. If you smoke a pipe, estimate the ounces of tobacco smoked per week:

$1 / 8$ oz. per week

$1 / 4$ oz. per week

$1 / 2$ oz. per week

$3 / 4$ oz. per week

One oz. per week

More than 1 oz. per week

Specify amount:

Brands : 


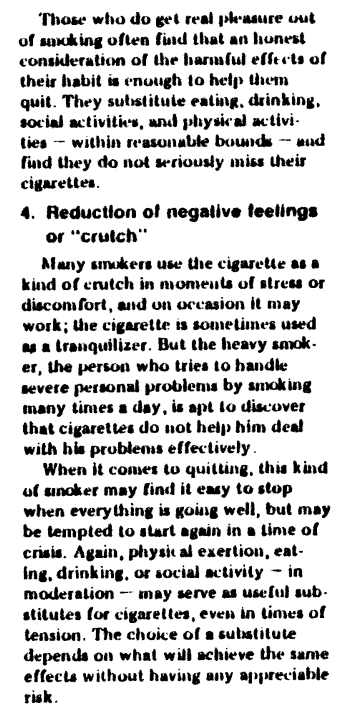

effee
risk.
5. "Craving" or payctrological "Cdalction

Qhietting suacting in difflicult for the person who scores high on the tactor

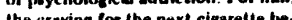
gins to bulld up the moment he pute one out, so lapering off it not litety to work. Me muar go cold curkey. More then noun for a dey oo two that the twoto for cigaretles is apoiled. and then irotale himself completely rine Giving difficult and couse so much discomfor diat once he does quit, he will find it emas to resiat the remplation to go that some day he will have io so through the anme agony again. 6. Habll

This thind of moker in no longer

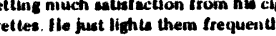
without even realizing he to doing so.

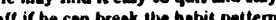
he has built up. Cutling down gradually may be quite effective if there is a

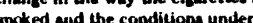
which they are unciked. The key wo arelte you amoke. This can be dome by

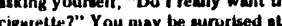
how muiy you do not want.
Summary

II you do not acore hieth on any of only hall-way dowu, uec tow- her / wikco-

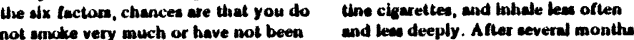

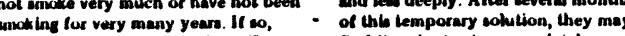
- find it eaver to ctop comptetely.

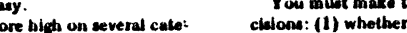

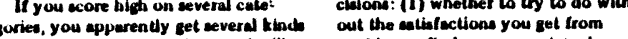
of antisfaction from smocking and with to try to cut out cigarettes atl at onces, that giving up encoking will be especally ditacult. Those who ceore bith thon of negetive feelling and creving. may have a particularly hard time in going off watiting and the staying of However, hiere are wayo to do

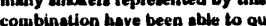
Others who ecore hith on lactors : and 6 may had it weenth bo chatos down at the cume tine. They can toy to sacke lewer civareflies, amcike then

Noj

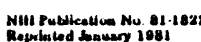

This wo lost III of the Brmuker's Bets. Testing Kit developed by Danitel H.
Hom, Ph. D. and orginally pronled by . ine and Heallh, DHEW.

\section{Why DoYou Smoke?}

Take this shorl lest. and you witt understand some of the reasons why you srioke Your answers to the lest questions will help you choose the best way lo quil

\section{Your scores thould gutsele you ho}

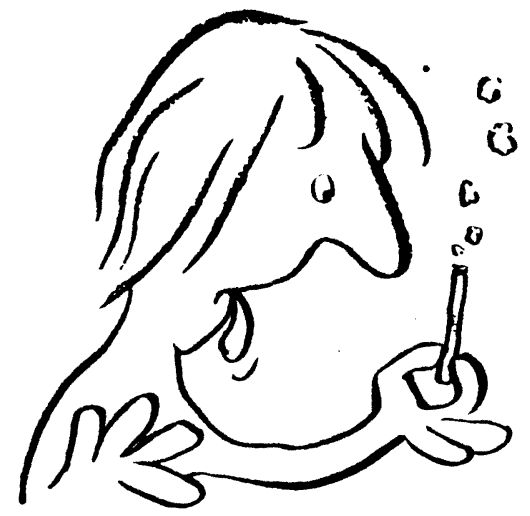

U.S. DEPARTMENT OF HEALTH AND HUMAN SER VICES Public Heallth Service Heall 


\section{Why do you smoke?}

Here are some atstements made by
people to deccribe what they get out

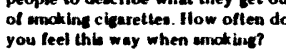

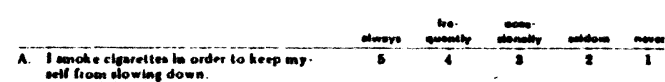

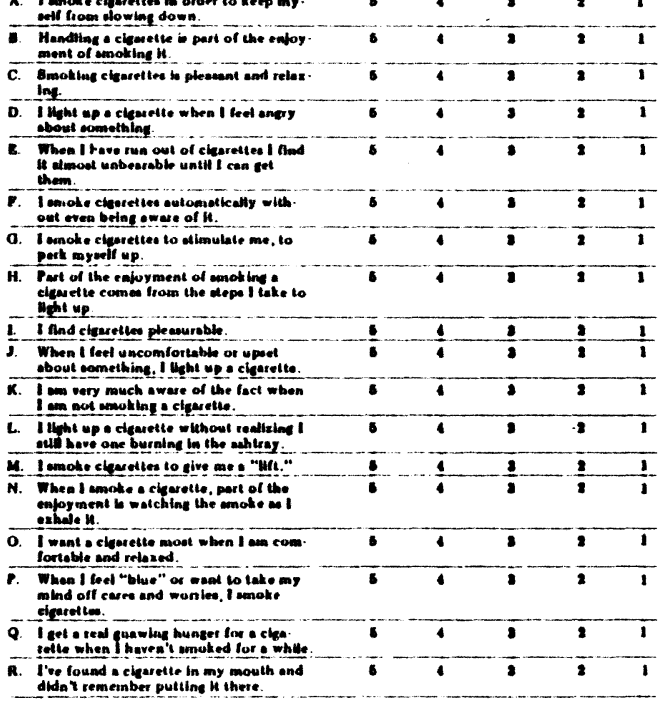

\section{How to score} 1. Enter the number you have circled
tos each question in the oppaces
below, puttling the number you heve circled to queation $A$ over Hioe

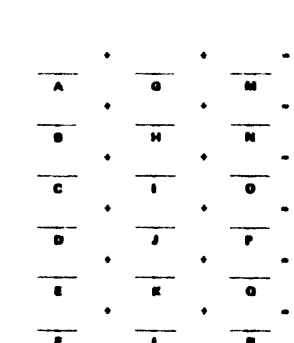

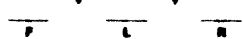

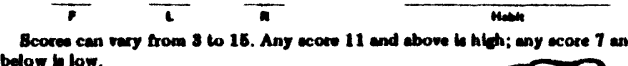

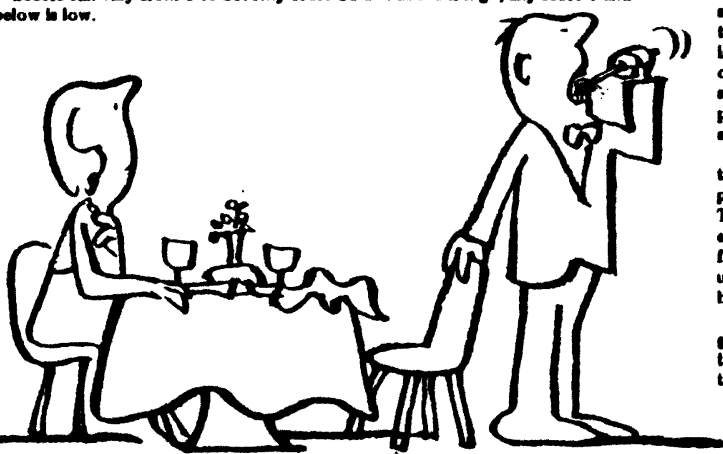

What thind of amoker are your? What What does

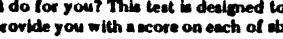
actors which deersibe many peopte be cherracterized by onty one of these Cactors, or by a combination of factor. wenter whet kind of metwiection you thing you pet from anckining. The dx crectors menesured by the encing or menering cert reelinga. Three of theese loetling statees repremant the post ive teelloge peopte ares or of bendlling or menipulatung thing: and the enthencing of plesourablo feet. ane ncompanying a atale of woll.

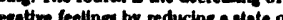
enetion or feelting of enxlety, ander.

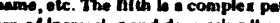

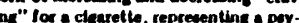
hotodical addiction to wnditing The

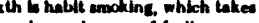
comatic amotitis. A The hathar your acore (16 the hil. cher the in your amakting and the moro weeful the drecuedion of that factor can

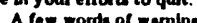
A up mocking, you may have to lean that anctine sives you.
Either that, of you wit have to find aced to know fust what it 6 you pet

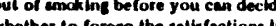
dves you or to find auother way to Sulmulation

If you acore bilth or folity thith on this factor, it means that you are one of those amokers who in stimulated by ante you up, orgenize your energles. usd keep you gothe II you try to give up unating, you may wanl a cale dub etcice, for example, whenever you leet to amoke.

Hiandling Uhinge can be cotisfylng. hendo buasy without linhting up or playlins with a cleserette. Why not toy ath or some other harmless object.

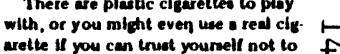
iifht li.

It to not dways enay to find out good, that $t$ to to get read pleate to teet I ancking (fector 3) or to keep from leeting co bed (lactor f). Aboult two. high on accentuation of plemure, and about half of those tea score mo hidt or higher on reduction of negative 
145

APPENDIX B 
Criteria for Abstinence-Refund

Individual

Reports Abstinence 4 Weeks

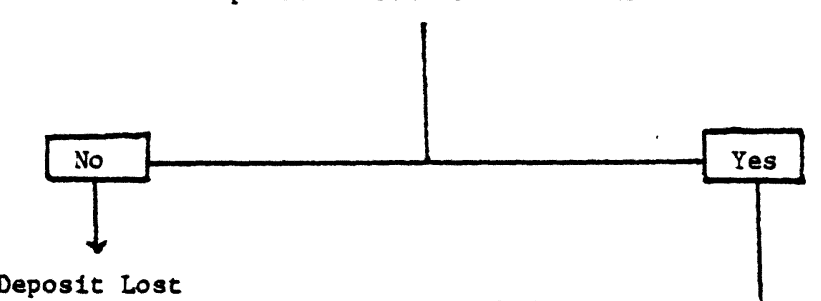

Deposit Lost
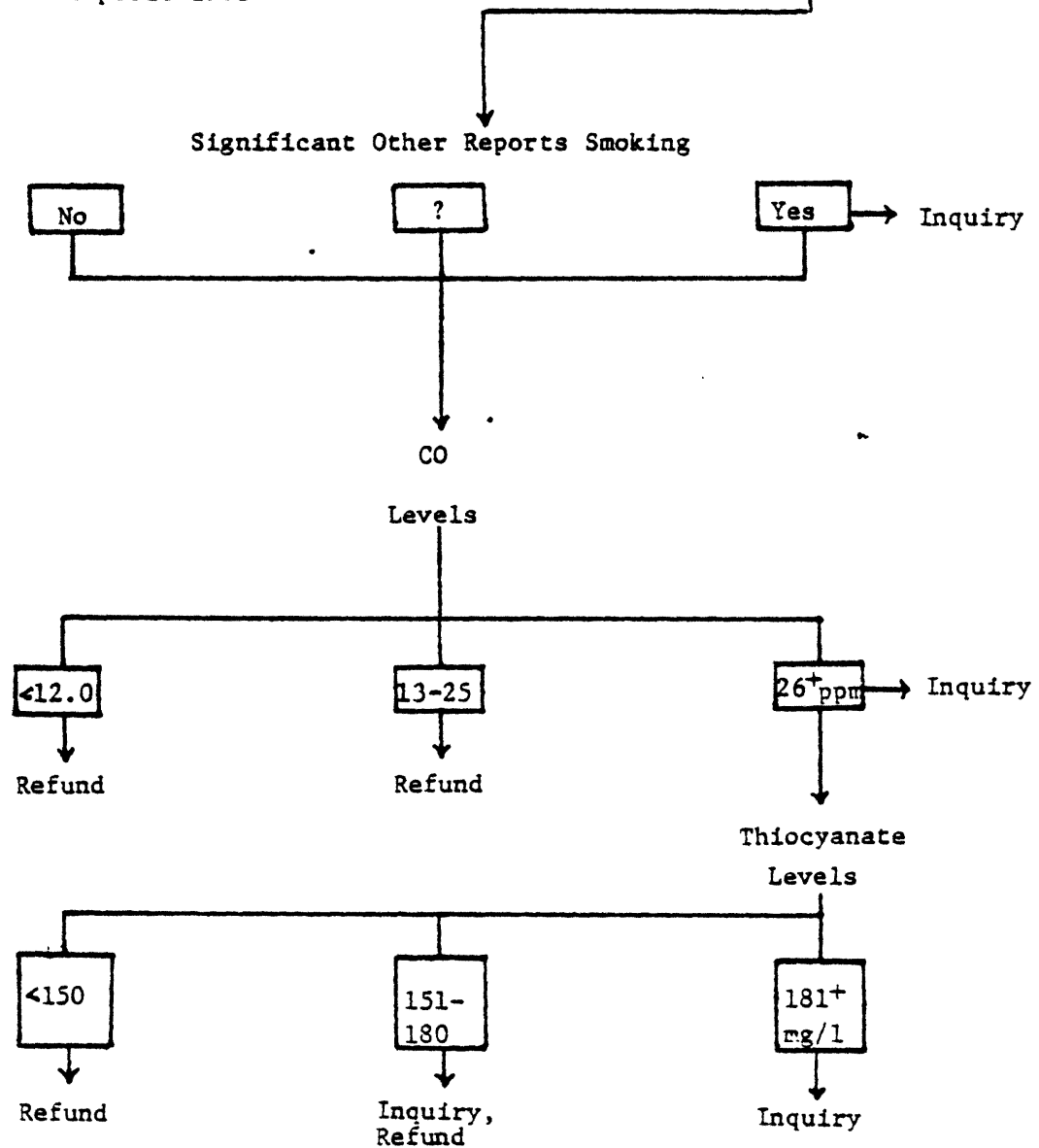

Thus, deposits are refunded unless smoking is indicated by the person involved or both lab measures of smoking. No deposits will be lost without discussing the circumstances with the individual. Any discrepant reports or results will be discussed with the individual. 
Healeh I-Z

D1rect10r3: In!a questionnalie has to do wth bellefs that people haye about their hesith. The questlornalre consists of a serles of scacements followed by a 6-poine rating scaie. Next to each statement cifcle the nisber that mose closely agrecs wh th your own beilefs. The higher the number the wore you agree ith 1t. Please answer every leem and do not - spend too much tibe thicklng about any one. Stnce this is a measure of bellef, there is so righe or wrong answer.

\begin{tabular}{|c|c|c|c|c|c|c|c|}
\hline \multirow[b]{2}{*}{1.} & \multirow[b]{2}{*}{$\begin{array}{l}\text { If I taics care of ayself, I can } \\
\text { avotd illness. }\end{array}$} & \multicolumn{2}{|c|}{$\begin{array}{l}\text { Strongly } \\
\text { C1sagree }\end{array}$} & \multicolumn{3}{|c|}{ CIRCLE ONE } & \multirow{2}{*}{$\begin{array}{l}\text { Strongly } \\
\text { Agree } \\
6\end{array}$} \\
\hline & & 1 & 2 & 3 & 4 & 5 & \\
\hline$\therefore$ & $\begin{array}{l}\text { Whenever I get sick it is because } \\
\text { of scaeching. I've done or not done. }\end{array}$ & 1 & .2 & 3 & 4 & $j$ & 6 \\
\hline 3. & $\begin{array}{l}\text { Good health is largely a sateer of } \\
\text { good fortur:s. }\end{array}$ & 1 & 2 & 3 & 4 & 5 & 6 \\
\hline 4. & $\begin{array}{l}\text { No masesr what I jo, is I an going } \\
\text { to get s1c:t I w:11 get 31cle. }\end{array}$ & 1 & 2 & 3 & 4 & is & 6 \\
\hline 5. & $\begin{array}{l}\text { Kose puopla do not realize the exient } \\
\text { to whlib thelr } 111 \text { resses are con- } \\
\text { trolled by accidantal happeniags. }\end{array}$ & te & 2 & 3 & 4 & 5 & 6 \\
\hline s. & $\begin{array}{l}\text { I can oriy do what my ductor tells we } \\
\text { to do. }\end{array}$ & 1 & 2 & 3 & 4 & $s$ & 5 \\
\hline 7. & 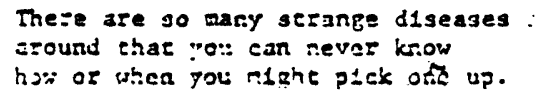 & $\therefore \cdots$ & 2 & 3 & 4 & 5 & 6 \\
\hline $3 x$ & 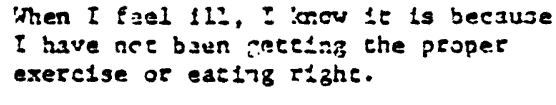 & e & 2 & 3 & 4 & 5 & 6 \\
\hline 9. & $\begin{array}{l}\text { People who gever get sick are fust } \\
\text { plaln lucky. }\end{array}$ & 1 & 2 & 3 & 4 & 5 & 6 \\
\hline 10. & $\begin{array}{l}\text { Peoplu's } 111 \text { healih residitg froos } \\
\text { theif orn carelessness. }\end{array}$ & 1 & 2 & 3 & 4 & $s$ & 6 \\
\hline 1. & I az c1rcesly zesponsible for my & 1 & 2 & 3 & 4 & 5 & 6 \\
\hline
\end{tabular}


CULLEGE OF ARTS AND KCIENCES

\section{VIRGINIA POLYTECHNIC INSTITUTE AND STATE UNIVERSITY}

DEPARTMENT OF PSYCHOLOOYY

Blacksburg, Virginia 24061 November 30,1982

Psychological Services Center

Dear

As you may already know, a friend, acquaintance or family member of yours is participating in a stop smoking profect. Your name was given as a person who could verfiy the smoking or non-swoking status of the individual. A caller from the Smoking Profect will concact you sometime between December and June to inquire whether the person in the profect is smoking or not. Th1s 1s the only question we will ask about the person, and a simple yes or no is suffictent. We appreciate your assistance in this matter. The name of the participant in the program is

Sincerely,

Thomas G. Bowers

Coordinator

Stop Smoking Project 


\section{Significant Others}

Provide the names and phone numbers of four individuals who could verify your smoking or nonsmoking status. Each of these persons would be contacted only once during one of the follow-up periods. The four follow-up perlods will be at one-month, two-months, three-months, and six-months post-quit day. Explain to these individuals that you are involved in a quitting-smoking project and that they will be contacted to confirm your smoking/nonsmoking status. We will mail the significant others a brief letter explaining the project and indicating that we will be contacting them later.

Name :

Address:

Phone:

Name:

Address:

Phone:

Name:

Address :

Phone:

Name :

Address :

Phone: 


\section{RELEASE OF INFORMATION}

If you wish to have your physiclan, counselor or therapist know of your participation in the project, please sign the form below. The Individuals you indicate will recelve the results of the Health Assessment and the self-monitoring of smoking. No information will be provided to any individual regarding your participation in the project without your written permission.

PLEASE RELEASE THE RESULTS OF MY PARTICIPATION TO:

Dr.

of

(town)

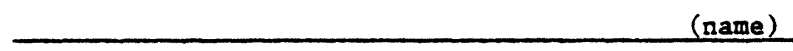

of (town)

I understand this consent will allow the exchange of information between the Smoking Profect and the individuals Indicated. 


\section{Maintenance Contract}

I, , agree to abide by the following:

I have made a refundable deposit of $\$$ - This deposit

will be returned to me for meeting the following conditions:

(1) Nonsmoking for 2 days after my quit date. W11l return $20 \%$ of my deposit or $\$$

(2) Nonsmoking for 4 weeks after my quit date, confirmed by others and lab results. Will return 30\% of my deposit or $\$$

(3) Nonsmoking for 4 weeks after my one-month follow-up, confirmed by others and lab results. Will return $20 \%$ of my deposit or $\$$

(4) Nonsmoking for 4 weeks after my two-month follow-up, confirmed by others and lab results. Will return $20 \%$ of my deposit or $\$$

(5) Completing my follow-up session at six months. Will return $10 \%$ of my deposit or $\$$

(6) I agree to participate in the follow-up sessions at one-month post-quit date, two-month post-quit date, three-month post-quit date, and six-month post-quit date. I agree to arrange for a make-up session if I am unable to attend any follow-up. I understand the make-up session meets refund requirements.

(7) I have received a copy of the criteria for refund and I understand the criteria. 


\section{Standard Contract}

I, agree to abide by the following:

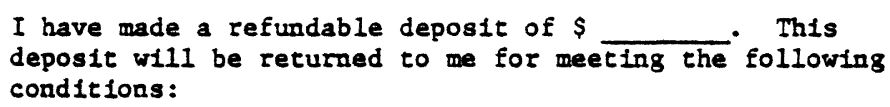

(1) Attending 5 of 6 group sessions and completing both assessment sessions. Will return $20 \%$ of my deposit or $\$$

(2) Attending the one-month follow-up session and completing the follow-up materials. Will return $30 \%$ of my deposit or $\$$

(3) Attending the two-month follow-up session and completing the follow-up materials. W111 return $20 \%$ of my deposit or $\$$

(4) Attending the three-month follow-up session and completing the follow-up materials. W11l return $20 \%$ of my deposit or $\$$

(5) Attending the six-month follow-up session and completing the follow-up materials. W111 return $10 \%$ of my deposit or $\$$

(6) I agree to arrange for a make-up session if any of the assessment or follow-up sessions cannot be attended. I understand that a make-up session meets refund requirements in the event of schedule conflicts or unexpected events. 


\section{TIME PLAN}

October 21

October 23 (Sat)

October 27

November 4

November 11

November 18

November 25

December 2

December 4 (Sat)

Janurary 6

Februrary 3

March 5 (Sat)

June 4 (Sat)

Introduction. Start self-monitoring.

Health Assessment. War Memorlal Gym, second floor.

Group \#2. Begin nicotine fading. Deposits due. Buddies.

Group \#3. Chart smoking, self-management steps.

Group \#4. Set goal date. Time fading.

Group \#5. Alternative rewards. Relapse prevention. Quit dates set.

Group optional, Thanksgiving break. Group to decide.

Group \#6. Last quit date! Responsibility.

Health Assessment. War Memorial Gym. Refund I.

Cheese \& Crackers. One month follow-up. TBA.

Behavioral rehearsal, refusing cigarettes. Refund II.

Beer, wine \& cheese. Two month follow-up. TBA.

Self-image, physical activity.

Health Assessment. War Memor1al Gym. Refund III.

Six month follow-up. Health Assessment. War Memorial Gym. Refund IV. 


\section{IIME PLAN}

October 20
October 23 (Sat)
October 27
November 3
November 10
November 17
November 24
December 1
December 4 (Sat)
December 8
December 15
Janurary 5
February 2
Jarch 5 ( Sat) 4 ( Sat)
June

Introduction. Start self-monitoring.

Health Assessment. War Memorial Gym, second floor.

Group \#2. Begin nicotine fading. Deposits due. Buddies.

Group \#3. Chart smoklng. Self-management steps.

Group \#4. Set goal dace. Time fading.

Group \#5. Alternative rewards. Relapse prevention. Quit dates set.

Thanksgiving break. Opt1onal, group to dec1de.

Group \#6. Last quit dace! Responsibility.

Health Assessment. War Memortal Gym. Refund I.

Group \#7. Recovery from smoking.

Group \#8. Coping with anger, depression, anxiety.

Cheese and Crackers. One month follow-up. TBA.

Behavioral rehearsal, refusing cigarettes. Refund II.

Beer, wine \& cheese. Two month follow-up. TBA.

Self-image, physical activity.

Health Assessment. War Memorial Gym. Refund III.

Six month follow-up. Health Assessment. War Memorial Gym. Refund IV. 
TABLE Deposit scale

\section{DEPOSIT SCALE}

Yearly Gross

Income $(3 / 4 \%)$

Dependents

$\begin{array}{rrrrrr}30-40,000 & \frac{0-1}{300} & \frac{2-3}{270} & \frac{3-4}{240} & \frac{5-6}{210} & \frac{7-8}{180} \\ 20-30,000 & 225 & 203 & 181 & 159 & 147 \\ 10-20,000 & 150 & 135 & 120 & 105 & 90 \\ 5-10,000 & 75 & 68 & 61 & 54 & 50 \\ 0-5,000 & 50 & -- & -- & -- & --\end{array}$


APPENDIX C 


\section{CIGARETTES PER DAY}

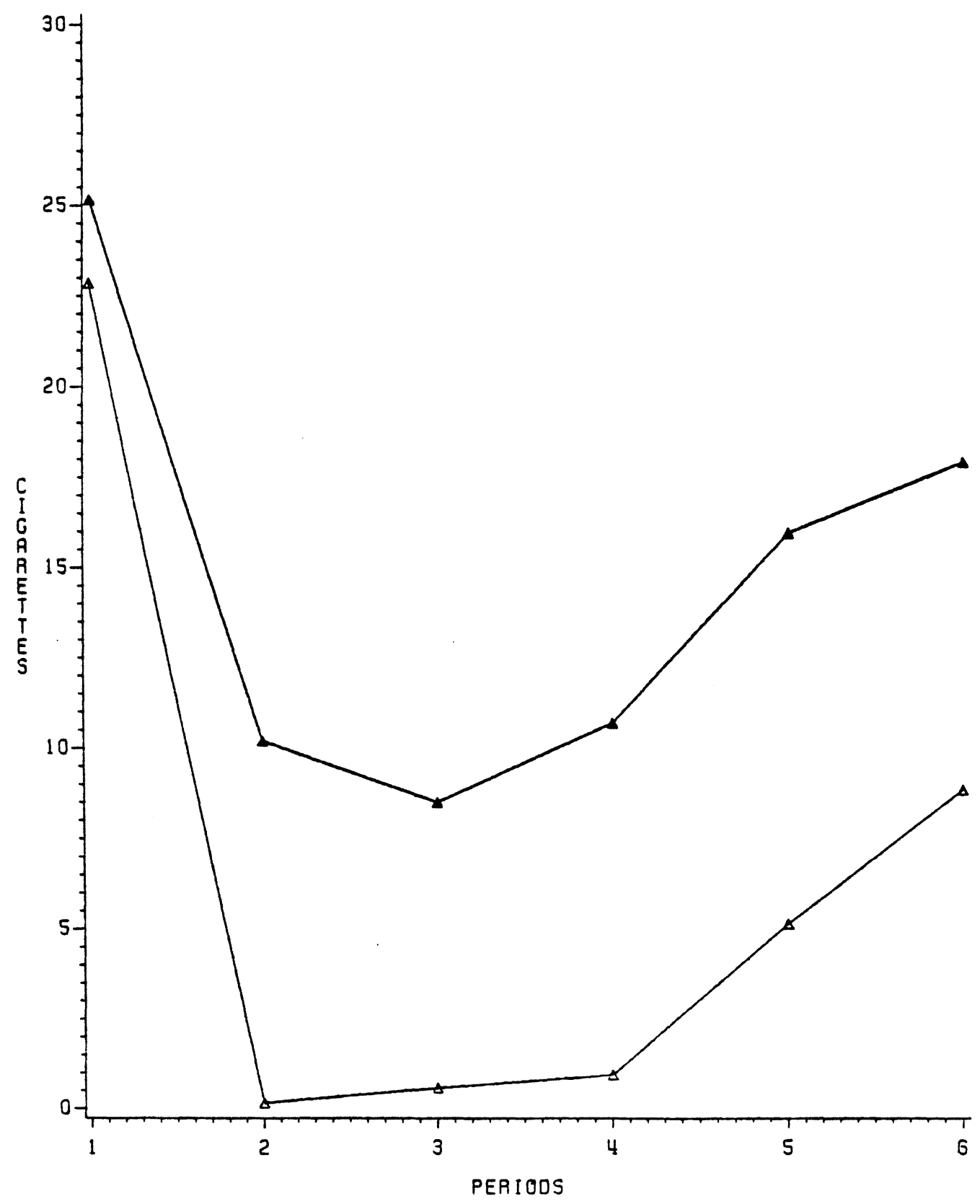

FIGURE I. Average cigarettes per day reported smoked for standard $(\Delta)$ and maintenance $(\Delta)$ conditions. 
CARBON MONOXIDE \%

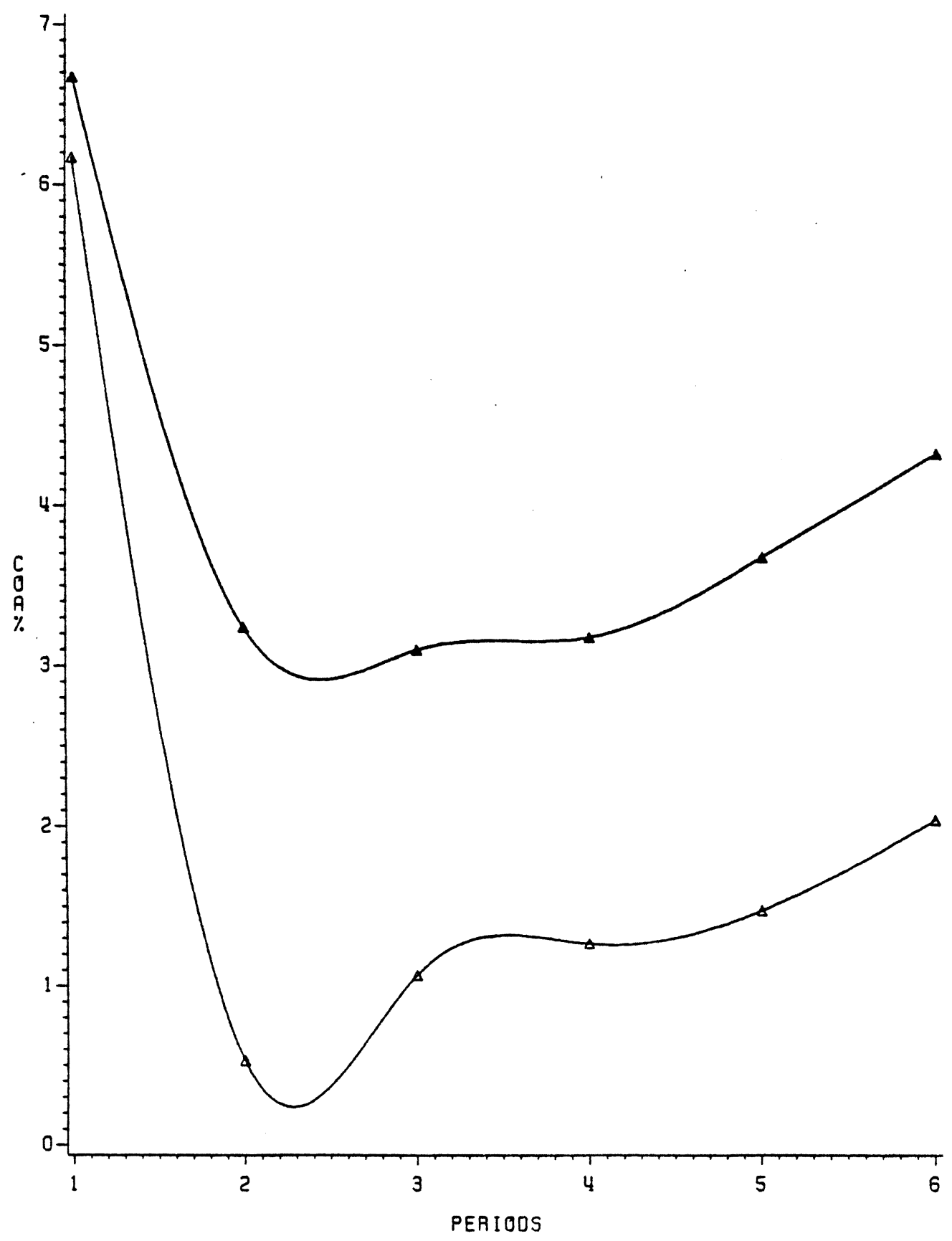

FIGURE II. Mean COa\% levels for standard $(\boldsymbol{\Lambda})$ and maintenance $(\Delta)$ conditions. 


\section{SCN CONCENTRATIONS}

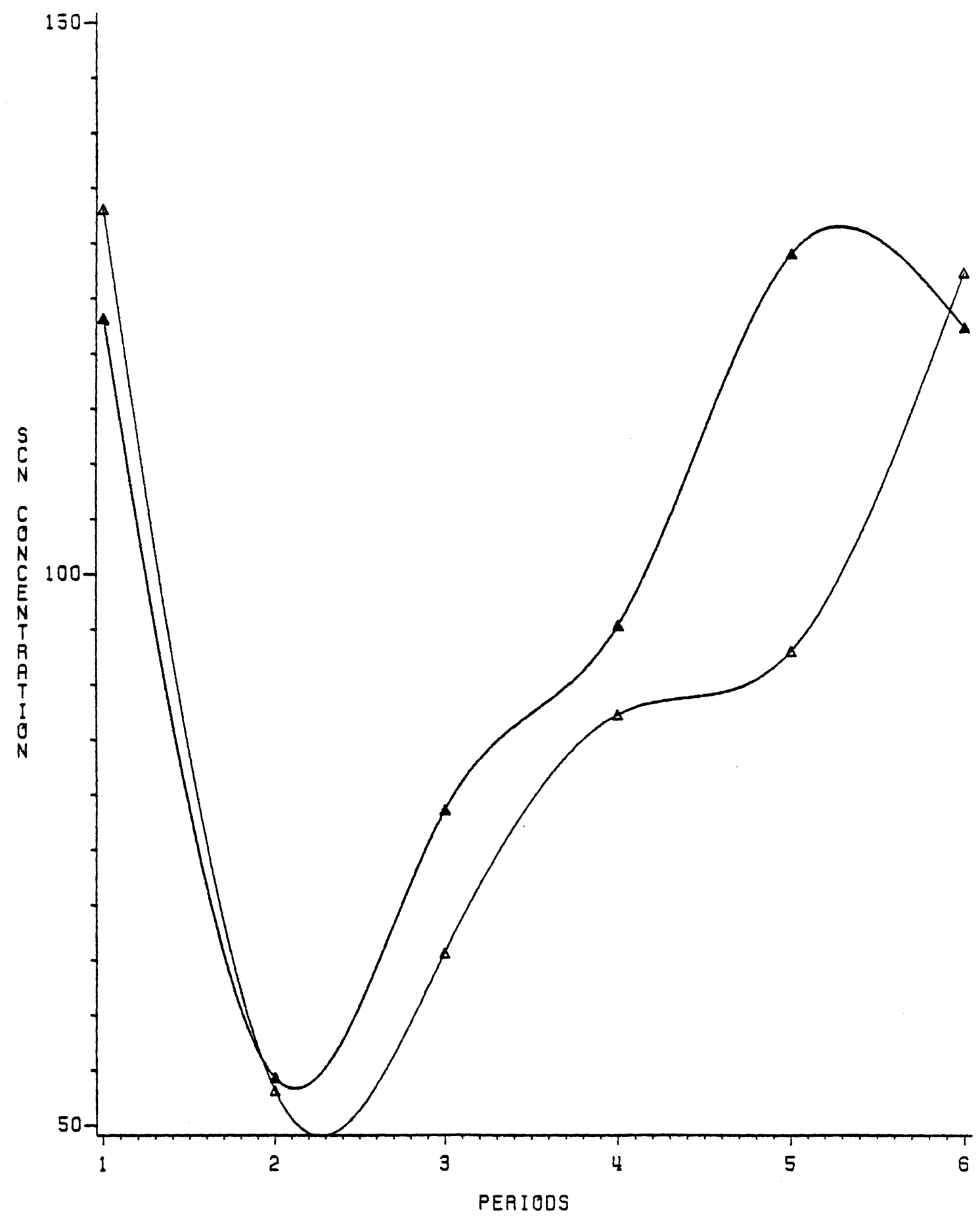

FIGURE III. SCN concentrations in $u g / m l$ for standard (A) and maintenance $(\Delta)$ conditions. 


\section{PERCENTAGE CESSATION}

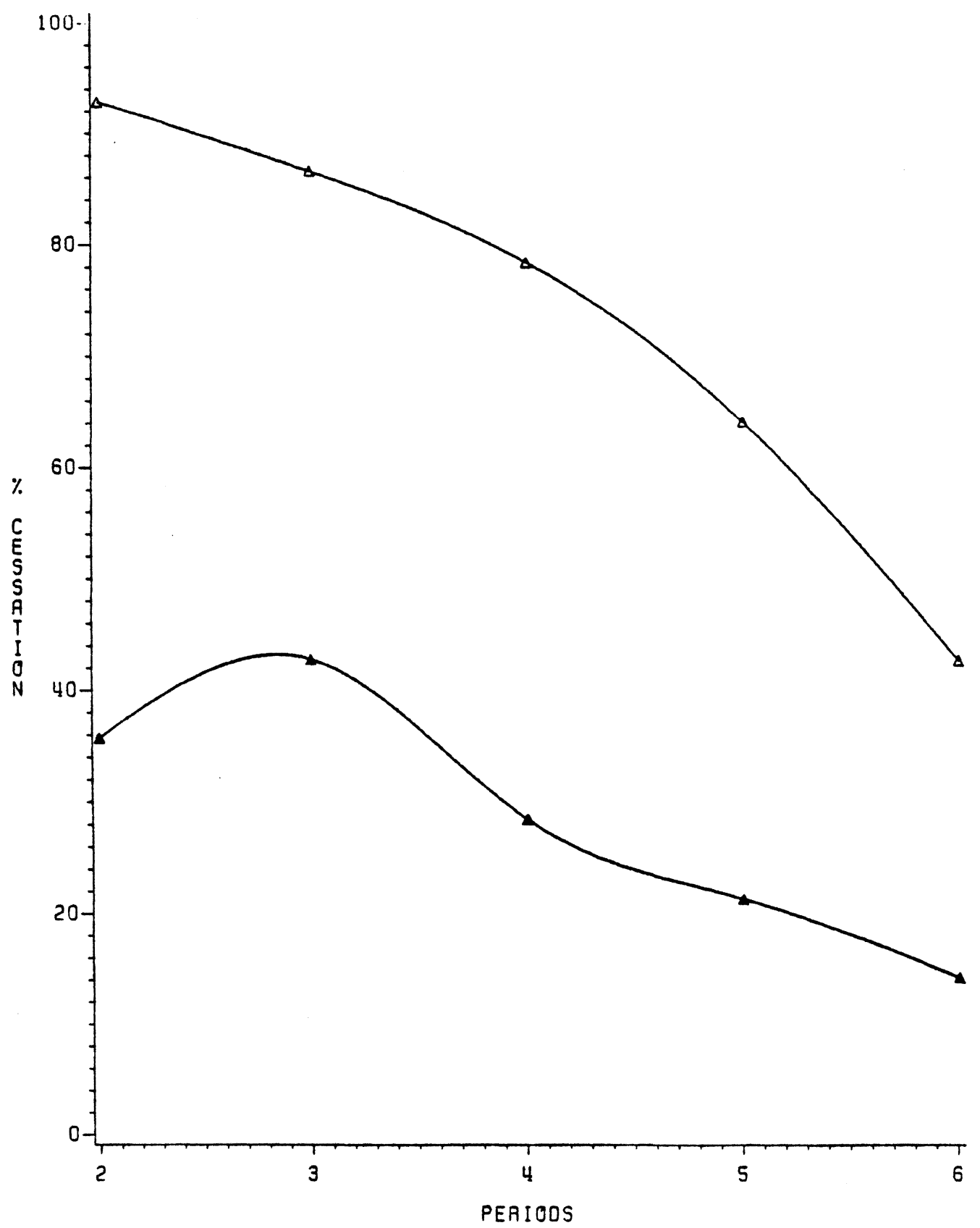

FIGURE IV. Cessation rates for standard $(\boldsymbol{\Lambda})$ and maintenance $(\Delta)$ conditions. 


\section{BLOOD PRESSURE}

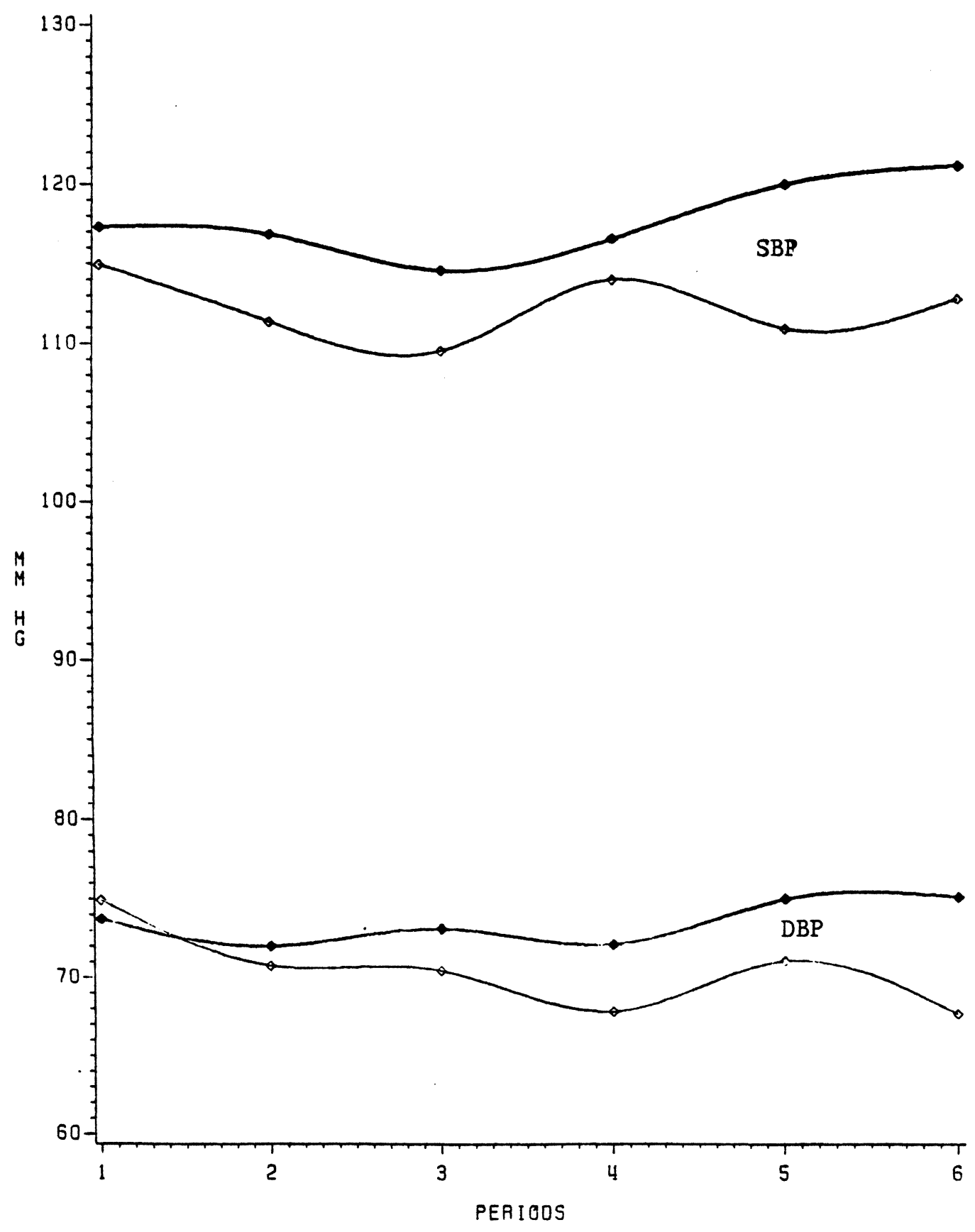

FIGURE V. Systolic (SBP) and diastolic (DBP) blood pressure for standard $(\diamond)$ and maintenance $(\diamond)$ conditions. 


\section{HEART RATE}

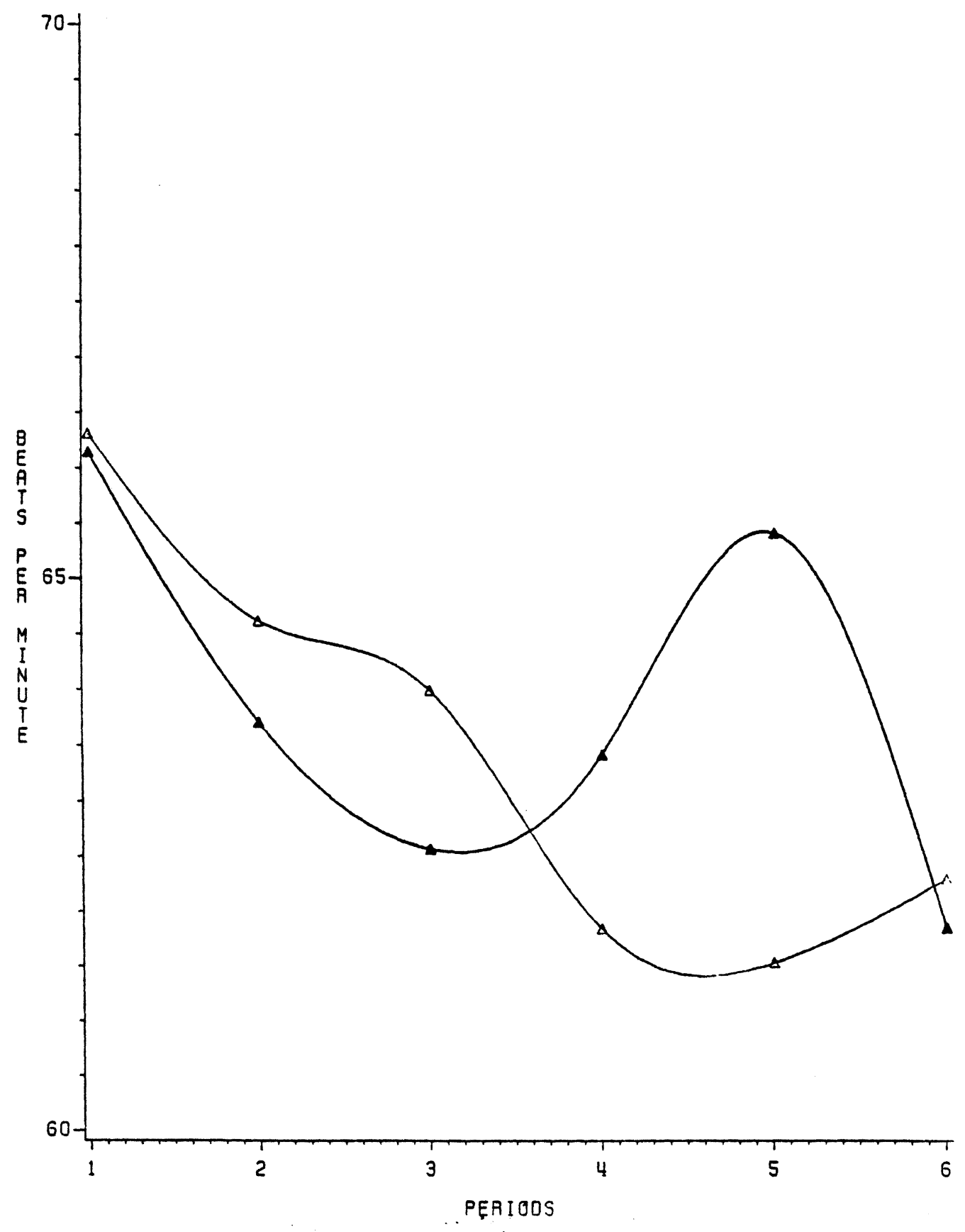

FIGURE VI. Heart rate for standard $(\Delta)$ and maintenance $(\Delta)$ conditions. 


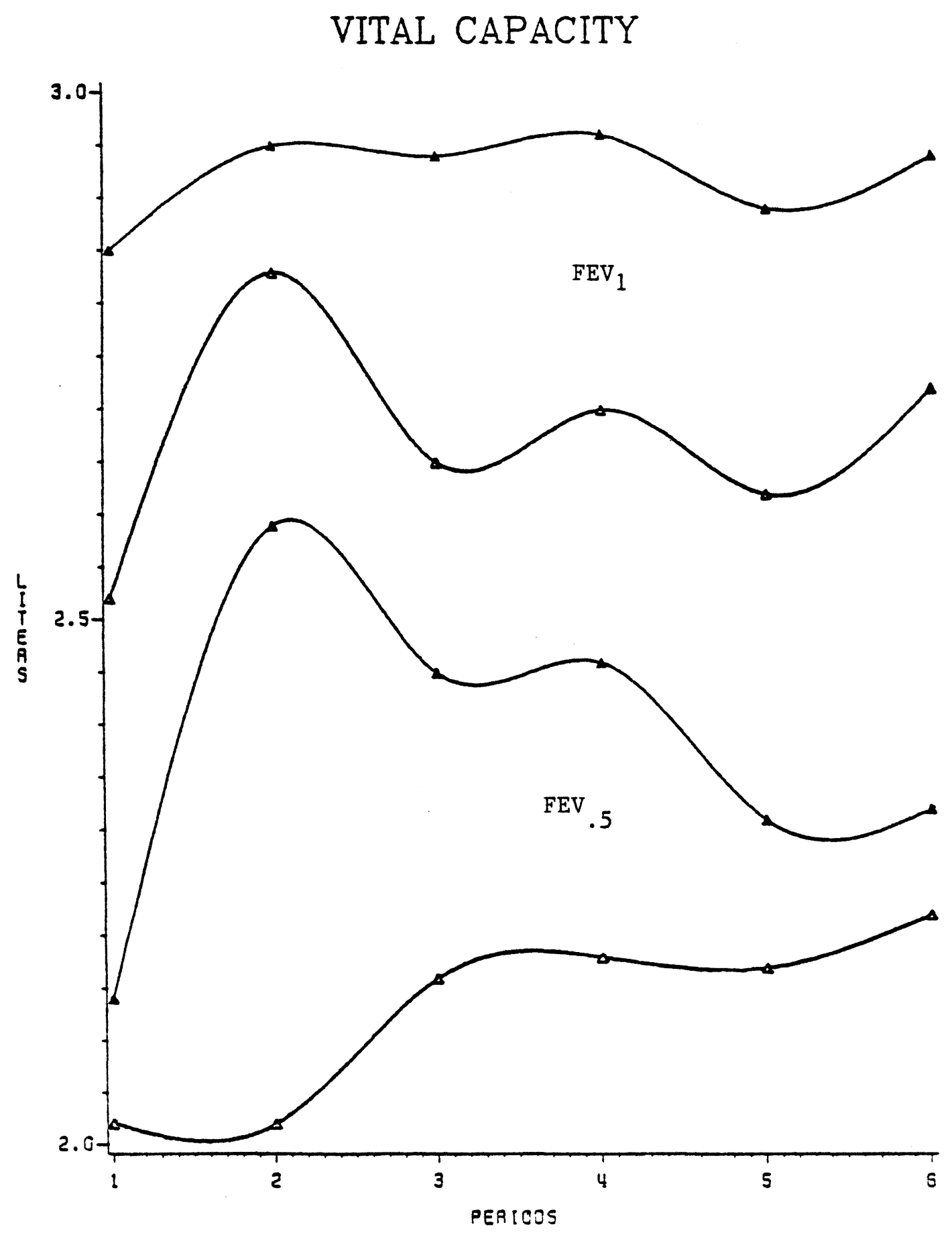

FIGURE VII. Vital capacity in $\mathrm{FEV}_{1}$ and FEV ${ }_{.5}$ for standard ( $\mathbf{\Lambda}$ ) and maintenance ( $A$ ) conditions. 


\section{The three page vita has been removed from the scanned document. Page 1 of 3}




\section{The three page vita has been removed from the scanned document. Page 2 of 3}




\section{The three page vita has been removed from the scanned document. Page 3 of 3}

